Florida International University FIU Digital Commons

FIU Electronic Theses and Dissertations

University Graduate School

3-29-2013

\title{
The Processing of Preposition-Stranding Constructions in English
}

Naomi R. Enzinna

Florida International University, nenzi001@fiu.edu

DOI: $10.25148 /$ etd.FI13042515

Follow this and additional works at: https://digitalcommons.fiu.edu/etd

Part of the Linguistics Commons

\section{Recommended Citation}

Enzinna, Naomi R., "The Processing of Preposition-Stranding Constructions in English" (2013). FIU Electronic Theses and Dissertations. 889.

https://digitalcommons.fiu.edu/etd/889

This work is brought to you for free and open access by the University Graduate School at FIU Digital Commons. It has been accepted for inclusion in FIU Electronic Theses and Dissertations by an authorized administrator of FIU Digital Commons. For more information, please contact dcc@fiu.edu. 


\title{
FLORIDA INTERNATIONAL UNIVERSITY \\ Miami, Florida
}

THE PROCESSING OF PREPOSITION-STRANDING CONSTRUCTIONS

IN ENGLISH

\author{
A thesis submitted in partial fulfillment of the \\ requirements for the degree of \\ MASTER OF ARTS \\ IN \\ LINGUISTICS \\ by
}

Naomi Enzinna 
To: Dean Kenneth G. Furton

College of Arts and Sciences

This thesis, written by Naomi Enzinna, and entitled The Processing of PrepositionStranding Constructions in English, having been approved in respect to style and intellectual content, is referred to you for judgment.

We have read this thesis and recommend that it be approved.

Tometro Hopkins

Phillip M. Carter

Ellen Thompson, Major Professor

Date of Defense: March 29, 2013

The thesis of Naomi Enzinna is approved.

Dean Kenneth G. Furton College of Arts and Sciences

Dean Lakshmi N. Reddi University Graduate School

Florida International University, 2013 
C COPYRIGHT 2013 by Naomi Enzinna

All rights reserved 


\section{DEDICATION}

I dedicate this thesis to my mother and best friend, Carolyn Enzinna. 


\section{ACKNOWLEDGMENTS}

First and foremost, I would like to express my deepest gratitude to Dr. Ellen Thompson, my thesis advisor, for being endlessly patient, encouraging, and supportive throughout the development of this thesis. Without her, the completion of this study would not have been possible.

I would like to thank Dr. Phillip M. Carter and Dr. Tometro Hopkins for their participation as members of my thesis committee. Their support and commitment of time has been invaluable. I would also like to thank the following people for their assistance and suggestions regarding this study: Dr. Virginia C. Mueller Gathercole, Dr. Charles Clifton Jr., Kezia Walker-Cecil, my informants, and the audiences at the 2012 Experimental Psycholinguistics Conference and the 2013 West Coast Conference on Formal Linguistics.

Special thanks should be given to Dr. James Sutton, the Linguistics faculty and students, and the English department for their support and counsel along the way. I would also like to extend my thanks to statistical consultant Angeline Low, who patiently processed the results of this study. Moreover, I would like to thank classmate Emily Byers, who shared her knowledge of the thesis process with me.

Finally, I would like to thank my family, who believed in and supported me throughout this study and always. 


\section{ABSTRACT OF THE THESIS \\ THE PROCESSING OF PREPOSITION-STRANDING CONSTRUCTIONS \\ IN ENGLISH}

by

Naomi Enzinna

Florida International University, 2013

Miami, Florida

Professor Ellen Thompson, Major Professor

One of the prominent questions in modern psycholinguistics is the relationship between the grammar and the parser. Within the approach of Generative Grammar, this issue has been investigated in terms of the role that Principles of Universal Grammar may play in language processing. The aim of this research experiment is to investigate this topic. Specifically, this experiment aims to test whether the Minimal Structure Principle (MSP) plays a role in the processing of Preposition-Stranding versus Pied-Piped Constructions. This investigation is made with a self-paced reading task, an on-line processing test that measures participants' unconscious reaction to language stimuli. Monolingual English speakers' reading times of sentences with Preposition-Stranding and Pied-Piped Constructions are compared. Results indicate that neither construction has greater processing costs, suggesting that factors other than the MSP are active during language processing. 


\section{TABLE OF CONTENTS}

CHAPTER P PAGE

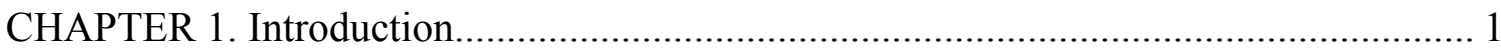

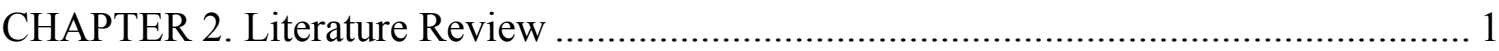

2.1. Preposition-Stranding Constructions Cross-Linguistically........................... 2

2.1.1. Law's "Preposition stranding" ..................................................... 3

2.1.1.1. Introduction.................................................................... 3

2.1.1.2. Syntactic Constraints on Extraction and P-

Stranding .......................................................................... 5

2.1.1.3. A Syntactic Reanalysis Account for P-Stranding ............. 8

2.1.1.4. Government-Theoretic Accounts of P-Stranding ............ 10

2.1.1.5. P-Stranding and Syntactic D-and P Incorporation........... 11

2.1.1.6. P-Stranding under A-movement and A-bar-

movement in Germanic........................................................ 12

2.1.1.7. Conclusion ............................................................... 15

2.1.2. Merchant's "The syntax of silence: sluicing, islands, and identity in ellipses" - "Preposition-stranding ............................... 15

2.1.3. Sugisaki's "Preposition Stranding: Its Parametric Variation

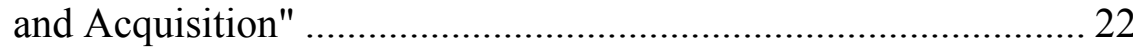

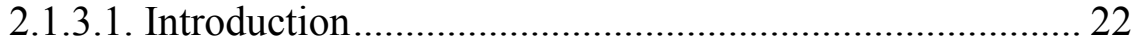

2.1.3.2. Parametric Variation in P-Stranding ............................... 22

2.1.3.3. Acquisitional Evaluations ............................................... 29

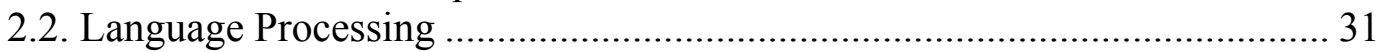

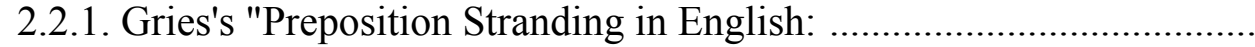

Predicting Speaker's Behaviour"............................................... 32

2.2.1.1. Introduction............................................................. 32

2.2.1.2. Previous Analyses...................................................... 36

2.2.1.3. Results (for Selected Variables Only)........................... 38

2.2.1.4. Summary/Conclusions ................................................... 43

2.2.2. Bader and Schmid's "Minimality in Verb-Cluster Formation"....... 43

2.2.2.1. Introduction ............................................................ 43

2.2.2.2. Minimal structure building and infinitival

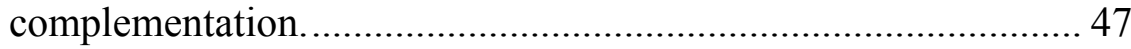

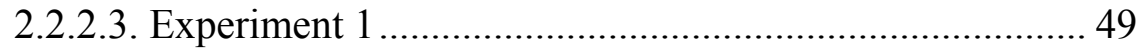

2.2.2.4. Experiment 2 2............................................................ 52

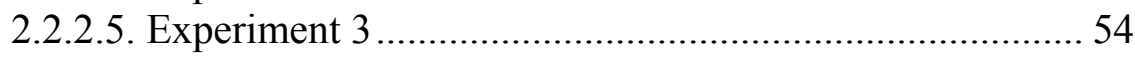

2.2.2.6. General Discussion ................................................... 56

2.2.3. Ferreira and Clifton's "The Independence of Syntactic

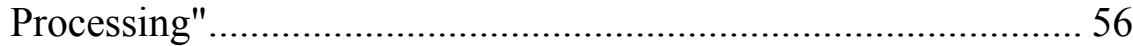

2.2.3.1. Introduction................................................................ 56

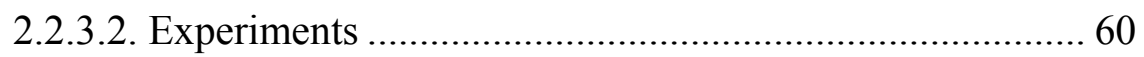


2.2.3.3. General Discussion 64

2.2.4. Weinberg's "A Minimalist Theory of Human Sentence

Processing". 64

2.2.4.1. Introduction 64

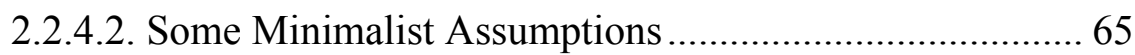

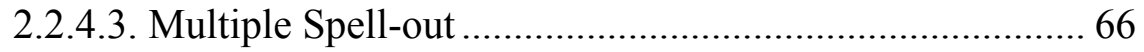

2.2.4.4. Minimalist Principles as a Parsing Algorithm ................. 67

2.2.4.5. Some Cases: Argument/Adjunct Attachment

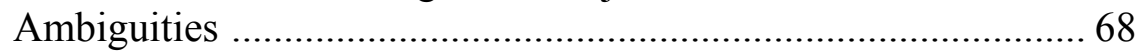

2.2.4.6. Constraint-Based Theories........................................... 73

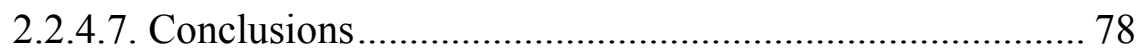

2.3. The Minimal Structure Principle ……………………........................... 78

2.3.1. Bošković's "Selection and the categorical status of infinitival

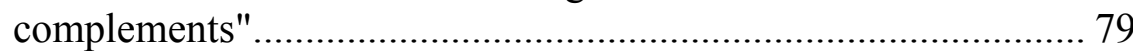

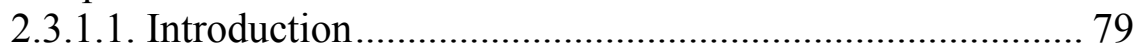

2.3.1.2. Infinitival Complementation and C-Selection ................. 79

2.3.1.3. Economy and the Categorical Status of Clauses............... 88

2.3.1.4. Conclusion .................................................................. 94

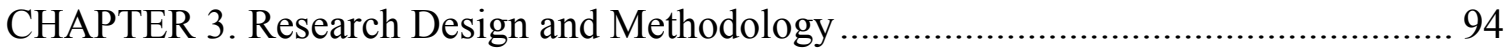

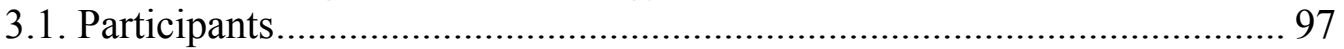

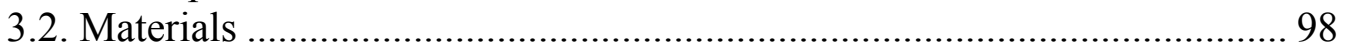

3.2.1. SPRT Instrument................................................................ 99

3.2.1.1. Target Sentences .......................................................... 100

3.2.1.2. Filler Sentences ........................................................... 101

3.2.2. Comprehension Question Task Instrument.................................... 102

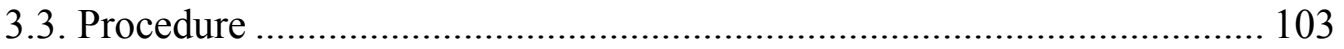

3.4. Explanation of the Procedure................................................................ 105

3.5. Methods of Analysis ................................................................................. 109

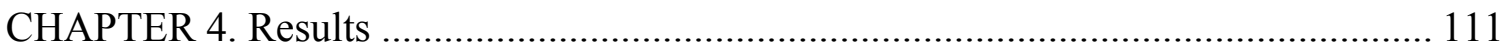

4.1. Comprehension Question Task ........................................................... 111

4.2. Self-Paced Reading Task ...................................................................... 112

4.2.1. Reading Times per Sentence Type …………………................ 113

4.2.1.1. Reading Times per Sentence Type: Whole

Sentence ................................................................................ 113

4.2.1.2. Reading Times per Sentence Type: Sentence per

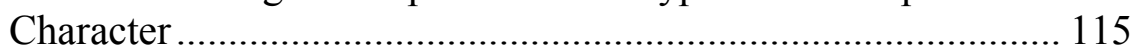

4.2.2. Reading Times per Sentence Type and Complement Type.......... 116

4.2.2.1. Reading Times per Sentence Type and

Complement Type: Whole Sentence

4.2.2.2. Reading Times per Sentence Type and

Complement Type: Sentences per Character.............................. 121

4.3. Summary of Results 
CHAPTER 5. Conclusion and Discussion .............................................................. 126

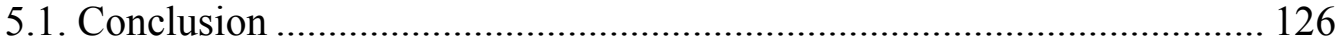

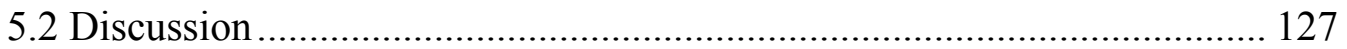

5.2.1. Transitive and Not-Transitive Sentences ................................. 127

5.2.2. Written Frequency .......................................................... 128

5.2.3. Minimal Attachment ......................................................... 129

5.2.4. Conclusion .......................................................................... 131

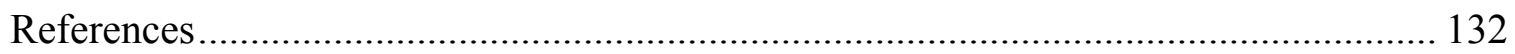

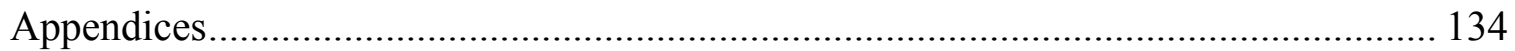




\section{LIST OF FIGURES}

FIGURE

PAGE

Figure 2.2.4.3 Structure for the man slept ..............................................................66

Figure 2.2.4.5a Structure for believed his sister with direct object ..............................69

Figure 2.2.4.5.b Structure for believed his sister with complement subject....................69

Figure 2.2.4.5.c Structure for after Mary mended the sock with direct object .................70

Figure 2.2.4.5.d Structure for after Mary mended the sock with subject complement ................................................................................. 71

Figure 2.2.4.5.e Spell-out of after Mary mended the socks fell .....................................71

Figure 2.2.4.5.f Structure for gave the man the dog with ditransitive object structure

Figure 2.2.4.5.g Structure for gave the man the dog with relative clause subject.............72

Figure 2.2.4.6 Structure for the cattle moved were …................................................77

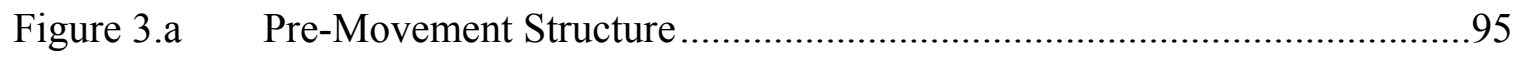

Figure 3.b Structure for which conference will the student will present the paper at each conference.

Figure 3.c Structure for at which conference will the student will present at which conference 96-97

Figure 4.1 Comprehension Question Task scores ..............................................112

Figure 4.2.1.1 Reading Times per Sentence Type: Whole Sentence .............................114

Figure 4.2.1.2 Reading Times per Sentence Type: Sentence per Character ..................116

Figure 4.2.1.1.a Reading Times per Sentence Type with wh-Complement what+noun: Whole Sentence .

Figure 4.2.1.1.b Reading Times per Sentence Type with wh-Complement which+noun: Whole Sentence 
Figure 4.2.2.1.c Reading Times per Sentence Type with wh-Complement whose+noun: Whole Sentence .................................................................120

Figure 4.2.2.2.a Reading Times per Sentence Type with wh-Complement what + noun: Sentence per Character

Figure 4.2.2.2.b Reading Times per Sentence Type with wh-Complement which+noun: Sentence per Character.

Figure 4.2.2.2.c Reading Times per Sentence Type with wh-Complement whose+noun: Sentence per Character 125 


\section{LIST OF TABLES}

TABLE

PAGE

Table 2.1.1.1 Analyzed data from the BNC (raw frequencies and column percentages)

Table 2.2.1.2 Variables that are argued to govern P-stranding...............................36-37

Table 2.2.1.3.a Distribution of constructions relative or VERB.....................................39

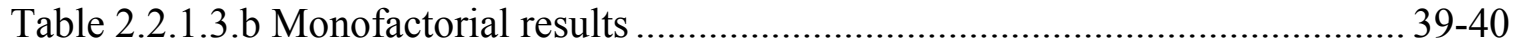

Table 2.2.1.3.c Factor loadings of the discriminant analysis................................... 41-42

Table 2.2.1.3.d The effect of transitivity on LENGTH_BS and BARRIER_BS...............43

Table 5.2.1 Distribution of constructions relative to VERB ....................................127

Table 5.2.2 Analyzed data from the BNC (raw frequencies and column percentages) 


\section{CHAPTER 1. Introduction}

The purpose of this study is to investigate the connection between the principles of Generative Grammar and the on-line processing of human language. Specifically, this study examines whether the Minimal Structure Principle (discussed in section 2.3) influences monolingual English speakers' processing of Preposition-Stranding (PStranding) and Pied-Piped Constructions. This investigation is made with a self-paced reading task, an on-line processing test that measures participants' unconscious reaction to language stimuli. The hypothesis of this study is that P-Stranding Constructions will have lower processing costs than Pied-Piped Constructions because there are fewer projections present in their representation, which is favored by the Minimal Structure Principle. However, results from the experiment show that P-Stranding and Pied-Piped Constructions do not differ significantly processing-wise. Proposed reasons for these

findings are discussed in Chapter 5, taking into account both Minimalist and frequencybased perspectives.

This thesis consists of five chapters. In Chapter 2, literature relevant to the purposes of this study is summarized. In Chapter 3, the study's hypothesis and methodology are discussed. The results of the experiment are presented in Chapter 4, followed by a discussion in Chapter 5 .

\section{CHAPTER 2. Literature Review}

In this chapter, seminal works are summarized with the purpose of providing a thorough background on specific topics related to this study. In section 2.1 , literature regarding Preposition-Stranding (P-Stranding) Constructions and their cross-linguistic 
variation are summarized. In section 2.2, works on language processing are summarized. In section 2.3, background on the Minimal Structure Principle and its application are provided. With these summaries, a hypothesis for this study is made in Chapter 3. Further, these summaries inform the conclusions made in Chapter 5.

\subsection{Preposition-Stranding Constructions Cross-Linguistically}

In this section, literature regarding Preposition-Stranding (P-Stranding) Constructions and their cross-linguistic variation are summarized.

Specifically, section 2.1.1 presents a summary of Paul Law's (2006) "Preposition stranding." Next, section 2.1.2 presents a summary of a chapter from Jason Merchant's (1999) dissertation "The syntax of silence: sluicing, islands, and identity in ellipsis," titled "Preposition-stranding." Last, section 2.1.3 presents a summary of Koji Sugisaki's (2011) "Preposition Stranding: Its Parametric Variation and Acquisition."

In Law's article, he explains and argues against several theories concerning why P-Stranding Constructions are not present in all languages. Next, he proposes that PStranding Constructions are not possible in languages that have Preposition and Determiner $(\mathrm{P}+\mathrm{D})$ suppletive forms.

Similarly, Merchant proposes a cross-linguistic generalization regarding PStranding under wh-movement and P-Stranding under sluicing in his dissertation. Last, Sugisaki reviews several proposed theories concerning the cross-linguistic variation of PStranding Constructions. Sugisaki tests a portion of these theories with children acquiring their first language. 
The purpose of providing an overview of these articles is to review the motivation for the cross-linguistic behavior of P-Stranding and Pied-Piping. All of the examples, figures, tables, and ideas provided in the summaries below are taken directly from the authors' articles.

\subsubsection{Law's "Preposition stranding"}

\subsubsection{Introduction}

When the complement of a preposition undergoes movement, stranding the preposition in its original position, the construction that results is a Preposition-Stranding (P-Stranding) Construction. This term was used by Ross in 1986 (Law, 2006). The extraction of prepositional complements can take place during A-movement (movement from one argument position to another argument position) or A-bar-movement (movement of a maximal projection to a non-argument position).

P-Stranding under A-bar-movement is more common cross-linguistically than under A-movement. In English and Scandinavian, for example, P-Stranding is allowed under both; examples from English are shown in (1):

(1) a. A-bar-movement:

Which book ${ }_{i}$ have they talked about $t_{i}$ ?

Which carpet $\mathrm{i}_{\mathrm{i}}$ did they step on $\mathrm{t}_{\mathrm{i}}$ ?

b. A-movement:

That book $\mathrm{k}_{\mathrm{i}}$ has been talked about $\mathrm{t}_{\mathrm{i}}$. This carpet $\mathrm{i}_{\mathrm{i}}$ was stepped on $\mathrm{t}_{\mathrm{i}}$. 
In Dutch and colloquial German, P-Stranding is only possible when an R-pronoun undergoes A-bar-movement. An example of this is shown in (2). Contrastingly, PStranding is not possible under any kind of movement in Romance languages (Law, 2006). An example of this is shown in (3).

(2) German

$\mathrm{Wo}_{\mathrm{i}} / * \mathrm{Was}_{\mathrm{i}}$ redest du von $\mathrm{t}_{\mathrm{i}}$ ?

what talk you from

'What are you talking about?'

(3) Italian

a. A-bar-movement:

*Che $\mathrm{i}_{\mathrm{i}}$ hai parlato di $\mathrm{t}_{\mathrm{i}}$ ?

what have-you talked about

'What did they talk about?'

b. A-movement:

*Questo libro è stato parlato di $\mathrm{t}_{\mathrm{i}}$ ?

this book has been talked about

'This book has been talked about.'

Therefore, while P-Stranding is not common cross-linguistically, it is possible in some languages with varying degrees of limitations. Law argues that these limitations are not the result of a grammatical principle permitting P-Stranding; instead, he claims that the possibility of P-Stranding depends on whether determiners (Ds) or determiner phrases (DPs) integrate into prepositions (Ps) or not. 


\subsubsection{Syntactic Constraints on Extraction and P-Stranding}

Law (2006) reviews the literature on the constraints and assumptions relevant to the possibility of P-Stranding in a particular language. For example, Van Riemsdijk (1978) claimed that P-Stranding is subject to the Head Constraint (HC), presented in (4).

(4) Head Constraint (HC):

"Movement out of PPs ... must move through the Spec position to avoid a violation of the $\mathrm{HC}$ if the head $\mathrm{H}$ is non-empty" (Law, 2006, p. 634).

Riemsdijk used the HC to explain the phenomena of Dutch, where R-pronouns are to the left of $\mathrm{P}$, in the $[\mathrm{Spec}, \mathrm{PP}]$ position, and R-pronouns can be moved out of PP. An example from Dutch is shown in (5):

(5) Dutch

a. Ik had niet $\left[\right.$ pp $\left.\mathrm{er}_{\mathrm{i}}\left[\mathrm{op}_{\mathrm{i}}\right]\right]$ gerekend.

I had not it on counted.

'I had not counted on it.'

b. Ik had er $r_{i}$ niet $\left[p p t_{i}\left[o p t_{i}\right]\right]$ gerekend.

Further, Emonds (1976) discusses the structure preserving constraint (SPC), presented in (6):

(6) Structure Preserving Constraint (SPC):

The SPC restricts "movement of a phrase to a position where it can be generated independently" (Law, 2006, p. 634).

If movement is permitted by this constraint, then non-R-pronouns cannot move out of PP through [Spec, PP] because they are not independently generated in [Spec, PP]. Similarly, neither can complements of $\mathrm{P}$ in Romance. Examples of this are shown in (7) and (8): 
(7) Dutch
a. Ik had niet [pP [op hem] $]$ gerekend.
I had not on him counted.
b. $\quad *$ Ik had niet $\left[\mathrm{pP}\right.$ hem $\left._{\mathrm{i}}\left[\mathrm{op} \mathrm{t}_{\mathrm{i}}\right]\right]$ gerekend.
c. $\quad *$ Ik had hem ${ }_{i}$ niet $\left[{ }_{p P} t_{i}\left[o p t_{i}\right]\right]$ gerekend.

(8) French

a. J'ai parlé à Jean.

I have talked to Jean.

'I talked to John.'

b. *J'ai parlé Jean à.

Thus, under this approach, if non-R-pronouns in Germanic or P-complements in Romance were to strand P, there would be a violation "either of the SPC if it moves through [Spec, PP], or the HC if it moves directly out of PP” (Law, 2006, p. 634).

If P-Stranding is subject to the $\mathrm{HC}$, then the complement of $\mathrm{P}$ must move through [Spec, PP] in English as well (Law, 2006). For this to be plausible, a wh-phrase must be able to be independently generated there, in order to satisfy the SPC. According to Riemsdijk (1978), wh-phrases occur in [Spec, PP] under sluicing; thus, the SPC is not violated (Law, 2006). Two examples are shown in (9):

(9) a. John left, but I don't know $\left[\mathrm{PP}^{\mathrm{who}} \mathrm{i}_{\mathrm{i}}\left[\right.\right.$ with $\left.\left.\mathrm{t}_{\mathrm{i}}\right]\right]$.

b. Mary bought some apples, but I don't know [pP what ${ }_{i}\left[\right.$ for $\left.t_{i}\right]$.

However, Law claims that sluicing is not evidence for this because the complement of know can only be a DP or CP, not a PP; this is shown in (10). 
(10) a. I knew John.

b. I knew when John was in class.

c. *I knew in the class.

Further, Law argues, if bare wh-phrases are able to occur in [Spec, PP], then non-bare wh-phrases should be able to as well; however, English does not permit sluicing with non-bare wh-phrases, as is shown in (11):

(11) *John left with some students, but I don't know [pp which ones i $_{i}$ with $\left.\mathrm{t}_{\mathrm{i}}\right]$ ]. (cf. John left with some students, but I don't know with which ones.) Therefore, if non-bare wh-phases are not permitted in [Spec, PP], then sluicing is not sufficient evidence to assume that wh-phrases can be independently generated there and that P-Stranding in English does not violate the HC.

Another problem Riemsdijk (1978) attempts to solve is one that appears in Dutch: in certain instances P-Stranding of a non-R-pronoun may occur (Law, 2006). An example of this is shown in (12):

(12) Dutch

a. Je zei dat hij [pP de boom in] geklommen is. you said that he the tree in climbed is 'You said that he climbed into that tree.'

b. Welke boom $_{\mathrm{i}}$ zei je dat hij [Pp $\mathrm{t}_{\mathrm{i}}$ in] geklommen is? which tree said you that he in climbed is 'Which tree did you say that he climbed into.'

Typically, non-R-pronouns may not be moved through [Spec, PP] because they do not occur there. Riemsdijk (1978) argues that examples like the one shown above are 
possible because "the $\mathrm{P}$ incorporates into V ... As a result, the head position of the PP is empty and the $\mathrm{HC}$ no longer applies; the wh-phrase in a PP whose head position is empty can now be extracted, observing the HC" (Law, 2006, p. 637). An example of this is shown below:

\section{(13) Dutch}

a. Je zei dat hij [pP de boom $\left.\mathrm{t}_{\mathrm{j}}\right] \mathrm{t}_{\mathrm{i}}$ is $\left[\mathrm{in}_{\mathrm{j}}+\text { geklommen }\right]_{\mathrm{i}}$.

b. Welke boom ${ }_{k}$ zei je dat hij $\left[p P t_{k} t_{j}\right] t_{i}$ is $\left[i_{j}+\text { geklommen }\right]_{i}$ ?

However, according to Law (2006), Riemsdijk's solution does not hold true for all cases, as there are instances when P distinctly does not become a part of V and P-stranding occurs (Law, 2006). An example is shown below:

Dutch

Welke boom $\mathrm{k}$ zei je dat hij [pP in $\left.t_{k}\right] t_{i}$ is geklommen ${ }_{i}$ ?

which tree said you that he in is climbed

'Which tree did you say that he climbed into?'

In the example above, the $\mathrm{HC}$ should be violated because there is P-Stranding of a non-Rpronoun. As previously stated, the $\mathrm{HC}$ requires that this movement pass through the [Spec, $\mathrm{PP}]$ position, an impossibility for non-R-pronouns because they cannot be basegenerated there, as required by the SPC.

\subsubsection{A Syntactic Reanalysis Account for P-Stranding}

Next, Law (2006) discusses Hornstein and Weinberg's (1981) Case-theoretic approach to P-Stranding. Under this approach, they assume that there is a reanalysis of 
the verb phrase (VP); this creates a complex verb, shown in (15b-c). Further, they assume that noun phrases (NPs) governed by prepositions (Ps) have [+oblique] Case, and Casemarking applies after reanalysis.
a. John [vp [v talked [pp to Harry] [pP about Fred]]].
b. John [vp [v talked to] Harry [pp about Fred]].
c. John [vP [v talked to Harry about] Fred].

According to Hornstein and Weinberg, the preposition complements shown above become the reanalyzed verb's direct objects. As a result, the preposition complements do not have [+oblique] Case and are able to undergo movement. Thus, P-Stranding is possible, as is shown in (16):
a. $\quad \mathrm{Who}_{\mathrm{i}}$ did John $\left[\mathrm{vp}\left[\mathrm{v}\right.\right.$ talk to $\mathrm{t}_{\mathrm{i}}[\mathrm{pP}$ about Fred] $]$ ?
b. $\quad \mathrm{Who}_{\mathrm{i}}$ did John $\left[\mathrm{vP}[\mathrm{v}\right.$ talk to Harry about $\left.] \mathrm{t}_{\mathrm{i}}\right]$ ?

However, there are issues with the reanalysis approach (Law, 2006). If $\mathrm{V}$ and $\mathrm{P}$ are reanalyzed into a complex verb, the $\mathrm{V}+\mathrm{P}$ complex verb should function like a syntactic unit, which is not the case. Evidence of this from Dutch is shown in (17) below:

\section{Dutch}

$*[\mathrm{v} \text { in klom }]_{\mathrm{i}}$ Jan de boom niet $\mathrm{t}_{\mathrm{i}}$ ?

in climbed Jan the tree not

'Did Jan not climb into the tree?

Second, when $\mathrm{P}$ and $\mathrm{V}$ are not positioned next to each other, it should be assumed that the $\mathrm{V}$ and $\mathrm{P}$ cannot incorporate into a complex verb. Thus, if $\mathrm{V}+\mathrm{P}$ reanalysis is not possible in these cases, P-Stranding should also not be possible. However, this is not the case, as is shown below: 


\section{(18) Dutch}

Welke boom klom Jan $\left[p p t_{i}\right.$ in]?

which tree climbed Jan in

'Which tree did Jan climb into?'

Third, from a cross-linguistic perspective, the reanalysis account of P-Stranding is not sufficient because it "assume[s] that languages [without P-Stranding cannot have a] syntactic rule of reanalysis" (Law, 2006, p. 640). Therefore, Law dismisses the reanalysis approach.

\subsubsection{Government-Theoretic Accounts of P-Stranding}

Next, Law (2006) discusses a "government-theoretic [account] of P-Stranding . . related to government and Case property of a lexical head" (p. 640). Under this account, Kayne (1984) agrees that there is reanalysis, but he proposes that the reanalyzed elements must be governed similarly (Law, 2006). In English, verbs (Vs) and prepositions (Ps) govern and assign Case similarly; thus, Vs and Ps can be reanalyzed into complex verbs

in English. Contrastingly, in French, Vs and Ps cannot undergo reanalysis because Vs and Ps do not govern similarly (Law, 2006).

Law (2006) disagrees with this approach because Kayne uses the differences between French and English P-complementizers, not PPs, as evidence, and those differences do not apply to PPs. Rather, French and English "Ps in PPs assign and check Case of their objects" similarly, as is shown below (Law, 2006, p. 642): 
a. English

I voted [pp for John].

b. French

J'ai voté [pp pour Jean].

I-have voted for John

'I voted for John.'

Therefore, under Kayne's approach, Vs and Ps should become complex verbs in French, which would permit P-Stranding. However, P-Stranding is not possible in Romance languages, proving this approach problematic.

\subsubsection{P-Stranding and Syntactic D-and-P Incorporation}

Considering the limitations of the analyses proposed above, Law (2006) argues a different approach: P-Stranding occurs in a language when the DP object is able to move away from P. In some languages, this is not possible because the P and the DP object are not separable. For example, in Romance and German, P can combine with its object's D to create a suppletive form. Examples of these suppletive forms are shown in (20). In example (20a), 'du' is a suppletive form of 'de' and 'le.' In example (20b), 'am' is a suppletive form of 'an' and 'dem.'

(20) a. French

Jean a parlé du sujet le plus difficile.

has talked about-the subject the most difficult.

'John talked about the most difficult subject.' 


\section{b. German}

Hans war am Schalter.

was at-the counter.

'Hans was by the counter.'

Because the suppletive form is a combination of both the $\mathrm{P}$ and $\mathrm{D}$, it impossible to separate the object from the P; the entire DP must move if movement is to take place, and the NP that follows the D cannot undergo movement without the D (Law, 2006).

According to Law (2006), there is a "syntactic constraint on suppletion: elements that undergo suppletive rules must form a syntactic unit $X^{0 \prime \prime}$ (p. 647). Thus, when D

incorporates into $\mathrm{P}$, the two constituents form a syntactic unit, $\mathrm{X}^{0}$. It should be noted that a suppletive form is not required for the $\mathrm{P}+\mathrm{D}$ to form a syntactic unit. Rather, "the null hypothesis is that all Ds incorporate into Ps in Romance and Germanic languages except English" (Law, 2006, p. 647). Under this approach, D+NP cannot move away from P in Romance and Germanic languages (except English) because P+D are a syntactic unit, making P-Stranding impossible.

\subsubsection{P-Stranding under A-movement and A-bar-movement in Germanic}

With this in mind, it should be assumed that P-Stranding is possible when D does not incorporate into P. However, in Germanic languages, even though there is D-to-P incorporation, P-Stranding of some R-pronouns is permitted under A-bar-movement. According to Law (2006), P-Stranding is possible in these cases because R-pronouns occur "to the left of P . . in [Spec, PP]" (p. 651). When the DP is to the left of P, the D 
and $\mathrm{P}$ cannot form a syntactic unit $\mathrm{X}^{0}$. Thus, the $\mathrm{D}$ and $\mathrm{P}$ are separable and the $\mathrm{DP}$ can be moved out of [Spec, PP]. An example of this is shown in (21):

\section{(21) German}

a. Es wurde völlig [da [mit]] gerechnet.

it became fully it on counted

'It has been fully counted on.'

b. Es wurde da $a_{i}$ völlig $\left[t_{i}[\right.$ mit $\left.]\right]$ gerechnet.

c. $\quad \mathrm{Da}_{\mathrm{i}}$ wurde völlig $\left[\mathrm{t}_{\mathrm{i}}[\mathrm{mit}]\right]$ gerechnet.

The example above may appear to be A-movement because there is not movement of a wh-phrase, as is expected of A-bar-movement. "However, for virtually all analyses of verb-second root clauses, a non-subject appearing before the verb in second position is in [Spec, CP], an A-bar position on standard assumptions" (Law, 2006, p. 654). Therefore, P-Stranding is not likely to be possible under A-movement in any Germanic language except English.

P-Stranding under A-movement is possible in English because English differs from other Germanic languages in regards to Case when it comes to passive constructions (Law, 2006). In English, the passive morpheme absorbs the object's accusative Case; this forces the object to take nominative Case and move to the subject position to check its Case. An example of this is shown below:

a. They killed John and Mary.

b. John and Mary ${ }_{i}$ were killed $t_{i}$.

In (22), the passive morpheme has absorbed the object Case of John and Mary, causing the DP to take nominative Case and move to subject position. In all Germanic languages 
except for English, Case absorption is not required. Because of this, impersonal passive constructions are possible in all other Germanic languages. An example of this is shown in (23):

a. Danish

... at der er blevet danset.

... that it there became danced

'. . that there was dancing.'

b. English

*... that there/it has been danced

Example (23b) shows that the impersonal passive construction is not possible in English; the expletive does not take nominative Case after having its accusative Case absorbed by the passive morpheme, and it is not moving from object position to [Spec, IP] (Law, 2006).

According to Law (2006), in all Germanic languages except English, P-Stranding under A-movement is not possible. Rather, $\mathrm{P}$ is stranded under A-bar-movement because the object moves to a non-Case position (a position other than [Spec, IP]). Therefore, the possibility of P-Stranding under A-movement is directly related to whether a language requires Case absorption when a passive is constructed. If impersonal passives are possible in a language, it is predicted that the language does not allow P-Stranding under A-movement. 


\subsubsection{Conclusion}

In conclusion, Law proposes that P-Stranding is the result of a DP moving out of a PP. When a D incorporates into $\mathrm{P}$, the DP is no longer separable from $\mathrm{P}$, meaning that $\mathrm{P}-$ Stranding is not possible. Because $\mathrm{P}+\mathrm{D}$ suppletive forms are present, $\mathrm{P}-\mathrm{Stranding}$ is not possible in Romance languages and has limited possibility in Germanic languages other than English. Lastly, in Germanic languages other than English, P-Stranding is possible with R-pronouns under A-bar-movement; however, P-Stranding under A-movement is not permitted.

\subsubsection{Merchant's "The syntax of silence: sluicing, islands, and identity in ellipsis" -} "Preposition-stranding"

In "Preposition-stranding," a chapter in Jason Merchant's (1999) dissertation

“The syntax of silence: sluicing, islands, and identity in ellipsis," Merchant makes a connection between languages that allow sluicing and languages that allow PrepositionStranding (P-Stranding). Sluicing, in this case, is a term used for when a Prepositional Phrase (PP) is elided and only the wh-Determiner Phrase (wh-DP) - formerly the preposition complement - remains. An example of this can be seen in (2a).

Specifically, Merchant makes the following generalization:

(1) "Form-identity generalization II: Preposition-stranding

A language $L$ will allow preposition stranding under sluicing iff $L$ allows preposition stranding under regular wh-movement" (1999, p. 126).

Therefore, if a language allows (2b), then it will allow (2a). 
(2) a. Sluicing

Peter was talking with someone, but I don't know (with) who.

b. P-Stranding

Who was he talking with?

Merchant (1999) explains that a language will either permit or not permit PStranding Constructions, and it is more common cross-linguistically for P-Stranding to not be permitted within a language. He uses the following as evidence:

Dryer 1997, in his sample of 625 languages, found no language outside of the Germanic family that productively allowed such displacement. The facts are simple and well-known: in English and the Scandinavian languages, wh-movement may strand a preposition in all the standard whmovement environments: interrogatives, topicalization, relativization (including clefts and psuedoclefts), and comparatives. (In the continental West Germanic languages, such preposition stranding . . . is restricted to a small class of displaceable elements known as 'R-pronouns') (Merchant, 1999, p. 126).

As Merchant explains, the only other option for a language that wants to move a wh-DP governed by a preposition is to displace both the preposition and the wh-DP together. The movement of a preposition and its wh-DP complement was called Pied-Piping, a term created by Ross in 1967 (Merchant, 1999).

In the following two examples from Germanic languages, the generalization proposed by Merchant (1999) is displayed. As in (2), (3a) shows an example of sluicing 
and (3b) shows an example of P-Stranding. Thus, in the examples below, P-Stranding is possible, so sluicing is possible.

(3) Swedish

a. $\quad$ Sluicing

Peter har talat med någon; jag vet inte (med) vem.

Peter has talked with someone I know not with who

b. P-Stranding

Vem har Peter talat med?

(4) Norwegian

a. $\quad$ Sluicing

Per har snakket med noen, men jeg vet ikke (med) hvem.

Per has talked with someone but I know not with who

b. P-Stranding

Hvem har Per snakket med?

(5) Danish

a. $\quad$ Sluicing

Peter har snakket med en eller anden, men jeg ved ikke (med) hvem.

Peter has talked with one or another but I know not with who

b. P-Stranding

Hvem har Peter snakket med?

Contrastingly, languages that do not allow P-Stranding do not allow sluicing. Examples of this are presented in (6-8): 
(6) Greek

a. Sluicing

I Anna milise me kapjon, alla dhe ksero *(me) pjon.

the Anna spoke with someone but not I.know with who

b. P-Stranding

*Pjon milise me?

(7) Russian

a. Sluicing

Anja govorila s kem-to, no ne znaju *(s) kem.

Anja spoke with someone, but not I.know with who

b. P-Stranding

*Kem ona govorila s?

(8) Spanish

a. Sluicing

Ana habló con alguien, pero no sé ??(con) quién.

Ana spoke with someone but not I.know with who

b. P-Stranding

*¿Quién habló con?

Merchant (1999) checked the examples from languages other than English with native speaker informants. In some cases, speakers of a language that does not allow PStranding judged the sluicing examples as somewhat grammatical. Merchant (1999) linked these judgments to the poor overt case systems of those particular languages. For highly case-marked languages, all of the informants found the sluicing sentences 
ungrammatical. Merchant (1999) explains, "It is difficult to believe that the correlation between overt morphological case and clarity in judging the P-stranding examples could be entirely due to chance. More likely is that sluicing might be able to give us a window into the mechanisms at work in controlling P-stranding across languages, with the nonvariation in certain languages indicating a stronger connection between case and Pmarking than in other languages" (p. 135).

On the scale of analyticity in regards to whether a language marks grammatical relations, English and Scandinavian languages are highly analytic, and languages like Lezgian are highly fusional. With this in mind, English and Scandinavian languages allow P-Stranding, while Lezgian (and similar languages) do not. While Merchant proposed this information for future investigation, he does not expand on it further.

Rather, Merchant (1999) provides more data in support of his hypothesis. First, he presents sluicing examples with argument PPs, headed by 'about,' selected by predicates of information transfer. Examples of this can be seen in (9-10).

\section{(9) German}

Peter hat über jemanden aus deiner Klasse gesprochen Peter has about someone from your class spoken rate mal, *(über) wen guess PRT about who.

'Peter was talking about someone from your class - guess who.'

(10) Greek

I gonis tou pedhiou malosan gia kati, the parents of.the child argued.3pl about something, 
alla arnite na mas pi *(gia) ti.

but refused.3sg SUBJ us tell about what

'The child's parents were arguing about something, but she refused to tell us what.'

Merchant also provides examples of sluicing with PP adjuncts. Example (11) shows sluicing with a locative adjunct, and example (12) shows sluicing with a comitative adjunct.

\section{(11) Greek}

I Anna apokimithike s'ena apo ta mathimata, alla dhe ksero *(se) pjo.

the Anna fell.asleep in-one of the classes but not I.know in which

\section{(12) Russian}

Pëtr tanceval s kem-to, no ja ne pomnju*(s) kem.

Pëtr was.dancing with someone but I not remember with who

These examples show that the generalization remains the same, even when the type of PP (argument or adjunct) differs.

Similarly, Merchant (1999) argues that the "generalization in [(1)] holds even 'across' islands" (p. 139). The following examples from English show that "although the sluiced wh-phrase must be associated with a gap 'inside' an island, nevertheless the language-particular constraints on P-stranding must continue to be respected" (Merchant, 1999, p. 139):

(13) English

a. Ben's mom will get angry if he talks with someone from his class, but I don't remember who. 
b. Abby wants to interview someone who lived in one of the Balkan counties, but I can't remember which.

(It should be noted that, according to Merchant, P-Stranding is considered better than Pied-Piping in English.) Similarly, in languages that do not allow P-Stranding, the generalization in (1) "holds even when the sluicing wh-phrase ... associates into an island" (Merchant, 1999, p. 140). Two examples of this from Greek are shown below:

(14) Greek

a. I mitera tou Gianni tha thimosi an milisi me kapjon the mom of Giannis FUT get.angry if he.talks with someone apo tin taksi tou, alla dhe thimame *(me) pjon. from the class his but not I.remember with who 'Gianni's mom will get angry if he talks with someone from his class, but I don't remember who.'

b. I Maria theli na milisi me kapjon pu na exei polemisi the Maria wants SUBJ talk with someone who SUBJ has fought s'enan apo tous Valkanikous polemous, ala dhen ksero *(se) pjon. in-one from the Balkan wars but not I.know in which 'Maria wants to talk to someone who fought in one of the Balkan wars, but I don't know which.'

According to Merchant (1999), the examples above are evidence that the generalization in (1) is true both when there is an island and when there is not.

In conclusion, Merchant (1999) proposes that a language that allows P-Stranding under wh-movement will allow P-Stranding under sluicing; moreover, a language that 
requires Pied-Piping under wh-movement will not allow P-Stranding under sluicing. As is shown above, there is much cross-linguistic evidence in support of this hypothesis. For more examples, I refer the reader to Merchant's article.

\subsubsection{Sugisaki's "Preposition Stranding: Its Parametric Variation and Acquisition"}

\subsubsection{Introduction}

Koji Sugisaki (2011) explores various cross-linguistic generalizations concerning P-Stranding in his article, "Preposition Stranding: Its Parametric Variation and Acquisition." Also, Sugisaki tests the reliability of several of these generalizations with children who are acquiring their first language.

\subsubsection{Parametric Variation in P-Stranding}

Sugisaki (2011) points out that P-Stranding is possible in English, while Pied-

Piping (referred to as P-pied-piping in the article) sounds odd in spoken English.

Contrastingly, P-Stranding in Spanish is not possible, and Pied-Piping is mandatory.

Consider the following examples:

(1) English

a. Who was Peter talking with t?

b. With whom was Peter talking t?

(2) Spanish

a. *Quién hablaba Pedro con t?

who was-talking Peter with 
b. Con quién hablaba Pedro t?

with who(m) was-talking Peter

According to Sugisaki (2011), several reasons for this cross-linguistic variation have been proposed by various authors in the recent past. First, Stowell (1981) proposed the following cross-linguistic generalization regarding the occurrence of P-Stranding: "Pstranding is possible only in those languages that permit transitive verb-particle construction[s] (especially the one with the order V-Particle-NP)" (Sugisaki, 2011, p. 2). As shown below, English permits this construction, but Spanish does not:
a. English

Mary lifted up the box.

b. Spanish

María levantó $($ arriba) la caja.

Second, Kayne (1981) proposed the following two cross-linguistic generalizations: the Prepositional Complementizers (PC) Construction and the Double Object/Accusative Construction are "possible only in those languages that allow PStranding" (Sugisaki, 2011, p. 3). Examples of this are shown below:

(4) PC Construction:

a. English

John wants (for) Mary to leave.

b. French

*Jean veut (de) Marie partir. 
(5) Double Accusative:

a. English

John gave Mary a book.

b. French

*Jean a donné Marie un livre.

As shown in (5), the PC Construction is possible in English, which permits P-Stranding; however, the PC Construction is not allowed in French, a language that does not permit P-Stranding. Similarly, in (6), the Double Accusative is possible in English but not in French.

Third, Maling and Zaenen (1985) proposed another cross-linguistic generalization: "P-stranding with A-movement (prepositional passives or psuedopassives) is possible only in those languages that allow P-stranding with [A-barmovement]" (Sugisaki, 2011, p. 3). For example, both English and Norwegian (and Swedish, not shown below) allow P-Stranding under both types of movement:

(6) English
a. What did they talk about t?
b. This problem was already accounted for $\mathrm{t}$.

(7) Norwegian

a. Hvem har Per snakket med? who has Per talked with

b. $\quad$... at Petter ble ledd av. ... that Peter was laughed at 
Fourth, Law $(1998,2006)$ proposed the following: "Pied-piping of prepositions (P-pied-piping) is obligatory in those languages that have suppletive forms of prepositions and determiners ( $\mathrm{P}+\mathrm{D}$ suppletive forms)" (Sugisaki, 2011, p. 4). Below is an example of a $\mathrm{P}+\mathrm{D}$ suppletive form $(\mathrm{du})$ occurring in French:

(8) French

Jean a parlé du sujet le plus difficile Jean have talked about-the subject the most difficult

'Jean talked about the most difficult subject'

Because the preposition and determiner have combined into the suppletive form, as shown above, the determiner phrase is no longer separable from the preposition; thus, only Pied-Piping is possible in languages with $\mathrm{P}+\mathrm{D}$ suppletive forms.

Fifth, Merchant (2001) proposed that P-Stranding is possible under sluicing if PStranding is possible under wh-movement. In English, for example, P-Stranding is possible under sluicing and under regular wh-movement, as shown in (9). Contrastingly, in German, P-Stranding is not allowed under regular wh-movement or under sluicing, as shown in (10):

(9) English

a. Peter was talking with someone, but I don't know (with) who.

b. Who was Peter talking with?

(10) German

a. Anna hat mit jemandem gesprochen, aber ich wei $\beta$ nicht *(mit) wem. Anna has with someone spoken but I know not with who. 
b. *Wem hat sie mit gesprochen?

who has she with spoken

Next, Sugisaki (2011) discusses swiping, which, according to Merchant (2002), is an acronym for sluiced wh-word inversion with prepositions in Northern Germanic. Hasegawa (2007) proposed that "swiping is possible only in those languages that allow P-Stranding" (Sugisaki, 2011, p. 6). For example, swiping can be found in English and Danish, as is shown below:

(11) a. English

Peter went to the movies, but I don't know who with.

b. Danish

Per er gået I biografen, men jeg ved ikke hven med.

Per is gone to cinema but I know not who with

'Per went to the movies, but I don't know who with.'

In addition, Truswell's (2009) proposed the following cross-linguistic generalization: “[A-bar-extraction] from Bare Present Participial Adjuncts (BPPA) is possible only in those languages which allow psuedopassivization" (Sugisaki, 2011, p. 6). A BPPA is an adjunct headed by a present participle. A-bar-extraction out of BPPA is possible in English and Norwegian, as is shown below:

(12) a. English

What did John arrive [whistling t]?

b. Norwegian

Hvilken sang kom han [plystrende på t]?

which song came he whistling on 
'Which song did he arrive whistling?'

Last, Sugisaki (2011) looks at Tokizaki’s (2010, 2011) PF approach to the parameter of P-Stranding. Tokizaki (2010, 2011) combined Stowell's (1981)

generalization about P-Stranding and transitive verb-particle constructions with Snyder's (2001) generalization, which states that "transitive verb-particle constructions are permitted only in those languages that permit recursive compounds," to create the following revised cross-linguistic generalization: "P-stranding is possible only in those languages that allow recursive compounds" (Sugisaki, 2011, p. 13-14).

Tokizaki $(2010,2011)$ claimed that there is a phonological constraint on these recursive compounds, which is that "the main stress location of compounds must correspond to the canonical word-stress location in that language" (Sugisaki, 2011, p. 14). In English, Swedish, and Norwegian, for example, the canonical word-stress location falls on the antepenultimate, penultimate, or ultimate syllable. An example from English is presented in (13). In French, Italian, and Spanish, the canonical word-stress location falls on the penultimate or ultimate syllable, not the antepenultimate. An example from Italian is shown in (14).

(13) English

a. Assign stress to the most deeply embedded element (Cinque 1993):

[ plan [ $\operatorname{disposal}\left[\begin{array}{ll}\text { waste }\end{array}\right]$ ] ]

b. Movement to the specifier position:

i. $\left[\begin{array}{lllllll}\text { plan } & {[} & \text { disposal } & {[} & \text { waste }\end{array}\right]$
ii.
i


(14) Italian

a. Assign stress to the most deeply embedded element (Cinque 1993):

[ piano [ smaltimento [ rifiuti $] \quad]$

b. Movement to the specifier position:

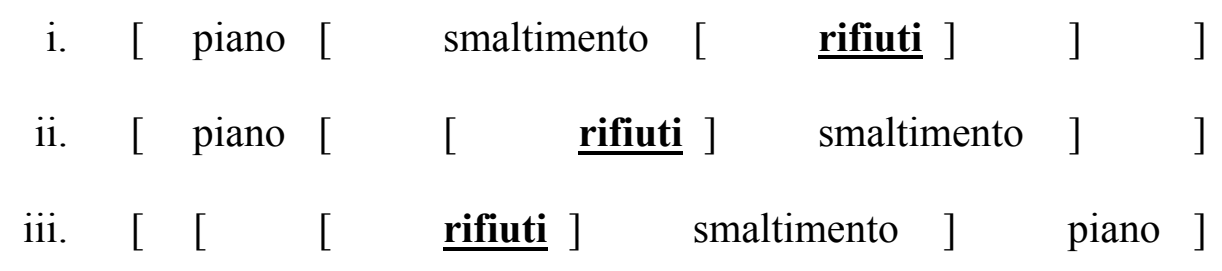

English has recursive compounds, and those recursive compounds satisfy this phonological constraint. For example, in waste disposal plan, the stress is applied to waste; thus, the stress falls on the antepenultimate. Contrastingly, Italian does not have recursive compounds. If * rifiuti smaltimento piano existed in Italian, the stress would be on the antepenultimate syllable, which is not a canonical word-stress location in Italian and would, therefore, violate the aforementioned phonological constraint.

Similarly, according to Tokizaki $(2010,2011)$, the same phonological constraint applies to P-Stranding (Sugisaki, 2011). "In order for P-stranding to be possible, the verb and the preposition must undergo 'phonological word-formation.' The resulting 'word' must conform to the canonical word-stress location in that language" (Sugisaki, 2011, p. 15). Examples from English and French are presented in (15):

a. English ... wórking with $\mathrm{t}$

b. French ... traváillez avec $\mathrm{t}$ 
In the both examples, the stress is on the antepenultimate. In English, this satisfies the phonological constraint, but in French it does not. For this reason, Tokizaki claims, PStranding is not permitted in French, as it is in English (Sugisaki, 2011).

\subsubsection{Acquisitional Evaluations}

Sugisaki (2011) performed experiments to test several of the theories mentioned above in order to see whether these cross-linguistic generalizations proved to be true for children acquiring their first language.

In regards to Stowell's (1981) prediction that the possibility of P-Stranding in a language is related to the existence of transitive verb-particle constructions in that language, Sugisaki (2011) predicted that children would produce V-Particle-NP Constructions before P-Stranding Constructions. Ten children were tested, and eight of those children acquired all three constructions during the testing period: the V-ParticleNP Construction, direct-object wh-question, and P-Stranding Constructions. The results showed that "six of the eight children acquired the V-Particle-NP construction significantly earlier than P-stranding ... the remaining two children acquired the VParticle-NP construction and P-stranding at approximately the same age ... [and] crucially, no child in [the] study acquired P-stranding significantly earlier than the VParticle-NP construction" (Sugisaki, 2011, p. 9). Therefore, Stowell's generalization was supported by the experiment's results.

When testing Law's $(1998,2006)$ approach, which links mandatory Pied-Piping in a language to the existence of $\mathrm{P}+\mathrm{D}$ suppletive forms in that language, Sugisaki (2011) predicted that a child learning French as his/her first language will produce Pied-Piped 
Constructions when he/she produces overt wh-movement and $\mathrm{P}+\mathrm{D}$ suppletive forms. Two children were tested, but only one acquired all three expected constructions during the time of the experiment: direct-object wh-questions, wh-questions with Pied-Piping, and $\mathrm{P}+\mathrm{D}$ suppletive forms. The results showed that the child "acquired P-pied-piping significantly later than overt wh-movement and $\mathrm{P}+\mathrm{D}$ suppletion, contrary to the prediction from the parametric proposal by Law" (Sugisaki, 2011, p. 11). Thus, the experiment's results did not support the proposal.

Next, Sugisaki (2011) evaluated Hasegawa's (2007) claim that only languages that permit P-Stranding Constructions will have swiping. He predicted that children learning English would produce P-Stranding with wh-movement constructions before or at the same time as they produce swiping constructions. Each child's first use of swiping and wh-movement involving P-Standing were recorded. Aran, one of the children, "exhibited the first clear use of swiping at the age of 2;07" and his first use of PStranding "at the age of 2;05" (Sugisaki, 2011, p. 12-13). Sugisaki discussed only Aran's results and claimed that the results support Hasegawa's (2007) generalization because Aran began to use P-Stranding before swiping constructions.

In conclusion, Sugisaki (2011) writes, "Child language is potentially a very useful tool to find out 'significant' cross-linguistic generalizations, those that should be subjected to minimalist/biolinguistic scrutiny and reformulation" (p. 15). Using child language acquisition data, Sugisaki is able to support Stowell's (1981) generalization and Hasegawa's (2007) generalization. However, Law's $(1998,2006)$ generalization is not supported by Sugisaki's experimental data. 


\subsection{Language Processing}

In this section, literature regarding language processing is summarized.

Specifically, section 2.2.1 presents a summary of Stefan Gries's (2002) "Preposition Stranding in English: Predicting Speakers' Behaviour." Gries, taking a Corpus Linguistics perspective, examines corpora to determine whether P-Stranding or Pied-Piped Constructions have greater processing costs. From his data, Gries concludes that PiedPiped Constructions are preferred in sentences with transitive verbs as a consequence of the bridging structure's length and barrierhood, which causes additional processing costs.

Next, section 2.2.2 presents a summary of Markus Bader and Tanja Schmid's (2009) "Minimality in verb-cluster formation.” Bader and Schmid argue that the parser favors derivations with less structure and fewer movement operations. They discuss the Minimal Attachment Principle and the Left-to-Right Constraint and then propose the following two hypotheses: the Clause-Union Preference hypothesis and the Verb Cluster Complexity hypothesis. They support their hypotheses with results from a speeded grammaticality judgment task in which native German speakers judged sentences with intraposed versus extraposed infinitival complements.

Following this, section 2.2.3 presents a summary of Fernanda Ferreira and Charles Clifton, Jr.'s (1986) “The Independence of Syntactic Processing.” Ferreira and Clifton examine whether the parser's initial syntactic analysis is influenced by semantic or pragmatic content. They test this with two eye-tracking experiments and one selfpaced reading task experiment. With the results, Ferreira and Clifton conclude that 
nonsyntactic information does not influence the parser; they use this as evidence to support the notion of a modular language processer.

Last, section 2.2.4 summarizes Amy Weinberg’s (1999) “A Minimalist Theory of Human Sentence Processing.” Weinberg argues that grammatical constraints specifically, economy principles and Spell Out - are present during language processing. Further, she argues that frequency of occurrence works together with grammatical constraints during in language processing.

The purpose of summarizing these works is to provide background on previously proposed theories concerning the language processor and processing costs. In this study, the focus is to compare the processing costs of Preposition-Stranding and Pied-Piped Constructions, and thus, these theories are central to the discussion. Note that all of the examples, figures, tables, and ideas provided in the summaries below were taken directly from the authors' articles.

\subsubsection{Gries's "Preposition Stranding in English: Predicting Speakers' Behaviour"}

\subsubsection{Introduction}

Stefan Gries (2002) takes a Corpus-Linguistics approach to language processing. From a Corpus-Linguistics perspective, it is believed that conclusions about linguistic preference can be made through the analysis of corpora. A corpus is a collection of text or speech, available for analysis by linguists and other researchers. The CorpusLinguistics approach is different from the Generative Grammar approach, which typically uses experimental methods to reach conclusions. For example, grammaticality judgment and self-paced reading tasks are often used to test a hypothesis. In the article "Preposition 
Stranding in English: Predicting Speakers' Behaviour," Gries investigates whether PStranding or Pied-Piped Constructions occur more frequently in spoken and written corpora; however, more importantly, he investigates whether different groups of variables influence a speaker's construction choice and tries to make predictions based on his findings.

\section{The Phenomenon}

English Prepositional phrases (PPs) consist of a preposition (P) followed by its complement; this is shown in (1a-b) (Gries, 2002). However, this word order can change when the PP undergoes a movement operation that affects the P-complement. In these cases, the $\mathrm{P}$-complement separates from the $\mathrm{P}$, stranding $\mathrm{P}$ in its original location. When this happens, a Preposition-Stranding (P-Stranding, PS, or SC) Construction is formed. In addition, when a movement operation affects a PP, a Pied-Piped Construction (PPC) can occur. Pied-Piping will move the entire PP; thus, the $\mathrm{P}$ will remain in front of the Pcomplement in its new position. A Pied-Piping example is presented in (2a); a PStranding example is presented in (2b).

(1) a. He has paid [pp for the room].

b. It is worth listening [PP to him].

(2) a. [pP To whom $]_{i}$ did John give the book $t_{i}$ ?

b. Who did John give the book $\left[\mathrm{pP}\right.$ to $\left.\mathrm{t}_{\mathrm{i}}\right]$ ?

Concerning the two construction types, Gries (2002) proposes three question presented below:

(3) 1. When are P-complements allowed to strand P? 
2. Why is P-Stranding allowed in English?

3. What variables determine which construction is used, and which variables have the greatest impact on construction choice? "On the basis of these variables, can we predict the constructional choice by native speakers of English?" (p. 3)

In regards to his second question, Gries (2002) argues that the existence of P-Stranding in English is unusual; his argument for this is presented in (4):

(4) a. P-Stranding "in interrogatives is prescriptively considered ungrammatical;

b. in general, English has a comparatively rigid word order allowing little word order variation;

c. filler-gap constructions are known for the processing load they impose on interlocutors compared to their pied-piped counterparts, which is why they are cross-linguistically quite rare: First, speakers need to process/produce the whole of the bridging structure while still having to produce the preposition. Second, hearers need to identify the gap to which the filler belongs ... only after the final word of the sentence has been processed do they know that the sentence initial NP is part of the PP" (p. 1-2).

However, it is question three that Gries focuses on in his article.

\section{Hypotheses and Objectives}

Processing costs are assumed by numerous studies to influence construction choice; however, these studies differ in regards to whether the author(s) believe(s) that this choice is made based on the processing costs of the hearer or the speaker (Gries, 
2002). For example, Hawkins $(1991,1994,1999)$ claims that the hearer's processing costs are of the most importance; Arnold and Wasow $(1996,2000)$ argue that it could be the speaker or the hearer's processing costs that make the most impact (Gries, 2002). Also, in Gries's 2000 article, he argued that the speaker's perspective is the most important for influencing construction choice, a standpoint he maintains in the present article.

Whose processing effort (the speaker or the hearer) is more significant is not the only difference in these studies, however. A second difference lies in the "determinants (or manifestations) of the processing efforts" (Gries, 2002, p.2). For example, Hawkins (1999) looked at both morphosyntactic determinants and lexico-semantic variables (Gries, 2002). Similarly, Arnold and Wasow (2000) looked at morphosyntactic variables and discourse-functional variables (Gries, 2002). Gries, in his 2000 work, suggested that "the processing cost of utterances differing only in terms of their constituent ordering is determined by (or, at least, correlates with) an even larger variety of variables, namely phonological, morphosyntactic, semantic, discourse-functional and other variables (such as structural priming or speed of lexical retrieval)" (2002, p. 3). Under his 2000 approach, thus, constituent ordering is influenced by many more variables than Hawkins or Arnold and Wasow pointed out in their studies.

Gries (2002) hypothesizes that P-Stranding Constructions are more difficult to process than Pied-Piped Constructions; further, he argues, a speaker will choose a construction type based on how high or low the processing costs of that sentence already are. Specifically, when processing costs are high, a speaker will choose the Pied-Piped Construction because it is less costly than the P-Stranding Construction. When processing costs are low, the P-Stranding Construction will be used. 
To test this hypothesis, Gries looks at "naturally-occurring corpus data," which he gathered through "a concordance program [that searched] the British National Corpus (BNC) for instances of the two constructions" (2002, p. 3). The chart presented in (5) displays Gries's corpus data:

(5) Table 2.2.1.1: Analyzed data from the BNC (raw frequencies + column percentages)

\begin{tabular}{|c|c|c|c|}
\hline & Written & Spoken & Row totals \\
\hline PPC & $122(49.39 \%)$ & $0(0 \%)$ & $122(40.53 \%)$ \\
\hline SC & $125(50.61 \%)$ & $54(100 \%)$ & $179(59.47 \%)$ \\
\hline Column totals & $247(100 \%)$ & $54(100 \%)$ & $301(100 \%)$ \\
\hline
\end{tabular}

\subsubsection{Previous Analyses}

The chart in (6) presents numerous variables that previous studies have said influence the choice between P-Stranding and Pied-Piped Constructions (Gries, 2002):

(6) Table 2.2.1.2: Variables that are argued to govern P-Stranding

\begin{tabular}{|c|c|c|}
\hline Value for PPC & Variable & Value for $\mathrm{SC}$ \\
\hline dominant & $\begin{array}{c}\text { dominance of extracted phrase } \\
\text { (Erteschik-Shir and Lappin 1979) }\end{array}$ & \\
\hline high & $\begin{array}{c}\text { attention attraction of the } \\
\text { extracted phrase (Deane 1992) }\end{array}$ & \\
\hline high & $\begin{array}{l}\text { topicality of extracted phrase } \\
\text { (Kuno 1987) }\end{array}$ & \\
\hline high & $\begin{array}{l}\text { semantic barrierhood of the } \\
\text { extracted phrase (Kluender 1990) }\end{array}$ & low \\
\hline high & $\begin{array}{c}\text { entrenchment of the extracted } \\
\text { phrase (Deane 1992) }\end{array}$ & \\
\hline low & $\begin{array}{c}\text { semantic barrierhood of the } \\
\text { bridging structure } \\
\text { (Kluender 1990) }\end{array}$ & high \\
\hline short & $\begin{array}{l}\text { syllabic length of the bridging } \\
\text { structure (Quirk et al. 1985) }\end{array}$ & long \\
\hline high & $\begin{array}{l}\text { relation between light verb and } \\
\text { extraction site (Deane 1992) }\end{array}$ & \\
\hline low & $\begin{array}{l}\text { attention attraction of the } \\
\text { bridging structure (Deane 1992) }\end{array}$ & \\
\hline VP-final & $\begin{array}{c}\text { position of extraction site } \\
\text { (Deane 1992) }\end{array}$ & \\
\hline
\end{tabular}




\begin{tabular}{|c|c|c|}
\hline $\begin{array}{l}\text { newer/more-important } \\
\text { than rest of } S\end{array}$ & $\begin{array}{c}\text { cognitive status of extraction site } \\
\text { (Takami 1992) }\end{array}$ & \\
\hline high & $\begin{array}{c}\text { attention attraction of extraction } \\
\text { site (Deane 1992) } \\
\end{array}$ & \\
\hline low & $\begin{array}{l}\text { entrenchment of the extraction } \\
\text { site (Deane 1992) }\end{array}$ & \\
\hline $\begin{array}{c}\text { attribute or } \\
\text { characteristic part }\end{array}$ & $\begin{array}{c}\text { referent/denotatum of extraction } \\
\text { site (Bolinger 1972) }\end{array}$ & \\
\hline \multirow[t]{2}{*}{ indefinite } & $\begin{array}{l}\text { definiteness of the extraction site } \\
\text { (Deane 1992) }\end{array}$ & \\
\hline & $\begin{array}{c}\text { semantic case role of the } \\
\text { extraction site (Deane 1992) }\end{array}$ & agent/subject \\
\hline non-specific & $\begin{array}{l}\text { specificity of the extraction site } \\
\text { (Deane 1992) }\end{array}$ & \\
\hline formal & $\begin{array}{c}\text { formality of register } \\
\text { (Quirk et al. 1985) }\end{array}$ & low/neutral \\
\hline \multirow[t]{2}{*}{ complex } & $\begin{array}{l}\text { syll. length of preposition } \\
\text { (Quirk et al. 1985) }\end{array}$ & short \\
\hline & $\begin{array}{l}\text { frequency of preposition } \\
\text { (Quirk et al. 1985) }\end{array}$ & frequent \\
\hline temporal/abstract & $\begin{array}{l}\text { meaning of preposition(al phrase) } \\
\text { (Quirk et al. 1985) }\end{array}$ & $\begin{array}{c}\text { spatial, instrum., } \\
\text { reason }\end{array}$ \\
\hline passive & voice of the verb & active \\
\hline strong & $\begin{array}{c}\text { relation between preposition and } \\
\text { its complement } \\
\text { (Quirk et al. 1985) }\end{array}$ & loose \\
\hline loose & $\begin{array}{l}\text { relation between preposition and } \\
\text { its verb (Quirk et al. 1985) }\end{array}$ & $\begin{array}{l}\text { strong/close } \\
\text { (prep.verbs) }\end{array}$ \\
\hline
\end{tabular}

Gries argues that this list has certain limitations. For example, the previous studies that determined the variables above were "based on intuitive and introspective examples and acceptability judgments," not corpus data (2002, p. 5). Additionally, the variables were typically examined without consideration of other variables; therefore, we do not know which variables have a greater impact on construction choice than other variables.

Further, no study has tried to look at several analyses at once, and "no satisfactory databased description has been offered so far" (Gries, 2002, p. 5). Last, no one has tried to predict whether a speaker will use a P-Stranding or Pied-Piped Construction based on these analyses (Gries, 2002). 


\subsubsection{Results (for Selected Variables Only)}

Gries (2002) presents the reader with the following list of variables, all of which he used in his study:

(7) Gries's Variables:

- MODALITY: spoken, written;

- VERB: transitive, intransitive, prepositional, copula, phrasalprepositional;

- VOICE: active, passive;

- PREP_SEM: prepositional semantics: abstract, metaphorical, spatial, temporal;

- AGENT_HEAD: agent, non-agent;

- CONCRETE_HEAD: abstract, concrete;

- FREQ_HEAD: infrequent, frequent;

- ENTRENCH HEAD: entrenchment of the head noun according to Deane's (1992) entrenchment hierarchy;

- FREQ-PREP: frequency rank of the preposition (in each modality);

- LENGTH_BS: syllabic length of the bridging structure;

- LENGTH_PREP: syllabic length of the preposition;

- BARRIER_BS: barrierhood of the bridging structure;

- LENGTH_EP: syllabic length of the extracted phrase;

- BARRIER_EP: barrierhood of the extracted phrase. 


\section{Monofactorial Results}

Several significant results were found. For example, there was a significant difference in the mean and standard deviations of the P-Stranding and Pied-Piped Constructions' bridging structure length (Gries, 2002). The P-Stranding Construction had a mean length of 4.5; the standard deviation was 2.3. The Pied-Piped Construction had a mean length of 13.3, and the standard deviation was 8.7. These results show that "longer bridging structures result in a preference for [the Pied-Piped Construction], whereas shorter bridging structures are more likely to license [the P-Stranding Construction]" (Gries, 2002, p. 6).

In addition to length, the distribution of P-Stranding and Pied-Piped Constructions across verb types, labeled VERB, was calculated. Results are presented in (8):

Table 2.2.1.3.a: Distribution of constructions relative to VERB

\begin{tabular}{|c|c|c|c|c|c|c|}
\hline & Transitive & Intransitive & Prep. & Phrasal-prep. & Copula & Totals \\
\hline PPC & 73 & 24 & 4 & 0 & 21 & 122 \\
\hline SC & 38 & 65 & 14 & 6 & 56 & 179 \\
\hline Total & 111 & 89 & 18 & 6 & 77 & 301 \\
\hline
\end{tabular}

The chart above shows that there is a preference to use Pied-Piped Constructions with transitive verbs and P-Stranding Constructions in all other cases.

Next, Gries (2002) discusses the chart presented in (9); this chart summarizes all of the results found for each of the variables. The results are listed in order of strength.

(9) Table 2.2.1.3.b: Monofactorial results

\begin{tabular}{|c|c|}
\hline Variable & Correlational Strength with PS \\
\hline LENGTH_BS & $\mathrm{r}_{\mathrm{pb}}=-0.6 ; \mathrm{p}<0.001 * * *$ \\
\hline BARRIER_BS & $\mathrm{r}_{\mathrm{pb}}=0.594 ; \mathrm{p}<0.001 * * *$ \\
VERB & $\boldsymbol{\varphi}=0.4 ; \mathrm{p}<0.001 * * *$ \\
\hline MODALITY (written=0; spoken=1) & $\boldsymbol{\varphi}=0.386 ; \mathrm{p}<0.001 * * *$ \\
\hline VOICE (act.=0; pass.=1) & $\boldsymbol{\varphi}=-0.28 ; \mathrm{p}<0.001 *$ \\
\hline LENGTH-PREP & $\mathrm{r}_{\mathrm{pb}}=0.246 ; \mathrm{p}<0.001^{* * *}$ \\
\hline
\end{tabular}




\begin{tabular}{|c|c|}
\hline ENTRENCH_HEAD & $\tau=0.14 ; \mathrm{p}<0.001 * * *$ \\
\hline CONCRETE_HEAD (abstr. $=0 ;$ concr. $=1)$ & $\boldsymbol{\varphi}=0.14 ; \mathrm{p}<0.016^{*}$ \\
\hline BARRIER_EP & $\mathrm{r}_{\mathrm{pb}}=0.13 ; \mathrm{p}=0.029^{*}$ \\
\hline AGENT_HEAD (no agent $=0 ;$ agent $=1)$ & $\boldsymbol{\varphi}=0.115 ; \mathrm{p}=0.054 \mathrm{~ns}$ \\
\hline PREP_SEM & $\boldsymbol{\varphi}=0.1103 ; \mathrm{p}=0.301 \mathrm{~ns}$ \\
\hline FREQ_HEAD (rare $=0 ;$ frequent $=1)$ & $\boldsymbol{\varphi}=0.096 ; \mathrm{p}=0.107 \mathrm{~ns}$ \\
\hline FREQ-PREP & $\tau=0.035 ; \mathrm{p}=0.362 \mathrm{~ns}$ \\
\hline LENGTH_EP & $\mathrm{r}_{\mathrm{pb}}=0.003 ; \mathrm{p} .959 \mathrm{~ns}$ \\
\hline
\end{tabular}

The chart above shows that bridging structure (both length and barrier) most strongly influences whether a P-Stranding or a Pied-Piped Construction is used. "On the whole, the following overall ranking of variables is found: bridging structure - verb - head noun - preposition" (Gries, 2002, p. 7).

\section{The Problem of Interactions}

Even though these results measure the importance of individual variables, Gries (2002) argues that speaker's choices cannot be predicted by monofactorial preferences alone, as variables sometimes conflict with each other. For example, according to the chart in (8), "transitive verbs prefer [Pied-Piped Constructions] while concrete head nouns prefer [P-Stranding Constructions]" (Gries, 2002, p. 7). If a sentence includes both a transitive verb and a concrete head noun, no prediction can be made from looking at the variables in isolation. According to Gries, "in monofactorial analyses, interactions of variables cannot be identified; [and] for purely mathematical reasons, the absolute values of the correlation coefficients must not be compared directly" $(2002$, p. 7$)$. 


\section{$\underline{\text { Multifactorial Results }}$}

Next, Gries (2002) attempts to answers the questions proposed in (3). To calculate a variable's influence when in the presence of other variables, the General Linear Model (GLM) was used. "The multiple correlation coefficient (with correction for shrinkage according to Wherry) for all above variables without interactions is quite high and highly significant: Rc=0.635; F18,273-17.01; p<0.0001***” (Gries, 2002, p. 7).

Additionally, in an attempt to try to predict speakers' constructional choices, a linear discriminant analysis (LDA) was conducted. An LDA "takes as input a set of independent variables and produces as output a categorial choice of the level of the dependent variable (STRUCTURE). Using cross-validation, a priori predictions of speakers' choices in one's analysis can be tested for accuracy while, at the same time, the analysis as a whole can be subjected to the most rigorous test conceivable, namely whether it enables the researcher to actually predict what native speakers do" (Gries, 2002, p. 8).

The results show that a native speaker's choice of construction can be predicted. The a priori prediction was correct in $86.1 \%$ of cases (Gries, 2002). "What is more, the predictions are arrived at by assigning to each variable a numerical weighting/loading, which can be interpreted as reflecting the importance of a variable in discriminating between PPC and SC" (Gries, 2002, p. 8). In the following table, these results are displayed:

(10) Table 2.2.1.3.c: Factor loadings of the discriminant analysis

\begin{tabular}{|c|c|c|}
\hline Variable & Factor Loading & Choice of Construction \\
\hline barrierhood of the bridging structure & -0.701 & high values for these variables \\
\cline { 1 - 2 } length of the bridging structure & -0.69 & $\rightarrow$ PPC \\
\cline { 1 - 2 } transitive verbs & -0.426 & \\
\hline
\end{tabular}




\begin{tabular}{|c|c|c|}
\hline voice of the verb & -0.256 & low values for these variables \\
\hline temporal meaning of the preposition & -0.089 & $\rightarrow \mathrm{SC}$ \\
\hline frequency of the head noun & -0.087 & \multirow{15}{*}{$\begin{array}{c}\text { according to the low } \\
\text { factor loadings }(-0.223 \leq \\
\text { loading } \leq 0.223), \text { these } \\
\text { variables do not } \\
\text { discriminate significantly } \\
\text { between the two } \\
\text { constructions }\end{array}$} \\
\hline metaphorical of the preposition & -0.009 & \\
\hline abstract meaning of the preposition & 0.014 & \\
\hline length of the extracted phrase & 0.036 & \\
\hline spatial meaning of the preposition & 0.04 & \\
\hline agentivity of the head noun & 0.104 & \\
\hline phrasal-prepositional verbs & 0.114 & \\
\hline frequency of the preposition & 0.115 & \\
\hline barrierhood of the extracted phrase & 0.119 & \\
\hline prepositional verbs & 0.126 & \\
\hline concreteness of the head noun & 0.132 & \\
\hline copula as a verb & 0.153 & \\
\hline entrenchment of the head noun & 0.165 & \\
\hline intransitive verbs & 0.165 & \\
\hline length of the preposition & 0.218 & \\
\hline modality & 0.382 & high/low value $\rightarrow$ SC/PPC \\
\hline
\end{tabular}

The table in (10) shows that the bridging structure and verb have the greatest impact on construction choice. Gries (2002) concludes that this is evidence to support his hypothesis, that high processing costs will cause a speaker to choose the Pied-Piped Construction, because a bridging structure's length and barrierhood "relate straightforwardly ... to the morphosyntactic and semantic processing effort" present in discourse (p. 9).

According to Gries (2002), the fact that transitive verbs prefer Pied-Piped Constructions also supports his hypothesis. Transitive verbs are followed by a direct object; as a result, the bridging structure has greater length and barrierhood because there is a direct object DP that is not present in not-transitive sentences. An example of a sentence with Pied-Piping and transitive verb is shown in (11a); an example of a sentence with P-Stranding and transitive verb is shown in (11b):

(11) a. To whom did John give $[\mathrm{NP}$ the book]?

b. Who did John give [NP the book] to? 
In the chart in (12), the mean length and barrierhood of the bridging structure for transitive and not-transitive sentences are shown.

Table 2.2.1.3.d: The effect of transitivity on LENGTH_BS and BARRIER_BS

\begin{tabular}{|l|c|c|c|}
\hline & $\begin{array}{c}\text { Transitive } \\
(111 \text { sentences })\end{array}$ & $\begin{array}{c}\text { Not transitive } \\
(190 \text { sentences })\end{array}$ & Total \\
\hline Length_BS: Mean (Std. dev.) & $10.9(7.7)$ & $6.5(6.4)$ & $8.1(7.2)$ \\
\hline Barrier_BS: Mean (Std. dev.) & $4(2.9)$ & $2.5(2.7)$ & $3(2.9)$ \\
\hline
\end{tabular}

As shown in the chart above, transitive verbs have greater bridging structure length and barrierhood than not-transitive verbs.

\subsubsection{Summary/Conclusions}

In summary, Gries (2002) concludes that processing efforts greatly influence construction choice. Further, he argues that "corpus-based and (multifactorial) statistical investigations," like his, yield more substantial results than introspective and monofactorial studies (Gries, 2002, p.7). In addition, Gries believes that the field of linguistics could benefit from adopting the research methods of other behavioral sciences; if linguists implemented their methods of data collection and hypothesis testing, results would be "more objective and reliable" than results concluded from grammaticality judgment tasks (2002, p. 10).

\subsubsection{Bader and Schmid's "Minimality in verb-cluster formation"}

\subsubsection{Introduction}

The Minimalist Program focuses on economy principles that favor derivations with less structure and fewer movement operations. According to Bader and Schmid 
(2009), the parser also favors these derivations. When psycholinguists investigate human sentence parsing, they look at the Human Sentence Processing Mechanism (HSPM) defined as "all processes involved in assigning syntactic structures to input sentences during language comprehension" - and its use of Minimality when facing situations of local syntactic ambiguity (Bader \& Schmid, 2009, p. 1459). Frazier (1979) introduced Minimal Attachment as a parsing principle, defined in (1) below:

\section{(1) Minimal Attachment}

"A word should be attached to the current phrase-structure tree using as few nodes as possible" (Bader \& Schmid, 2009, p. 1459).

Under this principle, the HSPM will produce the phrase-structure tree that is the least costly in every instance.

The focus of Bader and Schmid's (2009) article, "Minimality in verb-cluster formation," is infinitival complementation in German. "Since German is an OVlanguage, infinitival complements can easily occur to the left of their selecting matrix verb" (Bader \& Schmid, 2009, p. 1549). An example of this is presented in (2) ... dass Max [PRO den Roman zu lesen] versucht. that Max the novel to read tries '. . that Max tries to read the novel.'

The above infinitival complement is center embedded, which causes processing difficulties (Bader \& Schmid, 2009). The processing difficulty is caused by local syntactic ambiguity since there is nothing telling the HSPM to expect a new clause. For example, complementizers and relative pronouns in finite clauses tell the HSPM that there is a new clause. Because there is no signal for a new clause, when dass Max den 
Roman is processed, the parser will assume a sentence like (2) is mono-clausal, like the sentence below:

(3) ... dass Max den Roman liest.

that Max the novel reads

' . . that Max reads the novel.'

However, once both verbs have been processed, a bi-clausal structure will be formed. In cases like these, "overlooking a clausal boundary on first-pass parsing can cause additional parsing complexity, a so-called garden-path effect" (Bader \& Schmid, 2009, p. 1460).

Since center embedding causes parsing complexity, there are two additional ways to deal with infinitive clauses; both reduce processing costs (Bader \& Schmid, 2009). First, there is the possibility of extraposition, in which the infinitival clause occurs to the right of the matrix verb, shown in (4):

... dass Max versucht [PRO den Roman zu lesen].

Extraposition like this is typical of VO languages. Second, there is the option of clauseunion for West-Germanic OV-languages. Clause-union "does not affect the linearization of the string but only its syntactic structure" (Bader \& Schmid, 2009, p. 1460). Therefore, the linear order of (2) remains the same, and the two verbs combine to create a verb cluster. For instance, the verbs in (2), zu lesen and versucht, would be considered a verb cluster. If the two verbs become a verb cluster, the sentence is no longer a bi-clausal structure; rather, the sentence is mono-clausal. Although the verb cluster is not visible on the surface, the proposed mono-clausal structure would solve the issue of clausal ambiguity present in example (2). 
However, verb-clusters are not necessarily easy to process (Bader \& Schmid, 2009). For example, "both verbs ... (V2 read and V1 tries) assign two theta roles each. [When] V2 and V1 do not form a verb-cluster in the tree ... they can assign theta roles to their argument in a local and transparent way ... [However, in] the corresponding tree with verb-cluster formation... Neither the theta roles of V2 nor those of V1 can be assigned in the same local and transparent manner" (Bader \& Schmid, 2009, p. 1461). Thus, Bader and Schmid (2009) hypothesize that a tree with a verb-cluster formation would be costly processing-wise because it merges argument structures.

In their study, Bader and Schmid (2009) test this hypothesis by observing if verb clusters form a unit on both a phrase-structure and argument-structure level within longdistance passive constructions. In long-distance passives, the matrix verb becomes passive, and the object of the passivized verb becomes the subject of the internal argument. Therefore, if the two verbs form a verb cluster, the entire verb cluster should passivize, and the internal argument of the infinitive should move to the subject position. An example of a long-distance passive is shown in (5):

(5) ?dass [der Roman]-NOM [zu lesen versucht wurde].

that the novel to read tried was

'that someone tried to read the novel.'

To test their hypothesis, Bader and Schmid (2009) conducted a speededgrammaticality judgment task, in which participants judge whether a sentence is grammatical. Participants were required to judge each sentence within a specified amount of time (2000 ms) after the last word of a sentence was read. Their goal was to prove that 
extraposed structures are less costly to process than both bi-clausal ('non-coherent constructions') and mono-clausal structures ('coherent constructions') (Bader \& Schmid, 2009).

\subsubsection{Minimal structure building and infinitival complementation}

Next, Bader and Schmid (2009) discuss Minimality in regards to the Human Sentence Processing Mechanism (HSPM), as well as how German sentences with infinitival complementation are processed by the HSPM. The function of the HSPM is to create a syntactic representation for a sentence using the words that it receives as input. Bader and Schmid (2009) "make three general assumptions about how the HSPM accomplishes this task" (p. 1467). First, sentences are parsed by the HSPM item-by-item, as predicted by Frazier and Rayner's (1988) Left-to-Right Constraint, presented in (6):

\section{(6) Left-to-Right Constraint}

"Each item is incorporated into a constituent structure representation of a sentence (essentially) as the item is encountered" (Bader \& Schmid, 2009, p. 1467).

Second, Bader and Schmid assume that the HSPM forms one syntactic representation at a time, not multiple representations, when new input is received. This type of parser is known as a serial parser.

Last, they assume that the HSPM favors minimal structure building (Bader \& Schmid, 2009). More specifically, the HSPM builds a representation before having all of the information, even when faced with local syntactic ambiguity; the HSPM's decision on how to build this representation is guided by Minimality. Frazier (1979) first proposed this with the Minimal Attachment Principle, presented in (7): 
"Attach incoming material into the phrase-marker being constructed using the fewest nodes consistent with the well-formedness rules of the language under analysis" (Bader \& Schmid, 2009, p. 1467).

After a parser is confronted with local syntactic ambiguity, the structure formed with Minimal Attachment may need to be revised, once more information is given to the parser. While possible, this revision is costly.

Bader and Schmid (2009), considering the three assumptions above, proposed the following hypothesis for how the HSPM processes German sentences that have infinitival complements to the left of an embedded verb:

(8) Clause-Union Preference Hypothesis

"On first-pass parsing, the HSPM always assigns a mono-clausal structure to a sentence containing an intraposed infinitival complement" (p. 1467).

However, while a mono-clausal (verb-cluster) structure requires less structure for the HSPM to build, the arguments still need "to be merged in order to determine the correct distribution of case features and semantic argument properties" (Bader \& Schmid, 2008, p. 1468). Merge is not a minimal operation and can cause parsing complexity. Therefore, the prior hypothesis is supplemented by the following:

(9) Verb-Cluster Complexity Hypothesis

"The argument-structure operations involved in verb-cluster formation are costly for the HSPM" (Bader \& Schmid, 2008, p. 1468). 


\subsubsection{Experiment 1}

The first experiment Bader and Schmid (2008) conducted consisted of sentences with passivized controls verbs and intraposed infinitival complements. The sentences were varied in six ways within the experiment, presented in (10). Case and adjacency differ amongst the six sentence types.

(10) 1. Infinitival and control verb adjacent; masculine, nominative DP within the embedded clause

2. Infinitival and control verb adjacent; masculine, accusative DP within the embedded clause

3. Infinitival and control verb adjacent; feminine, ambiguous-case DP within the embedded clause

4. Infinitival and control verb non-adjacent; masculine, nominative DP within the embedded clause

5. Infinitival and control verb non-adjacent; masculine, accusative DP within the embedded clause

6. Infinitival and control verb non-adjacent; feminine, ambiguous-case DP within the embedded clause

To create sentences with non-adjacent infinitival complements, an adverbial was placed between the two verbs.

Of the six sentence types, Bader and Schmid (2009) predicted, "sentences with a feminine DP should be judged better than sentences with a masculine DP” (p. 1469). They predicted this because the same feminine DP can have either nominative or accusative Case. Thus, the parser will initially assume that the sentence is mono-clausal; 
if the parser is incorrect, the sentence can easily take a bi-clausal structure through reanalysis. Also, Bader and Schmid (2009) predicted that sentences with nonadjacent infinitival and control verbs would be easier to process than adjacent verbs when the DP has masculine accusative or ambiguous Case; this is because having an adverbial after the infinitival verb signals that the sentence is bi-clausal.

For the experiment, Bader and Schmid (2009) tested 36 students. All participants were native German speakers and were not aware of the experiment's purpose. (The last statement is true for all three experiments; thus, it won't be repeated hereafter.) There were 30 experimental sentences, all which were adapted to each of the six versions listed in (10). All experimental sentences had the following order:

(11) Main clause [dass DP ${ }_{[\mathrm{NOM} / \mathrm{ACC}]} \mathrm{V}$-infinitival (Adverbial) V-control wurde.

Only verbs that permitted clause-union and animate DPs were used. "From the total set of 30 sentences, six lists were created. Each list contained an equal number of sentences in each condition but no more than one version of any sentence appeared in a list" (Bader \& Schmid, 2009, p. 1470). Along with each of the six lists, there were 186 filler sentences. Filler sentences are used as distractions for participants, so the purpose of the experiment is not apparent. Of the fillers, there were both grammatical and ungrammatical sentences. One of the six lists was shown to each participant, and the order of the sentences was pseudo-randomized.

For the procedure itself, participants were presented with sentences on a computer screen in a word-by-word fashion (Bader \& Schmid, 2009). Participants were asked to judge whether or not they found the sentences grammatical once they reached the end of the sentence. To begin the experiment, participants would press the space bar. Then, a 
word would appear on the screen for " $225 \mathrm{~ms}$ plus an additional $25 \mathrm{~ms}$ for each character to compensate for length effects" (Bader \& Schmid, 2009, p. 1471). After a sentence was finished being displayed, participants would judge the grammaticality of the sentence by either "pressing the left or right shift key on a computer keyboard" (Bader \& Schmid, 2009, p. 1471). Participants only had $2000 \mathrm{~ms}$ to respond; if they did not do so within the allotted time, the computer showed the words zu langsam (meaning too slow) on the computer screen in red font.

Bader and Schmid's (2009) results show that the grammaticality judgments were affected, in most cases, by the presence or absence of an adverbial. For instance, sentences with masculine nominative DPs were judged as grammatical more frequently without an adverbial (50\% grammatical) than with one (37\%). Contrastingly, sentences with a masculine accusative DP were judged as grammatical more frequently with an adverbial (74\% grammatical) than without (63\%). Last, sentences with a (Case ambiguous) feminine DP were not affected significantly by the presence of an adverbial; without an adverbial, these sentences were judged grammatical $76 \%$ of the time, and with an adverbial, they were judged grammatical $72 \%$ of the time.

Bader and Schmid's (2009) results support their two hypotheses: Clause-Union Preference and Verb-Cluster Complexity. As hypothesized, sentences with intraposed infinitival clauses were difficult to process. As stated above, long-distance passives were judged as grammatical in only $50 \%$ of cases, which is low. Sentences with adjacent infinitival and control verbs, which form a bi-clausal structure indirectly because of Case, were only rated grammatical in $63 \%$ of cases. Contrastingly, sentences with nonadjacent verbs, which trigger bi-clausal structures, had a greater grammaticality rating of 74 . 
According to Bader and Schmid (2009), however, there is a problem with these results: both hypotheses assume "processing difficulties in all conditions" (p. 1472). Thus, another experiment was conducted in which a condition with low processing costs was included. The purpose of including this condition was to have a baseline to compare the higher processing costs against.

\subsubsection{Experiment 2}

Bader and Schmid's (2009) second experiment tested "whether sentences with long-distance passive containing an inanimate subject" would be judged as grammatical more frequently than those with an animate subject (p. 1473). In Experiment 1, only animate subjects were used. "A short study of the linguistic literature on long-distance passive reveals that almost all examples contain inanimate subjects" (Bader \& Schmid, 2009, p. 1473). Thus, the goal of this experiment was to establish if the subject type (animate or inanimate) had an effect on processing costs. The contrast between an animate and inanimate object was tested in the following three structural contexts:

(12) 1. Intraposed infinitival and control verb adjacent; nominative DP within the embedded clause

2. Intraposed infinitival and control verb adjacent; accusative DP within the embedded clause

3. Extraposed infinitival and control verb adjacent; accusative DP within the embedded clause 
While Bader and Schmid predicted that object animacy would not affect grammaticality judgments, they did expect higher acceptance rates for the sentences with extraposed infinitival complements.

As for the experiment method, Bader and Schmid (2009) conducted another speeded-grammaticality test. Fifty-four participants were tested. The experimental sentences were made up of 30 sentences. Each of the 30 sentences appeared in the three different contexts presented in (12) - once with an animate subject and once with an inanimate subject. Thus, there were six versions of every sentence. As in Experiment 1, six sentence lists were created and added to 178 filler sentences.

The results from this experiment showed that animacy did affect participants' grammaticality judgments (Bader \& Schmid, 2009). Sentences with inanimate DPs were judged as more grammatical than sentences with animate DPs in all contexts. This difference was not always significant, however. "For sentences with extraposition, the 4\% difference was not significant" (Bader \& Schmid, 2009, p. 1475). For sentences with intraposed complements, this difference was $29 \%$, which is a much greater difference. Thus, Experiment 2 had two key results:

First, with passivized control verbs, intraposed infinitival complements are substantially less acceptable than extraposed infinitival complements ... [Second,] animacy had a strong effect on long-distance passive clauses (infinitival clauses with a nominative DP), but marginal effects at best for the other two constructions. (Bader \& Schmid, 2009, p. 1475)

Therefore, long-distance passives are grammatical for native German speakers; however, they are somewhat less acceptable with animate subjects. Bader and Schmid note that 
inanimate subjects are cross-linguistically less acceptable in passive formations than animate subjects, so these results are somewhat rare.

\subsubsection{Experiment 3}

In Experiment 3, Bader and Schmid (2009) test the Clause-Union Preference Hypothesis with passivized control verbs and embedded infinitival verbs; in the experiment, the long-distance passive is not used. Further, two types of infinitival verbs are investigated: "verbs taking an accusative object and verbs taking a prepositional object" (Bader \& Schmid, 2009, p. 1476). These verb types are examined in both embedded clauses (V-end clauses) and main clauses (V-second clauses). In V-end clauses, an infinitival verb taking an accusative object will have a bi-clausal structure; this is difficult for the HSPM to process. Contrastingly, in V-end clauses, an infinitival verb taking a PP-argument, known as an impersonal passive, will have a mono-clausal structure; this will be easier for the HSPM to process because "PP-arguments are not affected by passivization" (Bader \& Schmid, 2009, p. 1476).

In addition to V-end clauses, Bader and Schmid (2009) look at V-second clauses; this is done to examine topicalization. In (13), (13a) shows an infinitival clause with an accusative object intraposed in the main (V-second) clause; (13b) shows this clause fronted in the main (V-second) clause for the purpose of topicalization:

(13) a. Gestern wurde den neuen Plan zu verbreiten versucht. yesterday was the new plan to distribute tried 'Yesterday, someone tried to distribute the new plan.' 
b. [Den neuen Plan zu verbreiten] wurde gestern versucht. the new plan to distribute was yesterday tried 'To distribute to the new plan, that was tried yesterday' Bader and Schmid (2009) predict that fronting of an accusative infinitival complement will cause these sentences to be judged as grammatical because the HSPM will be signaled that the sentence is bi-clausal at the beginning of the sentence. As for sentences with a PP-complement, Bader and Schmid predict that fronting will not impact grammaticality judgments, as these sentences will be easy to process either way.

As for the experiment method, 42 student participants completed a speededgrammaticality judgment task (Bader \& Schmid, 2009). The experiment contained 30 target sentences; each sentence had six variations "according to the two factors Structure (that-clause/intraposed versus main-clause/intraposed versus main-clause/topicalized) and Argument Type (DP versus PP complement)" (Bader \& Schmid, 2009, p. 1477). There were six sentence lists, each of which were added to 196 filler sentences.

The results supported Bader and Schmid's (2009) predictions. For both DP and PP arguments, there were insignificant differences in the grammaticality judgments for the two sentence structures with intraposed infinitival complements (embedded clause versus main clause). Also, as predicted, PP-sentences with intraposition had significantly higher grammaticality judgments (81\%) than DP-sentences (72.5\%). Last, DP-sentences with topicalization had higher grammaticality judgments (87\%) than DP-sentences with intraposition (72.5\%); topicalization, however, did not affect PP-sentences ( $80 \%$ for topicalized sentences, $81 \%$ for intraposed sentences). As expected, the improvement in grammaticality for DP-sentences with topicalization occurred because the infinitival 
clause (bi-clausal structure) was easier to identify; thus, for these sentences, "the ClauseUnion Preference Hypothesis does no longer apply" (Bader \& Schmid, 2009, p. 1478). Bader and Schmid (2009) conclude, "Experiment 3 lend[s] further support to the hypothesis that the HSPM computes a verb-cluster structure when possible, as in the sentences with PP complement. The need to switch to a bi-clausal structure, as in sentences with an accusative complement, is therefore an instance of costful reanalysis" (p. 1478).

\subsubsection{General Discussion}

In conclusion, the three experiments support Bader and Schmid's (2009) two hypotheses: The Clause-Union Preference Hypothesis and the Verb-Cluster Complexity Hypothesis. With their results, it can be assumed that both bi-clausal and mono-clausal intraposed infinitival complements have higher processing costs than extraposed structures.

\subsubsection{Ferreira and Clifton, Jr.'s "The Independence of Syntactic Processing”}

\subsubsection{Introduction}

In “The Independence of Syntactic Processing," Fernanda Ferreira and Charles Clifton, Jr., (1986) discuss the three experiments they conducted. The purpose of these experiments was to investigate whether the parser's initial syntactic analysis of a sentence is affected by semantic or pragmatic information. "Each experiment determined whether syntactic processing biases that have been observed in sentences presented in isolation

can be overcome" (Ferreira \& Clifton, 1986, p. 348). Two experimental methods were 
used. For two of the three experiments, subjects' eye movements were recorded. For the third experiment, subjects completed a self-paced reading task. Details about the experiments' set up and results will be provided in the following section. With these results, Ferreira and Clifton (1986) argue for "the existence of a syntactic processing module" (p. 348).

The syntactic processing module was proposed by Frazier and her colleagues (Frazier, 1978; Frazier \& Fodor, 1978; Rayner, Carlson, \& Frazier, 1983); Ferreira and Clifton (1986) summarize this module below:

(1) "The language processor is viewed as consisting of a number of autonomously functioning components, and each component corresponds to a level of linguistic analysis (phonological, lexical, syntactic)" (p. 348).

Thus, under this approach, the parser's initial construction of a syntactic structure is not influenced by nonsyntactic information sources. Contrastingly, if the parser is not modular, the construction of a syntactic structure can be influenced by any component of a person's language (phonology, semantics, syntax, pragmatics, etc.); further, the initial interpretation should be the most likely interpretation; "this will be referred to as the as the interactive position" (Ferreira \& Clifton, 1986, p. 349).

Examining how the parser deals with syntactic ambiguity helps to explain how the parser operates (Ferreira \& Clifton, 1986). It is assumed that the parser will build the most plausible syntactic structure, until more information becomes available. Frazier (1978) proposed that the parser favors Minimal Attachment when constructing a syntactic representation; this principle is presented in (2): 
(2) "Attach incoming material into the phrase-marker being constructed using the fewest syntactic nodes consistent with the well-formedness rules of the language" (Ferreira \& Clifton, 1986, p. 349).

Under this approach, the parser computes one representation at a time; as new information is inputted, the parser adds the input to the structure, favoring minimal structure building. If the parser finds that it has been "led down the garden path" (the first interpretation is incorrect), the sentence will undergo reanalysis to incorporate the new information (Ferreira \& Clifton, 1986, p. 349). This reanalysis adds processing costs to the sentence being analyzed, as the parser must abandon the first analysis of the sentence for the new one. Thus, the earlier analysis of the sentence would be considered less costly comparatively.

In addition, Rayner et al. (1983) proposed the thematic processor, which "examines alternative thematic structures listed for the heads of phrases and proposes plausible ones to the syntactic processor" (Ferreira \& Clifton, 1986 p. 350). The thematic processor was proposed after Rayner et al. conducted an experiment in which they found that subjects' initial interpretations of sentences were not influenced by pragmatic information (Ferreira \& Clifton, 1986). For example, the sentences in (3) were shown to participants.

(3) a. The spy saw the cop with binoculars but the cop didn't see him.

b. The spy saw the cop with a revolver but the cop didn't see him.

Under the modular model approach, (3a) has lower processing costs because the Minimal Attachment Principle favors the attachment of the prepositional phrase (PP) to the verb. In (3b), the PP attaches as a noun phrase (NP) modifying the cop. However, under the 
interactive model approach, (3a) and (3b) should not have different processing costs due to pragmatic information available to the parser. The results of the experiment showed that participants found (3b) more costly processing-wise than (3a). Therefore, the results are evidence that, despite pragmatic context, the Minimal Attachment Principle will choose the initial syntactic representation. However, Rayner et al. argue that pragmatic information plays a part in the reanalysis: "even a modular model must allow for some interaction between syntactic and nonsyntactic information sources" (Ferreira \& Clifton, 1986, p. 350). Therefore, the thematic processor was proposed.

Rayner et al.'s results have been interpreted in different ways by those who support the interactive position (Ferreira \& Clifton, 1986). First, it has been suggested that the parser can only be influenced by "world knowledge important enough to be encoded in the grammatical processing system" (Ferreira \& Clifton, 1986, p. 350). Thus, under this approach, it is not the case that all semantic or pragmatic information will influence the parser, but certain information will. Second, it has been suggested that the Minimal Attachment Principle will not guide the initial syntactic analysis when the information is "placed in appropriately biasing contexts" (Ferreira \& Clifton, 1986, p. 350). Last, Crain and Steedman (1985) go a step further and claim that "syntactic ambiguities are resolved by semantic and discourse plausibility, rather than by syntactic strategies. They posit a syntactic processor which independently 'proposes' alternative analyses, while a semantic processor 'disposes' of them” (Ferreira \& Clifton, 1986, p. 351). While Crain and Steedman did conduct an experiment to test their hypothesis, it was not an on-line processing task, which Ferreira and Clifton argue is important for evaluating sentence processing. 


\subsubsection{Experiments}

The three experiments conducted by Ferreira and Clifton (1986) address and test the aforementioned interpretations.

\section{Experiment 1}

In the first experiment, Ferreira and Clifton (1986) examined whether biasing thematic information guide the parser on-line when the parser is faced with syntactic ambiguity. To do this, an eye-tracking experiment was conducted with sixteen students; while reading, the participants' eye movements were recorded and measured. The sentences that participants read had reduced or unreduced relative clauses with animate or inanimate subjects. In (4), examples of a target sentence in each variation are shown:

a. animate, reduced

The defendant examined by the lawyer turned out to be unreliable.

b. inanimate, reduced

The evidence examined by the lawyer turned out to be unreliable.

c. animate, unreduced

The defendant that was examined by the lawyer turned out to be unreliable.

d. inanimate, unreduced

The evidence that was examined by the lawyer turned out to be unreliable. In (4a-b), there is syntactic ambiguity until by the lawyer and the verb are processed. Because of this, (4a-b) are "Nonminimal Attachment sentences," as there will be 
reanalysis when the parser reaches by the lawyer (Ferreira \& Clifton, 1986, p. 352). Contrastingly, (4c-d) are Minimal Attachment sentences because there is no syntactic ambiguity. Further, the difference between (4a) and (4b) (and (4c) and (4d)) is the subjects' semantic roles. The subject in (4a) is an agent, while the subject in (4b) is a theme. Ferreira and Clifton hypothesize that, if Minimal Attachment guides the parser, (4a-b) should be more costly than (4c-d). However, if semantic information influences the parser's interpretation, then processing costs of (4b) should be lower than (4a) because of the subject's semantic role.

The results of the first experiment showed that semantic content did not initially guide the parser in resolving syntactic ambiguity (Ferreira \& Clifton, 1986). When comparing the reading times of sentences with reduced relative clauses versus unreduced relatives clauses, the reading times for the reduced-relative sentences were significantly longer. When comparing the reading times of the reduced-relative sentences with animate versus inanimate subjects, the disambiguating region (by the lawyer) did not have significant differences (animate $40.4 \mathrm{~ms}$, inanimate $38.4 \mathrm{~ms}$ ), but the region containing the verb did (animate $33.3 \mathrm{~ms}$, inanimate $37.7 \mathrm{~ms}$ ). Therefore, the results support the notion that the parser is first guided by the Minimal Attachment Principle when faced with syntactic ambiguity; however, as indicated by the difference in reading times for the verb region, readers do process the anomaly later on. It should be noted that "reading times ... were divided by number of characters (including character spaces and 
punctuation marks)" to ensure that differences in sentence length did not attribute to reading time differences (Ferreira \& Clifton, 1986, p. 353).

\section{Experiment 2}

The second experiment was another that used eye movement recordings to determine reading times. The experiment "was conducted to determine whether the normal operation of the parser could be altered by the presence of contextual information that biases the interpretation of a syntactically ambiguous string" (Ferreira \& Clifton, 1986, p. 355). Again, 16 students participated. They were presented with both active and reduced relative sentences (Minimal and Nonminimal Attachment sentences, respectively), such as those in (5), in both biasing and neutral contexts.

a. Minimal Attachment

The editor played the tape and agreed the story was big.

b. Nonminimal Attachment

The editor played the tape agreed the story was big.

For biasing contexts, the Minimal Attachment context would indicate that there was one editor, while the Nonminimal Attachment context would indicate that there were two. As for a neutral context, the sentence would appear in a context that would allow for either one or two editors. In addition to this, Ferreira and Clifton (1986) looked at PP attachment ambiguity, such as that in (6):

(6) a. Minimal Attachment

Sam loaded the boxes on the cart before his coffee break. 


\section{b. Nonminimal Attachment}

Sam loaded the boxes on the cart onto the van.

Similar to the sentences in (5), the PP attachment sentences were placed in both neutral and biasing contexts.

Again, to calculate the results, reading times were divided by the number of characters present (Ferreira \& Clifton, 1986). The results showed Nonminimal Attachment sentences were initially more difficult to process than Minimal Attachment sentences. Further, context did not influence the reading times in any analysis. "This result confirms the predictions made by the modular model of syntactic processing. This model states that contextual information does not affect the initial syntactic decisions made by the syntactic processor, but is used to aid reanalysis of a misanalysed string" (Ferreira \& Clifton, 1986, p. 360).

\section{Experiment 3}

The third experiment conducted by Ferreira and Clifton (1986) was a self-paced reading task. The experiment was the same as the second experiment with the exception of the method used to conduct the experiment. "Therefore, Experiment 3 was conducted to explore the times taken to read such sentences, in the contexts used in Experiment 2, but using a task in which subjects controlled the presentation of segments of sentences using a button-press response" (Ferreira \& Clifton, 1986, p. 362). Further, the experiment was conducted with a self-paced reading task to compare the results of the two experiment types, as the eye-tracking software is not easily accessible for many 
researchers; thus, if the results are comparable, future research can be conducted on this topic with a different method.

The results for Experiment 3 support the findings of Experiment 2, proving selfpaced reading task experiments to be as reliable as eye-movement experiments.

"Nonminimal Attachment sentences are read more slowly in the critical disambiguating regions than are Minimal Attachment sentences, even in the presence of a context which has been predicted to guide sentence analysis and which demonstrably affects the eventual comprehension of sentences" (Ferreira \& Clifton, 1986, p. 364).

\subsubsection{General Discussion}

In conclusion, all three experiments support the existence of a modular language processor. Because of this, the parser will initially construct syntactic representations that are favored by the Minimal Attachment Principle, regardless of semantic, pragmatic, and contextual information.

\subsubsection{Weinberg's "A Minimalist Theory of Human Sentence Processing”}

\subsubsection{Introduction}

According to Amy Weinberg (1999), there are three common approaches to explaining human sentence processing. First, researchers use extralinguistic factors, such as limitations on working memory, to explain construction choices. Second, researchers claim that speakers/hearers are affected by frequency in their listening environment; structures that are heard more often are predicted to be preferred by the parser. Under the third approach, it is assumed that "the natural language faculty is extremely well designed 
in the sense that the same principles that govern language learning also contribute to a theory of sentence processing" (Weinberg, 1999, p. 283). Thus, the grammatical constraints active during language learning are also active during language processing. Weinberg adopts the third approach in her article, "A Minimalist Theory of Human Sentence Processing.” Accordingly, Weinberg discusses the Minimalist Program, how Minimalist principles can be interpreted as a parsing algorithm, and the advantages of the third approach.

\subsubsection{Some Minimalist Assumptions}

The Minimalist Program focuses on conditions of economy, which favor derivations that use the least amount of operations as possible. These conditions determine whether a structure can be derived, as a structure must satisfy economy conditions (not use more operations than is necessary) to be derived. In order to generate a structure, features (such as Case and $\theta$-role) are checked with Merge and Move operations. "Checking is satisfied when a category needing a feature is in construction with some other element in the sentence that can supply that feature" (Weinberg, 1999, p. 285). When a feature is checked, a constraint is satisfied and grammatical (movement or merger) operations are permitted. In (1) and (2), economy conditions that prevent overgeneration are given:

\section{(1) "Last Resort}

Operations do not apply unless required to satisfy a constraint. The minimal number of operations is applied to satisfy the constraint. 


\section{(2) Greed}

'The operation cannot apply to $\alpha$ to enable some different element $\beta$ to satisfy its properties . . . Benefiting other elements is not allowed.' (Chomsky 1995, 201)" (Weinberg, 1999, p. 285).

\subsubsection{Multiple Spell-Out}

In 1994, Kayne proposed the Linear Correspondence Axiom (LCA), presented in (3) (Weinberg, 1999). Weinberg adapts the LCA to make it applicable to language processing.

\section{“Linear Correspondence Axiom}

a. $\quad$ Base step: If $\alpha$ precedes $\beta$, then $\alpha$ c-commands $\beta$.

b. Induction step: If $\gamma$ precedes $\beta$, and $\gamma$ dominates $\alpha$, then $\alpha$ precedes $\beta$ "

(Weinberg, 1999, p. 286).

The definition of c-command is presented in (4):

(4) " $\alpha$ c-commands all and only the terms of the category $\beta$ with which $\alpha$ was paired by Merge or by Move in the course of the derivation" (Weinberg, 1999, p. 286). The LCA can be exemplified with the sentence in (5) below:

(5) Figure 2.2.4.3: Structure for the man slept

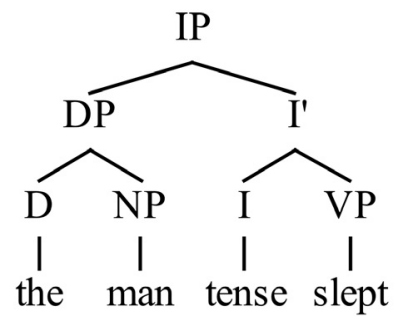


Because the determiner (D) precedes the noun phrase (NP) in the subject, the $\mathrm{D} c$ commands the NP, as is required by the base step in (3a). Next, as is required by the induction step in (3b), the determiner phrase (DP) precedes the verb phrase (VP) and dominates the $\mathrm{D}$ and NP, thus giving the $\mathrm{D}$ and NP precedence to the VP.

However, Uriagereka argues that the induction step in (3b) can be eliminated "if we allow Spell-Out to apply many times during the course of a derivation. Spell-Out is the operation that removes material from the syntactic component and feeds it to the interpretive components of Logical Form (LF) and Phonetic Form (PF) when it is ready for interpretation" (Weinberg, 1999, p. 287). Under Uriagereka's approach, command and precedence are still present. When merge or movement operations cannot create a dominating category, Spell-Out will occur; thus, the syntactic structure is turned into its phonological form, causing precedence to be maintained. Weinberg notes that "Spell-Out is a grammatical operation" and is governed by economy conditions (1999, p. 288).

\subsubsection{Minimalist Principles as a Parsing Algorithm}

Weinberg (1999) argues that economy conditions and multiple Spell-Out are present during parsing. Similar to Minimalist theory, features are checked during language processing. There is a preference to attach phrases as arguments rather than adjuncts during processing because $\theta$-roles can only be assigned to arguments, not adjuncts. Weinberg assumes that this "feature transfer is optimized locally" (1999, p. 288). "Since feature checking is subject to Greed in the Minimalist system, this theory allows optimal feature checking only on the particular category that is being attached, irrespective of whether this optimizes feature checking across the derivation as a whole" 
(Weinberg, 1999, p. 289). When a category is attached, the parser uses minimal structure and the least amount of operations required to check features. Thus, Spell-Out is used as a last resort, as it is not a feature-checking operation. Weinberg (1999) proposes the following algorithm for these principles:

(6) "A derivation proceeds left to right. At each point in the derivation, merge using the fewest operations needed to check a feature on the category about to be attached. If merger is not possible, try to insert a trace bound to some element within the current command path. If neither merger nor movement is licensed, spell out the command path. Repeat until all terminals are incorporated into the derivation" (p. 290).

\subsubsection{Some Cases: Argument/Adjunct Attachment Ambiguities}

The examples in the following sections provide evidence of Weinberg's (1999) argument above.

\section{Direct Object/Complement Subject Ambiguity}

In the example below, sentences with direct object/complement subject ambiguity are presented:

(7) a. the man believed his sister to be a genius

b. the man believed his sister 
c. $\quad$ Figure 2.2.4.5.a: Structure for believed his sister with direct object

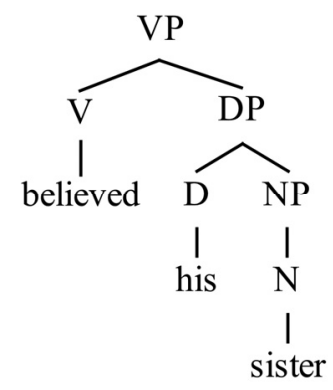

d. Figure 2.2.4.5.b: Structure for believed his sister with complement subject

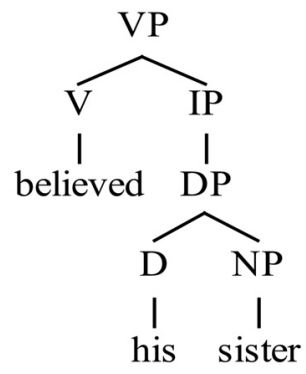

Features can only be assigned by the verb believe to the determiner phrase (DP) his sister if the verb is transitive, as in (7b). In (7a) the DP is not assigned features by the verb believe because it is the subject of the following clause. It is not until the following clause is processed that his sister will be assigned features in (7a). Due to this, (7c) is favored by the parser initially because features are checked by believe and the derivation is less costly. For both (7a-b), when his sister is attached, there is no Spell Out. "Since there has been no spell-out within the VP, both the verb and the object are available when the embedded verb is encountered in a case like [(7a)]. Therefore, the object NP is available for reinsertion as the embedded subject in [(7d)] even though the initial structure chosen for this case is [(7c)]" (Weinberg, 1999, p. 291). 


\section{Preposed Object/Matrix Subject Ambiguity}

Next, Weinberg (1999) examines the sentences in (8):

(8) a. after Mary mended the socks fell off the table

b. after Mary mended the socks they fell off the table

In the sentences above, $(8 \mathrm{a})$ is more costly processing-wise than $(8 \mathrm{~b})$ because the parser will attach the socks as the DP object of mended on first parse; then, after reanalysis, the DP will become the subject of the matrix verb. The reason the DP is attached as the object of mended is the same as in (7): attaching the DP as the object of the verb mended checks the features of the DP. Attaching the DP as the matrix subject does not allow this because the IP category has not yet been processed. In (9) below, (9a) shows the initial analysis of both sentences in (8); (9b) shows the structure of (8a).

(9) a. Figure 2.2.4.5.c: Structure for after Mary mended the socks with direct object

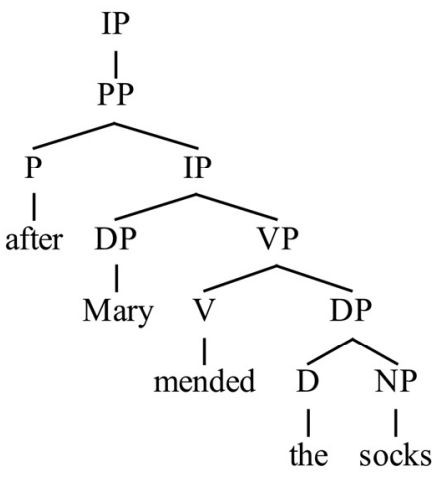


b. $\quad$ Figure 2.2.4.5.d: Structure for after Mary mended the socks with matrix sentence subject

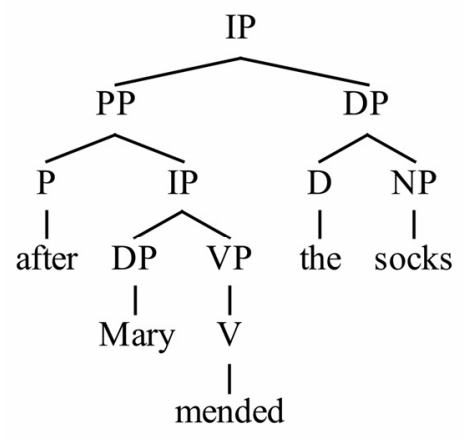

When the VP fell is added after the DP the socks in (8a), the VP is unable to be part of the adverbial. Instead, it is spelled out, as is presented in (10) below. "Since no further operations apply, and there is remaining unincorporated terminal material, the parse fails and a garden path is detected" (Weinberg, 1999, p. 292).

(10) Figure 2.2.4.5.e: Spell-Out of after Mary mended the socks fell

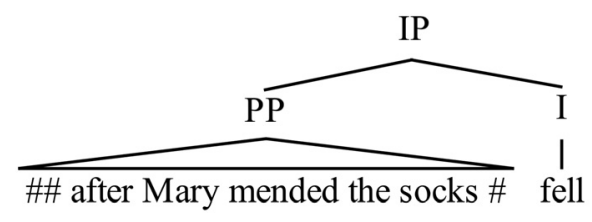

\section{Ditransitive/Complex Transitive Object Ambiguity}

Next, Weinberg (1999) examines the sentences presented in (11):

(11) a. John gave the man the dog for Christmas

b. John gave the man the dog bit a bandage

In the sentences above, the favored interpretation is one that attaches the determiner phrase (DP) the dog as the direct object of the VP gave. With this interpretation, the DP 
checks its features with gave. When the DP is treated as the relative clause subject modifying the man, as in (11b), features cannot be checked until the category is incorporated. Below, the structure for the sentence with the dog treated as a ditransitive object is shown in (12a); the structure for the sentence with the dog treated as a relative clause subject is shown in (12b). In (12b), there is Spell Out. For more examples of SpellOut, please refer to Weinberg's (1999) article.

(12) a. Figure 2.2.4.5.f: Structure for gave the man the dog with ditransitive object

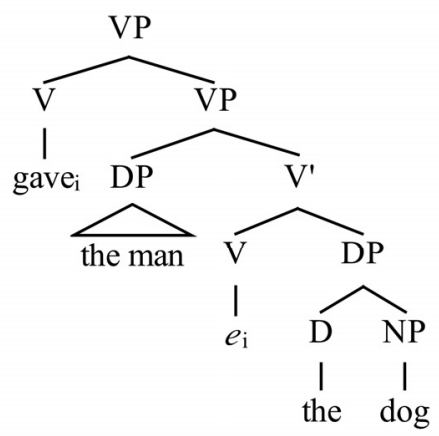

b. Figure 2.2.4.5.g: Structure for gave the man the dog with relative clause subject

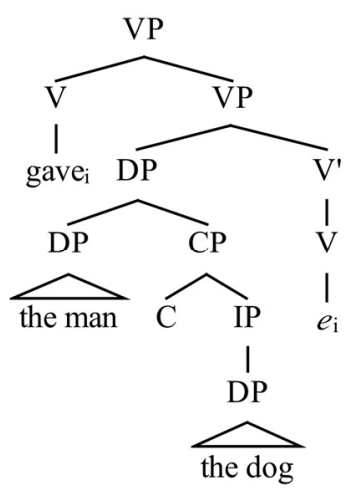




\subsubsection{Constraint-Based Theories}

Next, Weinberg (1999) “contrasts a grammaticality-based approach . . . with frequency-based or probabilistic constraint-based approaches" (p. 305). Frequency-based approaches claim that frequency of a lexical item or construction type affects processing. Specifically, "speakers can tune either to the fact that believe is used much more frequently with a simple NP as its direct object than with a sentential complement, or to the fact that simple sentences occur more frequently in the language than sentences with embeddings" (Weinberg, 1999, p. 306). Weinberg does not disregard the role of frequency in language processing; rather, she argues that frequency and grammatical constraints work together.

To test frequency's role in parsing, Weinberg (1999) investigates whether lexical choice affects grammaticality judgments. Stevenson and Merlo (1997) claimed that unaccusative and transitive verbs are preferred over unergative verbs in reduced relative clauses (Weinberg, 1999). For example, the sentences in (13a-b) are preferred to the sentence in $(13 \mathrm{c})$.

(13) a. the student found in the classroom was asleep

b. the butter melted in the pan was burnt

c. the horse raced past the barn fell

When grammaticality judgments of unaccusative and transitive verbs in reduced relative clauses were compared, Stevenson and Marlo discovered that both verb types were rated similarly; further, unergatives verbs had lower ratings than unaccusative and transitive verbs (Weinberg, 1999). 
Next, Stevenson and Marlo calculated the frequency of unergative, unaccusative, and "ordinary" verbs in the Wall Street Journal corpus (Weinberg, 1999). Weinberg (1999) defines ordinary verbs as "distinguished from unergative and unaccusative verbs in that adding the second argument does not invoke a 'causative interpretation on the predicate"' (p. 307). Further, they calculated the frequency of the three verb types in both main clauses and reduced relative clauses. Results showed that there were more instances of ordinary verbs (16 times) than unaccusative verbs (6 times) and unergative verbs (1 time).

Following this, Stevenson and Merlo looked at passive voice (Weinberg, 1999). They did this because "reduced relative clauses can only be formed from passivized transitive verbs" (Weinberg, 1999, p. 307). Thus, looking at whether a lexical verb class occurs in passive voice gives insight into whether a verb class will occur in reduced relative clauses. Results showed that both unergative and unaccusative verbs rarely occur in passive voice; further, the difference between the two verb types was insignificant. However, the difference in frequency of ordinary verbs and unaccusative verbs in passive voice was significant, as ordinary verbs had a much higher number of instances. According to Weinberg (1999), "this would predict that speaker preference for a reducedrelative clause analysis should be most strongly correlated with ordinary verbs, less strongly with unaccusative verbs, and least strongly with unergative verbs" (p. 308-309). While their grammaticality study did not look at ordinary verbs, unergative and unaccusative verbs were tested, and their ratings were similar to each other.

While Stevenson and Merlo's results somewhat support the frequency-based approach, Macdonald (1994) had different results (Weinberg, 1999). MacDonald 
conducted a self-paced reading task experiment to compare the processing costs of the underlined (disambiguating) portion in sentences like those presented below:

(14) a. the dictator fought in the violent coup was hated throughout the country

b. the dictator chased in the violent coup was hated throughout the country

c. the dictator overthrown in the violent coup was hated throughout the country

In (14a-b), "fought is an 'ordinary' verb, as is chased. Chased, however, occurs overwhelmingly as a transitive verb, whereas overthrown is an unambiguous passive participle that is obligatorily transitive" (Weinberg, 1999, p. 309). MacDonald's results showed that verbs like fought were more difficult to process than verbs like chased and overthrown because verbs like fought were initially read as matrix verbs, rather than as verbs in reduced relative clauses (Weinberg, 1999). Participants had difficulty disambiguating these verbs, which lead to longer reading times for those sentences.

The results from MacDonald's experiment are curious because frequency does not seem to play a role. In Merlo and Stevenson's work, they also looked at how frequently unergatives, unaccusatives, and ordinary verbs appeared as transitive or intransitive verbs (Weinberg, 1999). The data showed that ordinary verbs were frequently transitive. According to Weinberg (1999), "five of the eight 'ordinary' verbs [in Merlo and Stevenson's data] were part of the fought class tested by MacDonald" (p. 309). Thus, even though fought class verbs frequently occur as transitives, participants had difficulty processing these verbs in reduced relative clauses. "If this is correct, it poses a problem for frequency-based approaches, which would predict that this class should be the least 
difficult to interpret as it most frequently appears in constructions that relative-clause interpretations presuppose" (Weinberg, 1999, p. 310).

Last, Weinberg (1999) looks at work by Filip et al, in which they explain Merlo and Stevenson's results with a constraint-based approach. (They do not look at ordinary verbs, only unergative and unaccusative.) Their hypothesis is presented below:

(15) "The acceptability of sentences with reduced relative clauses, headed by past participles derived from unergative and unaccusative verbs, increases when the passive participle and the main verb of a matrix clause assign their subject-NPs more Proto-Patient and fewer Proto-Agent properties" (Weinberg, 1999, p. 310). Proto-agents are defined as sentient, animate beings that act with intent; contrastingly, proto-patients can be animate or inanimate but must "undergo a change of state" caused by the verb; they do not act with intent (Weinberg, 1999, p. 310). The sentences in (16) support the hypothesis in (15):

(16) a. "the horse raced past the barn fell

(Horse is sentient, causes the movement, and exists independently both as the object of race and as the subject of fell.)

b. the fish fried in the pan made me sick

(Fish undergoes a change of state, is the incremental theme, and is affected by fry in the reduced-relative-clause reading. It is a proto-agent of the predicate make sick because it is causal, does not undergo a change of state, and so on)" (Weinberg, 1999, p. 311). 
While the examples above support the hypothesis of Filip et al., the sentence in (17), from MacDonald (1994) does not.

(17) the cattle moved into the crowded room were afraid of the cowboys

Despite the cattle being given a patient $\theta$-role by both verbs, the sentence is still unparsable, which goes against Filip et al.'s hypothesis in (15). Weinberg argues that ordinary verbs are processed as intransitive when they are interpreted as a matrix verb. However, once the parser reaches the true matrix verb were, move must be reanalyzed as the verb of the reduced relative clause. "By the time that happens, the material preceding were is already spelled out, and the trace necessary for interpreting moved ... room as a reduced relative cannot be inserted" (Weinberg, 1999, p. 311). The structure in (18) illustrates this.

(18) Figure 2.2.4.6: Structure for the cattle moved were

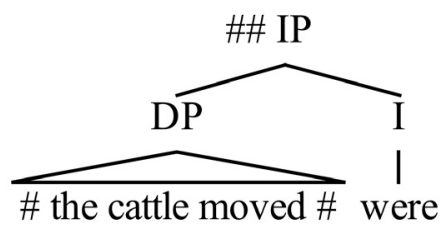

Thus, reanalysis is not possible is these cases. On the other hand, when an accusative verb is processed, a trace is automatically inserted after the verb, permitting reanalysis. Weinberg (1999) concludes that this is evidence that "frequency ... may drive the initial preference for a given verb to be part of either a main-clause or a reduced relative" (Weinberg, 1999, p. 312). However, frequency is working together with grammaticalitybased principles. 


\subsubsection{Conclusions}

In her article, Weinberg (1999) argues that the Minimalist's Program's economy principles and Spell-Out are present during language processing. In addition, Weinberg argues in favor of excluding the induction step of the Linear Correspondence Axiom (LCA). Rather than the induction step, she supports the theory of multiple Spell-Out, providing several examples as evidence. Last, Weinberg reasons that frequency and economy principles work together during language processing; she provides examples to support this conclusion as well.

\subsection{The Minimal Structure Principle}

In this section, Željko Bošković’s (1997) “Selection and the Categorical Status of Infinitival Complements" is summarized. In this work, Bošković argues in favor of a Case-theoretic approach to the distribution of PRO and argues that government and cselection can be removed from the grammar. Further, he argues that control infinitives hold an IP status, not a CP status, due to the Minimal Structure Principle (MSP), which favors syntactic representations with fewer projections. The MSP is discussed in section 2.3.1.3. The purpose of summarizing this work is to provide background on the MSP, as the role of the MSP in language processing is examined in this study. Note that all examples, figures, tables, and ideas provided in the summary below were taken directly from the author's work. 


\subsubsection{Bošković's "Selection and the Categorical Status of Infinitival Complements"}

\subsubsection{Introduction}

Željko Bošković (1997) argues for the reduction of infinitival complementation and the distribution of PRO. Specifically, he argues that government and c-selection are no longer necessary to explain this phenomena and can, thus, be eliminated from the grammar. Consider the following examples:
a. $\quad * \mathrm{John}_{\mathrm{i}}$ is illegal $\left[\mathrm{CP} \mathrm{t}_{\mathrm{i}}\right.$ to park here $]$
b. It is illegal [CP PRO to park here]
c. $\quad \mathrm{John}_{\mathrm{i}}$ appears [IP to like Mary]
d. $\quad$ *It appears to Bill [IP PRO to like Mary].

Under the standard approach, the grammaticality/ungrammaticality of (1a-d) is explained with c-selection. The ungrammatical sentences, (1a) and (1d), show c-selection of CP and IP complements, respectively. Under c-selection, (1a) "is ruled out because it involves NP movement across a CP boundary. [(1d)], on the other hand, is excluded because PRO is governed by appear" (Bošković, 1997, p. 8). However, in his article, Bošković explains the phenomena in (1a-d) without c-selection and government. Rather, he explains (1a-d) with a Case-theoretic account of the distribution of PRO and infinitival complementation.

\subsubsection{Infinitival Complementation and C-Selection}

To do this, Bošković (1997) looks at the following examples and explains how the standard c-selection approach would account for their grammaticality/ungrammaticality: 
(2) a. John believed ${ }_{i}\left[\operatorname{AgroP} \operatorname{him}_{\mathrm{i}}[\mathrm{IP}\right.$ to be crazy $\left.]\right]$

b. $\quad *$ John believed [IP PRO to be crazy]

c. John tried [CP PRO to win]

d. *John tried ${ }_{\mathrm{i}}\left[\mathrm{AgroP}_{\mathrm{him}} \mathrm{t}_{\mathrm{i}}\left[\mathrm{CP}\left[\mathrm{IP} \mathrm{t}_{\mathrm{j}}\right.\right.\right.$ to win] $\left.]\right]$

In regards to c-selection, the verbs try and believe take CP and IP complements, respectively. Thus, when him moves to the SpecAgroP position to check case in (2a) and (2d), there is ungrammaticality in (2d). As in (1a), an NP him cannot move across a CP boundary, so the sentence fails. As Bošković writes, the $\mathrm{CP}$ acts as a block, which is beneficial for (2c). However, this is not beneficial for $(2 b)$, which is ungrammatical because there is no CP to block the government of PRO.

Bošković (1997) argues that there are three problems with using the standard approach to explain (2): First, the standard approach assumes that PRO does not have Case. Second, it assumes that nonfinite I does not govern PRO. Third, it assumes that believe c-selects IP and try c-selects CP. To avoid these three problems, (2a-d) can be analyzed without the standard c-selection/binding-theoretic approach if Chomsky and Lasnik’s (1993) proposal is adopted (Bošković, 1997).

Under Chomsky and Lasnik's (1993) proposal, PRO has null Case, and its Case is "checked via Spec-head agreement with nonfinite I" (Bošković, 1997, p. 11). Bošković (1997) explains the following example with their proposal:

(3) a. John tried $\mathrm{PRO}_{\mathrm{i}}$ to be arrested $t_{\mathrm{i}}$

b. $*$ John tried $\mathrm{PRO}_{\mathrm{i}}$ to seem to $\mathrm{t}_{\mathrm{i}}$ that the problem is unsolvable According to the Last Resort Condition, an NP cannot undergo movement from one Case-checking position to another. As a result, (3b) is ungrammatical because there is 
movement from a position that checks Case to another. Contrastingly, (3a) is grammatical because the Last Resort Condition is not violated.

Bošković (1997) adds to Chomsky and Lasnik’s (1993) proposal by adopting Martin's (1992) modification of their proposal: "not every nonfinite I has the ability to check null Case ... only [+tense] nonfinite I can check null Case” (Bošković, 1997, p. 11). Further, assuming Stowell's (1982) proposal, Martin (1992) explains that control infinitives have Tense ([+tense]), and ECM infinitives do not ([-tense]) (Bošković, 1997). Bošković (1997) illustrates this with the following example:

(4) a. John tried to bring the beer.

b. *John believed Peter to bring the beer.

Above, (4a) contains a control infinitival; therefore, PRO's null Case is checked by the [+tense] nonfinite I, and "the Tense of the control infinitival can serve as a binder for the temporal argument of bring" (Bošković, 1997, p. 12). As a result, the sentence is grammatical. Contrastingly, the ECM infinitival in (4b) does not have the tense necessary to bind the temporal argument; thus, PRO's null Case is not checked, and the sentence is ungrammatical. Therefore, according to Martin (1992), the checking of PRO's null Case is affected by the Tense of nonfinite I; Bošković (1997) adopts this approach.

Next, Bošković (1997) explains that s-selection may be the reason that the complements of believe and try differ in Tense. Believe takes Proposition arguments, whereas try takes irrealis, or non-propositional, arguments. An irrealis complement is not necessarily true or false when spoken. For example, it is possible to say "John believed Peter to have played football, which was false" (Bošković, 1997, p. 13). Therefore, at the time of speech, it is known that Peter did not play football. However, it is not possible to 
say "*John tried to play football, which was false" because the falseness of the

complement of try would not be known at that time (Bošković, 1997, p. 13). Because try s-selects irrealis arguments, the complement of try has an unrealized tense; therefore, the infinitival complement of try cannot be finite or [-tense]. Believe, on the other hand, cannot s-select an irrealis complement due to its s-selectional requirements. "In summary, under the Case-theoretic approach to the distribution of PRO, like other NP arguments, PRO is always Case-marked. Its Case is checked via Spec-head agreement with [+tense, finite] I. As a result of the s-selectional properties of the relevant predicates, this element is present in the infinitival complement of try-class verbs but not believe-class verbs" (Bošković, 1997, p. 14).

\section{Case Checking with ECM Verbs}

Next, Bošković (1997) returns to (2a-b), repeated below in (5a-b), and analyzes the grammaticality/ungrammaticality presented using the Case-theoretic approach to the distribution of PRO.

$$
\begin{aligned}
& \text { a. John believedi }\left[\operatorname{Agrop}_{\text {him }}\right. \text { [IP to be crazy]] } \\
& \text { b. *John believed [IP PRO to be crazy] }
\end{aligned}
$$

Under this approach, (5b) is ungrammatical because PRO is unable to check its null Case. Therefore, the grammaticality of the embedded clause is not dependent on whether it is a $\mathrm{CP}$ or IP, as the standard c-selection/binding-theoretic approach would suggest. "Under the Case-theoretic approach to the distribution of PRO there is no need to appeal to cselection to account for [(5a-b)]” (Bošković, 1997, p. 15). 


\section{Try-Class Verbs and Case Checking}

The type of complement that control verbs take is dependent on which account is adopted (Bošković, 1997). Under the standard approach, control verbs take CP complements. However, "since the Case-theoretic account permits PRO to be governed, there is nothing wrong with the complement of try being an IP” (Bošković, 1997, p. 15). Thus, under this account, the complement of PRO can be an IP or CP. Consider the following example:
a. $\quad * \mathrm{John}_{\mathrm{i}}$ was tried $\left[\mathrm{t}_{\mathrm{i}}\right.$ to leave $]$
b. *John tried [him to leave]
c. $\quad * \mathrm{Who}_{\mathrm{i}}$ did John try $\left[\mathrm{t}_{\mathrm{i}}\right.$ to leave $]$

As shown in (2c), it is possible for try to have PRO as its complement's subject, proving this position to be a Case-checking position. In the (6a), John appears in this subject position. Consequently, (6a) is ungrammatical because it violates the Last Resort Condition; as previously stated, this condition prevents NP-movement from one Casechecking position to another. Similarly, (6b-c) are ungrammatical because him and who "must move to the SpecAgroP position for Case checking” (Bošković, 1997, p. 16). Therefore, Bošković (1997) argues that "control verbs can take either a CP or an IP complement, [and] ECM and passive raising with control verbs are ruled out by the Last Resort Condition" (p. 16). 


\section{Case Checking with Want-Class Verbs}

Next, Bošković (1997) discusses want-class verbs. Want-class verbs differ from try-class and believe-class verbs because the infinitival complements of want can be either PRO or a lexical subject; this is shown below:
a. I want him to leave.
b. I want PRO to leave.

Above, (7a) may seem questionable under the Case-theoretic approach because him is in a position that PRO can occur in, a Case-checking position; thus, (7a) should violate the Last Resort Condition. However, Lasnik and Saito (1991) show that "him in [(7a)] does not move into the matrix clause" (Bošković, 1997, p. 17). This is illustrated below:

a. ?Joan wants him ${ }_{i}$ to be successful even more fervently than Bob's ${ }_{i}$ mother does

b. $\quad$ ?*Joan believes $\operatorname{him}_{\mathrm{i}}$ to be a genius even more fervently than Bob's $\mathrm{s}_{\mathrm{i}}$ mother does

In (8b), the embedded subject "raises to SpecAgroP in LF for Case checking, . . . ccommands the matrix adverbial at LF, thus causing a Condition C violation" (Bošković, 1997, p. 17). Contrastingly, (8a) is grammatical because the embedded subject does not move into the matrix clause.

Bošković (1997) argues that the Case of the embedded subjects in (7a) and (8a) are checked by a null complementizer within the infinitival complement. The complementizer is "phonologically null" and similar to for in the example below (Bošković, 1997, p. 18):

(9) I want (very much) for him to leave. 
According to Bošković, want may be able to take for and its similar null complementizer as its complement because of l-selection. Pesetsky's (1992) 1-selection approach is the following: "L-selection is limited in scope and involves arbitrary selection for lexical items and features associated with them that cannot be reduced to either s-selection or cselection. L-selection does not refer to syntactic categories, but instead refers to individual lexical items ad specific features such as [+/-finite]" (1997, p. 19).

With this approach, for example, individual lexical items are able to select which prepositions are compatible with them. The example Bošković uses is love and desire: "Love allows either for or of, whereas desire requires for" (1997, p. 19). In the same way, it is proposed that for and the null complementizer are l-selected by want. In conclusion, the Case-theoretic approach is able to account for why lexical subjects and PRO are both possible subjects of want-class verb complements.

\section{The Categorial Status of Control Infinitives}

In the previous sections, Bošković (1997) has shown that c-selection of CPs by control verbs is arbitrary. Next, he illustrates that there are some grammatical constructions in which control verbs must take an IP complement, not a CP, which would not be allowed by the c-selection approach.

\section{Empty Complementizers and the ECP}

According to Stowell (1981), "the distribution of empty complementizers can be accounted for if they are subject to the [Empty Category Principle (ECP)]" (Bošković, 1997, p. 21). Consider the following examples: 
(10) a. It is believed [ ${ }_{\mathrm{CP}} \mathrm{C}$ [IP he is crazy]]

b. $\quad *\left[{ }_{\mathrm{CP}} \mathrm{C}[\mathrm{IP} \mathrm{He}\right.$ would buy a car $\left.]\right]$ was believed at that time

c. *It was believed at that time [CР C [IP you would fail her]]

Examples (10b-c) are ungrammatical because the empty complementizers are not properly governed. While this ungrammaticality occurs with finite clauses, it does not occur with infinitival clauses, as is shown in (11).

(11) a. I tried at that time [CP $\mathrm{C}[\mathrm{IP}$ PRO to fail her] $]$

b. $\quad[\mathrm{CP} C[$ IP PRO to buy a car] $]$ was desirable at that time Under the Case-theoretic approach, the grammaticality of (11a-b) can be explained if the infinitives are IPs and not CPs (Bošković, 1997). Thus, Bošković accounts for the unexpected grammaticality by assuming that there are no $\mathrm{CP}$ projections in the sentences above. If this is the case, the ECP is satisfied.

Next, consider the following examples:

(12) a. What the terrorists tried was [a PRO to hijack an airplane]

b. They demanded and we tried [ $\alpha$ PRO to visit the hospital]

c. *What the terrorists believe is [ $\alpha$ they will hijack an airplane]

d. $\quad *$ They suspected and we believed [ ${ }_{\alpha}$ Peter would visit the hospital]

Above, (12c-d) are ungrammatical because "the null head of $\alpha$ is not properly governed," and the ECP is not satisfied (Bošković, 1997, p. 21). Under the Case-theoretic approach, the grammaticality of (12a-b) can be explained if it is assumed that the infinitival complements are IPs. Under the c-selection approach, (12a-b) would be considered ungrammatical because the $\mathrm{CP}$ complement would violate the ECP. Therefore, it can be 
concluded that control verbs must take IP complements in certain instances, which is further evidence against the standard binding-theoretic account of the distribution of PRO.

\section{$\underline{\text { Scrambling out of Control Infinitives }}$}

Another way in which Bošković (1997) supports the Case-theoretic account of the distribution of PRO is by looking at the scrambling out of control infinitives. "In contrast to scrambling out of finite $\mathrm{CPs}$, scrambling out of control infinitives exemplifies Amovement" (Bošković, 1997, p. 23). Consider the Serbo-Croatian examples in (13); the scrambled quantifier is nekoga, meaning 'someone.'

a. $\quad$ Nekoga $_{\mathrm{i}}$ njegov $_{\mathrm{j} / ? *_{\mathrm{i}}}$ otac veruje da oni mrze $t_{\mathrm{i}}$ someone his father believes that they hate 'Someone, his father believes that they hate'

b. $\quad$ Nekoga $_{\mathrm{i}}$ njegov $_{\mathrm{i}}$ otac planira PRO kazniti $t_{\mathrm{i}}$ someone his father is-planning to punish 'Someone, his father is planning to punish'

Quantifiers are able to locally bind pronouns from A-positions, not A-bar-positions. Above, (13a) shows that the quantifier "cannot be coindexed with the pronoun it ccommands," meaning that someone is in an A-bar-position (Bošković, 1997, p. 23). Because the quantifier crosses a CP boundary, the quantifier in (13a) cannot locally bind his. However, the quantifier in (13b) is able to locally bind his. Thus, in (13b) someone moves into an A-position, meaning that there is no A-movement out of a CP. This claim, Bošković (1997) argues, supports the Case-theoretic approach. 


\subsubsection{Economy and the Categorial Status of Clauses}

Next, Bošković (1997) discusses Law’s (1991) principle of economy of representation. With this principle, he aims to show that control infinitives must be an IP and cannot be a CP.

\section{$\underline{\text { Null-Operator Relatives and Economy of Representation }}$}

In the following examples, both null-operator relatives introduced by that (shown in (14a)) and zero null-operator relatives (shown in (14b)) are presented:

(14) a. the man $\left[O p_{i}\right.$ that John likes $\left.t_{i}\right]$

b. the man [Op $\mathrm{p}_{\mathrm{i}}$ John likes $\left.\mathrm{t}_{\mathrm{i}}\right]$

Under the standard approach, both relative clauses in (14) hold a CP status. According to Law (1991), however, the zero null-operator relative in (14b) is necessarily an IP, not a CP, due to the principle of economy of representation (Bošković, 1997). Bošković's (1997) version of this principle is presented in (15):

"The Minimal Structure Principle (MSP)

Provided that lexical requirements of relevant elements are satisfied, if two representations have the same lexical structure and serve the same function, then the representation that has fewer projections is to be chosen as the syntactic representation serving that function" (Bošković, 1997, p. 25).

According to the MSP, the number of projections present in a representation is dependent on the fulfillment of lexical requirements. If there are two possible representations, the 
one with the fewest projections will be favored by the MSP. As a result, the relative clause in (14b) must be an IP, not a CP, as shown in (15):

(15) a. the man [IP $\mathrm{Op}_{\mathrm{i}}$ [IP John likes $\left.\left.\mathrm{t}_{\mathrm{i}}\right]\right]$

b. the man [CP Opi $\left[\mathrm{C}^{\prime}\left[\right.\right.$ [IP John likes $\left.\left.\left.\mathrm{t}_{\mathrm{i}}\right]\right]\right]$

According to Bošković (1997), the proposal that relative clauses must be IPs explains why short zero-subject relatives with Op are not possible; this is shown in (16a). If the relative clause in (16a) must be an IP due to the MSP, then the Op takes the IPadjoined position, causing ungrammaticality, as there cannot be movement from [Spec, IP] to the IP-adjoined position. This ungrammaticality is similar to that of short subject topicalization, shown in (16b).
a. *the man [IP Op [IP $_{\mathrm{i}}$ likes Mary]]
b. $\quad *$ I think that [IP $J{ }^{\prime} n_{i^{\prime}}\left[\right.$ [IP $t_{i}$ likes Mary]]

Further, "as noted by Saito and Murasugi (1993), if who could move from SpecIP to the IP-adjoined position, the Comp-trace (C-trace) effect would be voided in [(17)], since the original trace $t$ would be licensed by t"' (Bošković, 1997, p. 27).

*Who do you think [CP $\mathrm{C}{ }_{\mathrm{i}}\left[\mathrm{C}\right.$, that $\left[{ }_{\mathrm{IP}} \mathrm{t}_{\mathrm{i}}{ }_{\text {[IP }} \mathrm{t}_{\mathrm{i}}\right.$ likes Mary $\left.\left.\left.]\right]\right]\right]$

As a result, Saito and Marasugi (1993) proposed the following:

(18) Condition on the length of chain links:

a. "A chain link must be at least the length of 1 .

b. A chain link from A to B is of length $n$ iff there are $n$ 'nodes' (X, X', or XP, but not segments of these) that dominate A and exclude B” (Bošković, 1997, p. 27). 
Thus, according to the conditions described above, a chain link must have at least the length of 1 , which further explains the ungrammaticality of (16a-b) and (17).

Next, Saito (1985) notes that adjunction structures, like zero relatives, do not permit resumptive pronouns (Bošković, 1997). Consider the following:

(19) a. *the book [IP Op [IP I was wondering whether I would get it in the mail]]

b. the book [ $\mathrm{CP}$ Op [c' that I was wondering whether I would get in the mail]] As is shown in (19a), the IP-adjoined position is filled by Op, preventing a resumptive pronoun from also occurring in that position. Contrastingly, in (19b), "Op is located in SpecCP rather than in an adjoined position, [and] the gap can be filled by a resumptive pronoun" (Bošković, 1997, p. 28). Therefore, the ungrammaticality of (19a) and the grammaticality of (19b) can be explained by the IP status of zero null-operator relatives; this supports the existence of the MSP.

\section{Finite Declarative Complements and Economy of Representation}

If zero null-operator relatives are IPs due to the MSP, then it is expected that finite declarative complements are also IPs (Bošković, 1997). An example of this is the "embedded clause in I believe John likes Mary" (Bošković, 1997, p. 29). If there is movement out of the finite declarative complement, there are no C-trace effects. If the embedded clause is an IP, this is easily explainable. However, if the embedded clause is a $\mathrm{CP}$, it is unclear as to why there are no $\mathrm{C}$-trace effects. An example of this can be seen below: 
(20) a. Who do you believe likes Mary

b. *Who do you believe that likes Mary

Bošković (1997) argues that the example above is further evidence for the MSP.

\section{Topicalization}

The IP analysis can also explain why topicalized embedded clauses must begin with that (Bošković, 1997). Consider the following examples:
a. [IP Mary, [IP John likes]]
b. Peter doesn't believe that [IP Mary, [IP John likes]]
c. * * Peter doesn’t believe [IP Mary, [IP John likes]]

"Given that the embedded clause in $[(21 c)]$ is an IP and that topicalization involves adjunction to IP, $[(21 \mathrm{c})]$ is ruled out because it involves adjunction to an argument, which . . . is not allowed" (Bošković, 1997, p. 30). Thus, the embedded clause is unable to receive its $\theta$-role because it is blocked by the adjoined elements. As a result, the sentence is ungrammatical because there is a $\theta$-Criterion violation.

Further, Rochemont (1989) argues, “topicalization involves clausal adjunction (i.e., adjunction to either CP or IP)," not simply IP adjunction (Bošković, 1997, p. 31). In the following examples, (22b) and (22d) show adjunction to a CP argument, which is not allowed, causing ungrammaticality. Contrastingly, in (22a) and (22c), the IP and CP "are not arguments, [and] no adjunction to arguments takes place in these constructions" (Bošković, 1997, p. 31). As a result, (22a-c) are (marginally) grammatical.

(22) a. ??[CP To John, [cP which book should Peter give]]

b. $\quad *$ I wonder [CP to John, [CP which book Peter should give]] 

c. ??I wonder [CP to whom [IP this book, [IP Peter should give]]]
d. *John believes [CP this book, [CP that Peter should give to Mary]]

\section{$\underline{\text { Wanna-Contraction }}$}

Bošković (1997) uses the following PF contraction examples, from Bošković (1994), to show that zero declaratives are IPs:
a. $\quad * \mathrm{Who}_{\mathrm{i}}$ do you wanna $\mathrm{t}_{\mathrm{i}}$ buy a car?
b. cf. I wanna PRO buy a car.

Previously, (23a) was seen as ungrammatical because there is a wh-trace preventing the contraction of want and to. However, this is not always the case. In the following examples, from Schachter (1984), PF contraction is permitted, despite the presence of wh-traces (Bošković, 1997):
(24) a. What $t_{i}$ do you think's $t_{i}$ happening there tomorrow
b. $\quad$ cf. What ${ }_{i}$ do you think $t_{i}$ is happening there tomorrow
c. What ${ }_{i}$ do you think's $t_{i}$ been happening there today
d. $\quad$ cf. What ${ }_{i}$ do you think $t_{i}$ has been happening there today

The grammaticality of these sentences can be explained if it is assumed that " $w h$-traces are invisible at PF" (Bošković, 1997, p. 35). If this is true, then the ungrammaticality of (23a) must be caused by something other than a $w h$-trace: a null $\mathrm{C}$. Thus, this null $\mathrm{C}$ is blocking contraction, as is shown below:

(25) $\mathrm{Who}_{\mathrm{i}}$ do you want $\left[\mathrm{CP} \mathrm{C}\left[\mathrm{IP} \mathrm{t}_{\mathrm{i}}\right.\right.$ to buy a car $\left.]\right]$ 
In (24a) and (24c) there is no null C, causing contraction to be possible. Bošković argues that this further supports the MSP and the notion that zero finite declarative complements are IPs.

\section{$\underline{\text { Infinitival Complementation and Economy of Representation }}$}

In (26), the infinitival complement could be either a CP or an IP. However, due to the MSP, the infinitival complement is an IP because it has fewer projections than if it were a CP, while meeting the same lexical requirements (Bošković, 1997).

John tried [IP PRO to kiss Mary]

According to Bošković (1997), other authors have proposed comparable principles of economy of representation. A few of these principles are presented in (27):

a. "Minimal Projection (Grimshaw, 1994)

A functional projection must be functionally interpreted.

b. Structural Economy Principle (Safir, 1993)

At any point in a derivation, a structural description for a natural language string employs as few nodes as grammatical principles and lexical selection require.

c. (Speas, 1994)

Project XP only if XP has content. A node X has content if and only if X dominates a distinct phonological matrix or a distinct semantic matrix.

d. Minimal Projection Principle (Radford, 1994)

S-structures are the minimal well-formed projections of the lexical items they contain. 
e. (Chomsky, 1995)

$\alpha$ enters the numeration only if it has an effect on output" (Bošković, 1997, p. 38)

While these principles vary, they are all principles of economy of representation, and they all assume that infinitival complements of control verbs are IPs. Therefore, they all support the theory presented in Bošković's article.

\subsubsection{Conclusion}

In conclusion, Bošković (1997) argues that government and c-selection can be eliminated from the grammar. Instead, he favors the Case-theoretic approach to the distribution of PRO. Further, he argues that the Minimal Structure Principle (MSP), a principle of economy of representation, requires control infinitives to hold an IP status, not a CP status.

\section{Research Design and Methodology}

One of the prominent questions in modern psycholinguistics is the relationship between the grammar and the parser. Within the approach of Generative Grammar, this issue has been investigated in terms of the role that Principles of Universal Grammar may play in language processing. The aim of this research experiment is to investigate this topic. Specifically, this experiment aims to test whether the Minimal Structure Principle (MSP) plays a role in the processing of Preposition-Stranding (P-Stranding) versus PiedPiped Constructions. P-Stranding and Pied-Piped Constructions are used to investigate the role of the MSP in language processing because the two construction types have the 
same lexical structure and serve the same function; however, they have a different number of projections present in their syntactic representations.

The P-Stranding version of a sentence has fewer projections than its Pied-Piped counterpart. Consider the following sentence: The student will present the paper at a conference. If a person wants to know which conference, they could ask this question using a sentence with either a P-Stranding or Pied-Piped Construction, as shown in (1):

a. P-Stranding

[DP Which conference $\left.\mathrm{i}_{\mathrm{i}}\right]$ will the student present the paper $\left[\mathrm{PP}\right.$ at $\left.\mathrm{t}_{\mathrm{i}}\right]$ ?

b. Pied-Piping

[PP At which conference $\mathrm{i}_{\mathrm{i}}$ ] will the student present the paper $\mathrm{t}_{\mathrm{i}}$ ?

Before movement, both of the structures in (1) have the same structure and, thus, the same number of projections; as is shown below:

(2) Figure 3.a: Pre-Movement Structure

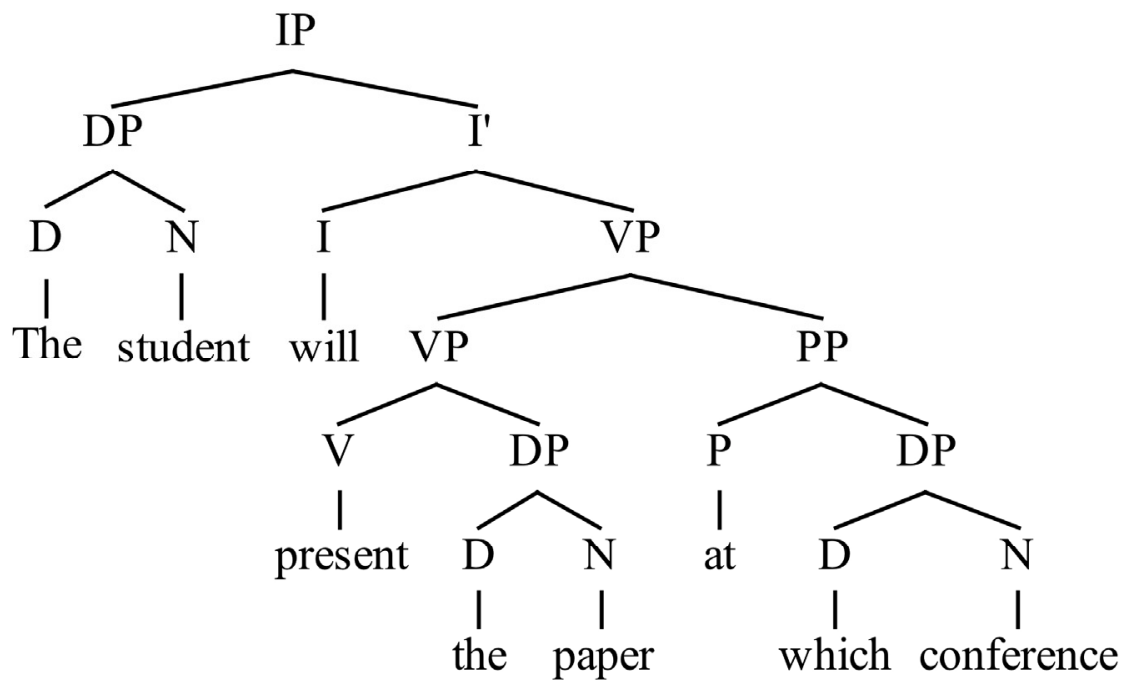


Assuming the COPY and DELETE approach to Movement, for the P-Stranding derivation, the DP which conference is copied and raised to [Spec, CP], leaving behind the copy. At this point in the derivation, we have the structure in (3):

(3) Figure 3.b: Structure for Which conference will the student will present the paper at which conference?

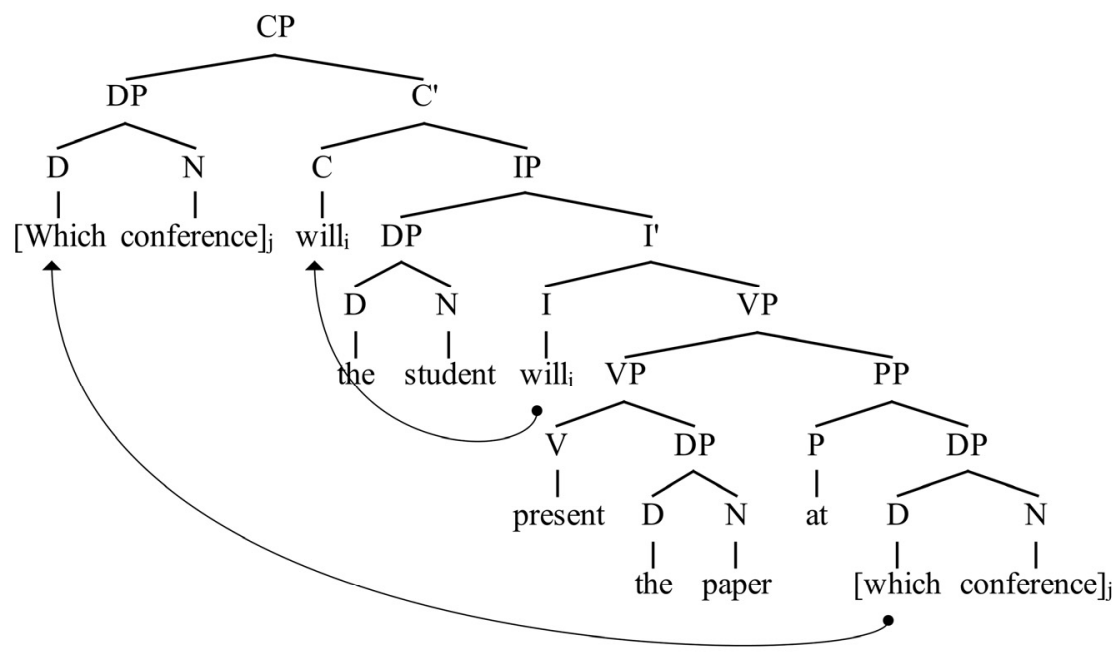

The movement process created a total of 23 projections.

As for the comparable derivation with Pied-Piping, the PP at which conference is copied; thus, the structure is as in (4). This movement process has created a total of 25 projections.

(4) Figure 3.c: Structure for At which conference will the student will present at which conference? 


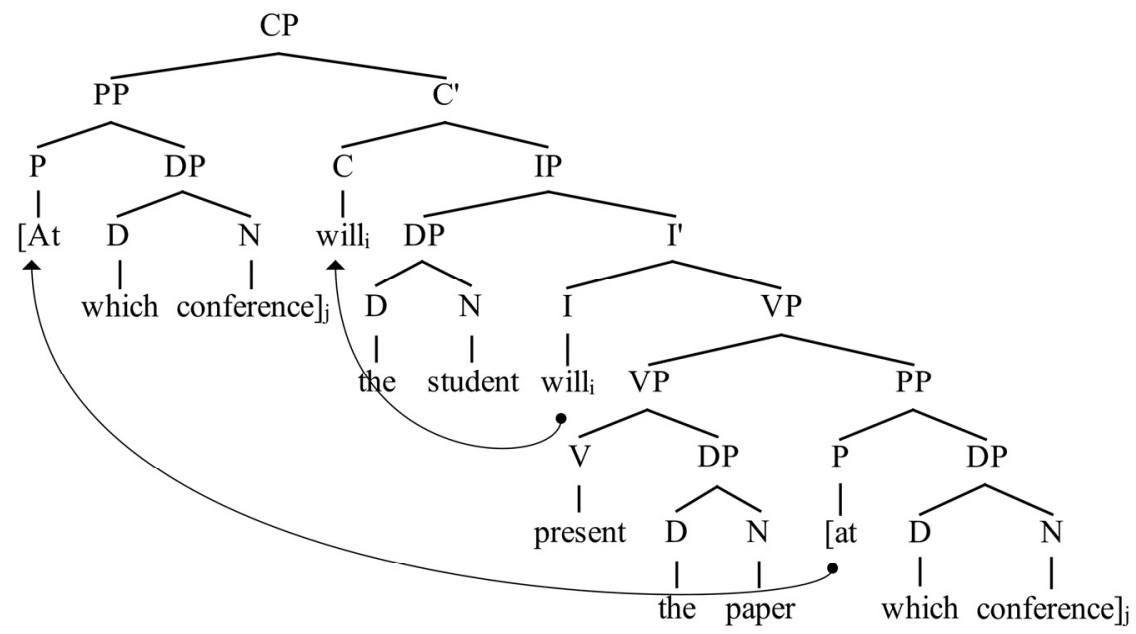

Therefore, according to the MSP, the derivation with P-Stranding is preferred over the derivation with Pied-Piping because it has fewer projections. If the MSP is active during language processing, then sentences with P-Stranding Constructions should be less costly processing-wise. To test this, a self-paced reading task was conducted. The details of the experiment are discussed in the following sections.

\subsection{Participants}

In this experiment, thirty monolingual English speakers were tested. For the purposes of this study, monolinguals were defined as native speakers of English, who spoke no language other than English. Only monolingual English speakers were used for this study because, as mentioned in the previous chapter, P-Stranding Constructions are cross-linguistically rare; thus, if a participant spoke another language in which PStranding Constructions are not possible, these constructions may be difficult to process for this reason. To determine if a participant was a monolingual English speaker, a language history questionnaire was used; to view this questionnaire, see Appendix A. If a 
participant studied a second language during secondary school, this was not cause for disqualification from the study, provided that the participant was not able to use that second language with more than very limited fluency; this means that participants may know words or phrases in a second language but cannot hold full conversations.

All participants included in this study were between the ages of 18 and 65 with a mean age of 36 ; the range is 45 . The participants were split up into two groups because two versions of the target sentences were created. (This is explained further in section 3.2.1.1.) The mean age of the participants who were tested with version one of the target sentences (Experiment 1) was 32.4; the range was 45. The mean age of the participants who were tested with version two of the target sentences (Experiment 2) was 39.6; the range was 37 . The participants were of both male and female gender; 17 males and 13 females were tested. Experiment 1 tested 9 males and 6 females; Experiment 2 tested 8 males and 7 females. All of the participants were required to have at least a high school diploma or equivalent (such as a GED).

\subsection{Materials}

The type of experiment conducted was a Self-Paced Reading Task (SPRT). For this type of task, participants read sentences at their own pace and their reading times (RTs) are recorded. The rationale behind this type of task is that RTs are reflective of processing difficulties (Marinis, 2010, p. 145). Thus, this study compares participants' RTs of sentences with P-Stranding Constructions (P-Stranding Sentences) to their RTs of sentences with Pied-Piped Constructions (Pied-Piped Sentences). Based on the assumption that longer RTs show greater processing difficulties, significant differences in 
the RTs of the two constructions indicate whether one construction type has greater processing costs than the other. To ensure that participants were unfamiliar with the purpose of the study, the experiment consisted of both target and filler sentences, as well as a secondary task in which participants were required to answer comprehension questions about the sentences they were reading. The SPRT and Comprehension Question Task (CQT) are explained in the following sections.

\subsubsection{SPRT Instrument}

The Self-Paced Reading Task (SPRT) consisted of a total of 100 sentences. There were 52 filler sentences and 48 target sentences. The target sentences were divided evenly between P-Stranding Sentences and Pied-Piped Sentences. The target and filler sentences will be explained in the following two subsections.

Note that precautionary measures were taken in order to ensure that reading times (RTs) were reflective of processing difficulties regarding the construction types and not extraneous factors. For example, all of the sentences included sentence-final optional modifiers in order to mitigate Wrap-Up Effects. According to Hirotani (2006), when a reader reaches the final word of a clause or sentence, they pause to finish interpreting the sentence. Therefore, by using sentence-final optional modifiers, the two constructions being investigated in this study were not positioned at the end of the sentence, which may have multiplied the processing costs of those constructions.

In addition, to ensure that processing costs were not affected by priming effects, no verbs or nouns (other than those used in the sentence-final optional modifiers) were repeated. No pronouns were used, in order to prevent participants from having to recall 
information used in previous sentences or earlier in that same sentence, adding to processing costs. Lastly, no prepositional phrases (PPs) were used in any of the sentences outside of the constructions being investigated; this was done to ensure that participants would not notice an overuse of prepositions, which may have called attention to the purpose of the experiment.

\subsubsection{Target Sentences}

Two types of target sentences were used in this study: P-Stranding Sentences and Pied-Piped Sentences. Of the 48 total target sentences, 24 were P-Stranding Sentences and 24 were Pied-Piped Sentences. To counterbalance the type of preposition complement used, the 24 sentences were split evenly between three different complement types: what followed by a noun, which followed by a noun, and whose followed by a noun. Examples of P-Stranding and Pied-Piped Sentences with each prepositioncomplement type are shown below:

a. P-Stranding:

(i) What remark did Jack apologize for yesterday?

(ii) Which computers did the sixth graders learn to type on last year?

(iii) Whose friend did Mary go to the theatre with last night?

b. Pied-Piping:

(i) At what restaurant does the businessman eat every week?

(ii) Behind which platform did the conductor stand every day?

(iii) To whose birthday did Gina bring a cake last week? 
In order to control for variation due to lexical, semantic, and syntactic factors and general content differences between sentences, two versions of the target sentences were created; thus, there were two different experiments (Experiment 1 and Experiment 2) used with participants. Half of the participants (15 participants) were tested with Experiment 1 and the other half (the remaining 15 participants) were tested with Experiment 2. Sentences that appeared with one construction in Experiment 1 would occur with the other construction in Experiment 2. Thus, the P-Stranding Sentences in Experiment 1 appeared as the Pied-Piped Sentences in Experiment 2; the Pied-Piped Sentences in Experiment 1 appeared as the P-Stranding Sentences in Experiment 2. The sentences shown in examples (5a) and (5b) belong to Experiment 1; the Experiment 2 version of those sentences are shown below:

a. P-Stranding:

What restaurant does the businessman eat at every week?

Which platform did the conductor stand behind every day?

Whose birthday did Gina bring a cake to last week?

b. Pied-Piping:

For what remark did Jack apologize yesterday?

On which computers did the sixth graders learn to type last year? With whose friend did Mary go to the theatre last night?

\subsubsection{Filler Sentences}

The experiment contained 52 filler sentences, which were used to distract participants from the purpose of the experiment. The filler sentences did not contain 
either of the target constructions and did not appear in question form. Participants' reading time (RTs) for the filler sentences were not recorded or used in the results. The same 52 filler sentences were used in Experiment 1 and 2. Examples of the filler sentences from the experiment are shown below:
a. Fillers:

Carolina climbed a mountain two years ago.

Autumn seemed picturesque last year.

Bananas develop dark spots when overripe.

\subsubsection{Comprehension Question Task Instrument}

After half of the total sentences ( 50 of the 100 sentences), participants were asked a yes or no question about the sentence that immediately preceded the comprehension question. The reason for including a Comprehension Question Task (CQT) was to ensure that participants were reading and comprehending the content of the sentences being shown. The comprehension questions were spread evenly throughout the experiment, and there was an equal number of yes and no questions. Of the 52 filler sentences, 26 sentences were followed by a comprehension question; of those 26,13 required a 'yes' answer and 13 required a 'no' answer. Of the 48 target sentences, 24 were followed by a comprehension question, split evenly between the P-Stranding and Pied-Piped Sentences (12 comprehension questions per sentence type).

In addition, the 12 comprehension questions were divided amongst the complement types, so that each of the three complement types were followed by four 
comprehension questions; two of the four required 'yes' answers and two required 'no' answers. Participants were able to distinguish a comprehension question from a reading sentence because the comprehension questions were shown in all capital letters.

Examples of sentences and their comprehension questions (in capital letters) are shown below:

a. Filler

The couple held hands all night.

DID THE COUPLE HOLD HANDS ALL NIGHT? (Yes)

b. P-Stranding:

What walls did Aaron hang the posters on this afternoon?

DID AARON HANG A MIRROR ON THE WALL? (No)

c. Pied-Piping:

Over whose land did the neighbors fight all the time?

DID THE NEIGHBORS FIGHT OVER LAND? (Yes)

For a complete list of target sentences, filler sentences, and comprehension questions, see Appendix B.

\subsection{Procedure}

Participants were seated at a table, in front of a laptop computer, in a quiet and distraction-free environment. The Self-Paced Reading Task (SPRT) and Comprehension Question Task (CQT) were presented to participants on the laptop with the SuperLab 4.5 software. Before beginning the experiment, participants were presented with instructions 
and a pre-trial experiment. During the pre-trial, participants completed a short practice experiment, consisting of 10 sentences to read and 5 comprehension questions; during this time, participants were watched to ensure that they understood the experimental set up and were encouraged to ask questions. Their reading times and responses for the pretrial were not recorded. Once a participant felt comfortable with the experiment set up, they were allowed to begin the experiment.

Before the experiment began, the instructions, presented in (9), appeared on the laptop screen once more; these were the same instructions that the participant received before the pre-trial experiment (with minor alterations to explain the pre-trial). Instructions on screen

INSTRUCTIONS:

NOTE: *** Once you begin the experiment, it is important that you focus solely on the experiment. Please do not hold outside conversations, answer the phone, get up from your seat, etc. Please make sure that your testing environment is distraction-free and that your phone is turned off/on silent. Thank you for your cooperation! ***

For this experiment, you will be reading sentences to yourself. You do not need to read them aloud. Also, you do not need to rush through the sentences; read at a normal and comfortable pace. Half of the sentences will be in question form. Once you are finished reading a sentence, click the space bar to move to the next sentence. (Note: Please keep you hands on the keyboard throughout the experiment.)

Additionally, after half of the sentences, you will be prompted with a simple yes/no question in CAPITAL letters about the content of the immediately preceding sentence. When answering a question, you should assume that any information given in the prior sentence is true. To answer yes, press the $\mathrm{Y}$ key. To answer no, press the $\mathrm{N}$ key. Once you answer a question, you will be presented with the next sentence to read. Do not worry if you make a mistake. Just continue to read and answer questions until you reach the end of the experiment.

Click the space bar once you are ready to begin the experiment.

When the participant pressed the space bar, a single sentence appeared on screen. When they finished reading the sentence, they pressed the space bar to be presented with another sentence or with a comprehension question. The experiment continued in this manner until the participant reached the end of the experiment. The sentences appeared in a random order for every participant. Throughout the experiment, SuperLab 4.5 recorded participants' reading times (RTs) for every sentence, which was time from the presentation of that sentence of screen to the time the participant pressed the space bar. 
The software also recorded participants' CQT responses. The RTs and CQT responses were automatically saved as a text file, which was later analyzed.

\subsection{Explanation of the procedure}

The Self-Paced Reading Task (SPRT) is an on-line processing task, meaning that this type of task measures participants' unconscious and automatic response to language stimuli. As previously mentioned, the SPRT records participants reading times (RTs) with the purpose of understanding processing costs, and longer RTs are assumed to be reflective of greater processing costs. Because the aim of this study is to investigate whether P-Stranding or Pied-Piped Constructions have greater processing costs for monolingual English speakers, the SPRT was an appropriate task to use in the study.

A SPRT can be set up in several different ways. For example, sentences can be presented to participants as a whole sentence, phrase-by-phrase, or word-by-word. Further, when sentences are broken up into words or phrases, the sentences can be presented to participants in three different ways: cumulative presentation, linear noncumulative presentation, and centre non-cumulative presentation. In the case of the SPRT conducted in this study, sentences were presented as a whole to participants.

While the goal of any on-line processing experiment is to record participants' most natural reaction to stimuli, there are limitations to any research design. Thus, for each of the presentation types mentioned, there are drawbacks. For example, when using the cumulative presentation, which presents a sentence word-by-word or phrase-byphrase, participants are first shown the sentence covered by dashes, so that dashes appear in the place of the letters that will appear. As they read the sentence and press a button to 
make new words/phrases appear, the dashes for the presented words/phrases disappear. The presented word/phrase stays on screen until the entire sentence is completed. While this type of presentation allows the researcher to measure the RTs for particular words/phrases, the reading is unnatural because it is broken up into parts. Further, the participant is aware of how near they are to the end of the sentence. "Knowledge of the length of a sentence and how close a word is to the end of the sentence can cause the development of expectations and predictions about incoming words" (Marinis, 2010, p. 147). However, this presentation type provides a more natural reading than other presentation types because it allows participants to review earlier portions of the sentence, as is possible when reading in their daily life.

Similarly, the linear non-cumulative presentation has limitations. Like the cumulative presentation, participants are first shown dashes in place of the sentence's words. When the participant presses a button to be shown a word/phrase, words/phrases appear in the place of those dashes; however, as a participant continues to press the button, the dashes cover the previously presented words/phrases as the newly presented words/phrases appear on screen. Thus, in addition to participants being aware of how close a word/phrase is to the end of the sentence, they are unable to review earlier portions of the sentence if necessary. While this is seen as a drawback to some researchers, others view the noncumulative presentation as "a more accurate picture of how participants process sentences on-line compared to the cumulative presentation" because participants are unable to go back to early portions of the sentence in spoken language (Marinis, 2010, p. 147). 
The third presentation type in which sentences are broken up into words or phrases is also non-cumulative: the centre non-cumulative reading presentation. With this presentation type, participants are shown a sentence in a word-by-word or phrase-byphrase fashion without any dashes; also, they are unable to view previous portions of the sentence. As stated before, some researchers claim that this type of presentation provides a more accurate depiction of on-line processing. Further, with this presentation type, there is not the drawback of the dashes creating end-of-the-sentence expectations for participants. However, as mentioned previously, not allowing participants to read earlier portions in the sentence is seen as an unnatural to some researchers (Marinis, 2010). Further, breaking a sentence up into segment creates an unnatural reading flow. Therefore, each presentation type has limitations.

While some of these limitations may be argued to affect the whole-sentence presentation type used in this experiment, there are also many advantages to conducting the experiment this way. As with the cumulative presentation and linear non-cumulative presentation, participants are aware of where the end of the sentence is, which is said to create expectations. However, because the sentence is not broken up into words or phrases, the end-of-sentence expectation is equal to that which a person experiences during natural reading. Further, participants are able to review earlier portions of the sentence if necessary, and their reading is not constantly interrupted by breaks in the sentence. Thus, presenting sentences as a whole to participants provides them with a more naturalistic reading experience.

Further, presenting sentences as a whole to participants is beneficial for the purposes of this experiment because of the types of constructions being investigated. As 
previously mentioned, sentence-final optional modifiers were added to the end of every sentence in order to mitigate Wrap-Up Effects; this is because the PP or DP preposition complement leaves a trace of itself in its original position, at the end of the sentence. If the experiment's sentences were broken up into words or phrases, all of the sentence-final optional modifiers would be required to be two or more words because the portion following the location of the trace would be the critical segment to measure.

The reason for this is that movement creates a syntactic dependency between the moved item (the "filler") and the trace, according to the Trace Activation Hypothesis, presented in (10) below:

\section{Trace Reactivation Hypothesis}

"When we encounter a filler, we store it in short-term memory and we try to integrate it as soon as possible into the sentence. When the parser identifies a gap, i.e. a potential position for integration, it retrieves the filler from shortterm memory and sets up a filler-gap dependency by reconstructing the grammatical and semantic features of the filler at the position of the gap" (Marinis, 2010, p. 148).

Thus, in the case of this study's experiment, participants reading a sentence would store the moved phrase (in this case, the PP or the DP-complement of the PP) in their shortterm memory. Then, when the participants reach the portion of the sentence where the trace is expected to be (in this case, the sentence-final modifier), the grammatical and semantic features of the moved phrase are reconstructed. Unless there were at least two words following the trace, presented to participants one at a time, it would be unclear whether the final portion of the sentence being measured reflected processing costs 
related to trace reactivation or simply Wrap-Up Effects. While it is possible to use modifiers with more than one word, longer modifiers can create structurally awkward sentences in some cases, adding to processing costs. Therefore, presenting sentences as a whole to participants provided them with the most natural reading possible in regards to this study.

To control for differences in sentence length, two methods were used in this study. First, as explained earlier, two versions of the target sentences were used with participants: Experiment 1 and Experiment 2. Any difference in length between Experiment 1's P-Stranding Sentences and Pied-Piped Sentences would be reversed in Experiment 2. Therefore, length differences between sentences would not make an impact on reading times (RTs) in this regard. In addition, differences in sentence length were accounted for during the analysis by dividing each sentence by the number of characters in that sentence. Accordingly, RTs per character, as well as RTs per whole sentence, are compared in the results section.

\subsection{Methods of Analysis}

As this study investigates the processing costs of P-Stranding versus PiedPiped Constructions, the reading times (RTs) for sentences containing these constructions were compared. For each participant, the mean RTs for P-Stranding Sentences and for Pied-Piped Sentences were calculated. Next, the mean RTs of all participants for both PStranding and Pied-Piped Sentences were calculated. The statistical test chosen to determine whether there was a significant difference in the processing costs of the two sentence types was a paired-samples t-test. A paired samples t-test is designed to 
determine whether two groups are statistically different from each other; most often, and in the case of this study, a t-test is used to compare means. Parameters for significance were fixed at .05; thus, any number greater than .05 was considered insignificant, while a lower number was considered significant.

In addition to comparing means between P-Stranding and Pied-Piped Sentences, additional variables were analyzed. First, a paired samples t-test compared the means of the two sentences types for both Experiment 1 and Experiment 2 separately. The purpose of doing this was to see whether there were significant values for one of the Experiments, both of the Experiments, or none of the Experiments. If there were significant values for both or none of the Experiments, this would clearly show that there was a preference for one of the construction types or that both of the construction types had equal processing costs, respectively.

Second, a paired-samples t-test was completed for all three wh-complement types: what followed by a noun, which followed by a noun, whose followed by a noun. The purpose of this was to see if there was a preference for either construction type when the complement was different and to control for outside factors that may have affected the results. Further, this t-test per wh-complement was completed for both Experiment 1 and Experiment 2 separately. As previously stated, this was done to ensure that the Experiment type did not affect the results.

Prior to calculating means, however, measures were taken to ensure that participants RTs represented solely the time it took them to read and process a sentence, excluding times affected by environmental distractions or other factors. To do this, RTs that were three standard deviations from the mean of that particular sentence were 
removed. Also, if a participant answered a comprehension question incorrectly, the RTs for those sentences were removed. A participant was required to have an RT for at least $75 \%$ of the experimental sentences; otherwise, their RTs were removed from the data entirely.

\section{CHAPTER 4. Results}

\subsection{Comprehension Question Task}

As previously mentioned, participants completed a Comprehension Question Task (CQT) to ensure that sentences were being read and processed. The highest score received for this task was $100 \%$, meaning that participants who received this score answered 50 out of 50 questions correctly. The lowest score received was $86 \%$; the participant who received this score answered 43 out of 50 questions correctly. Accordingly, the score range was $14 \%$. Further, the mean score was a $96.33 \%$, and the mode score was $100 \%$.

If results for the CQT are analyzed separately for Experiment 1 and Experiment 2, the scores are similar to the overall results. For Experiment 1, the mean score was $96.26 \%$, the mode score was $100 \%$, and the score range was $14 \%$. For Experiment 2 , the mean score was $96.4 \%$, the mode score was $100 \%$, and the score range was $12 \%$. Therefore, the CQT results for Experiment 1 and 2 varied only slightly, both from each other and from the overall results. In Figure 4.1a below, the number of participants who received scores between 100\% and 86\% for Experiment 1 and Experiment 2 are shown. 
(1) Figure 4.1 Comprehension Question Task scores

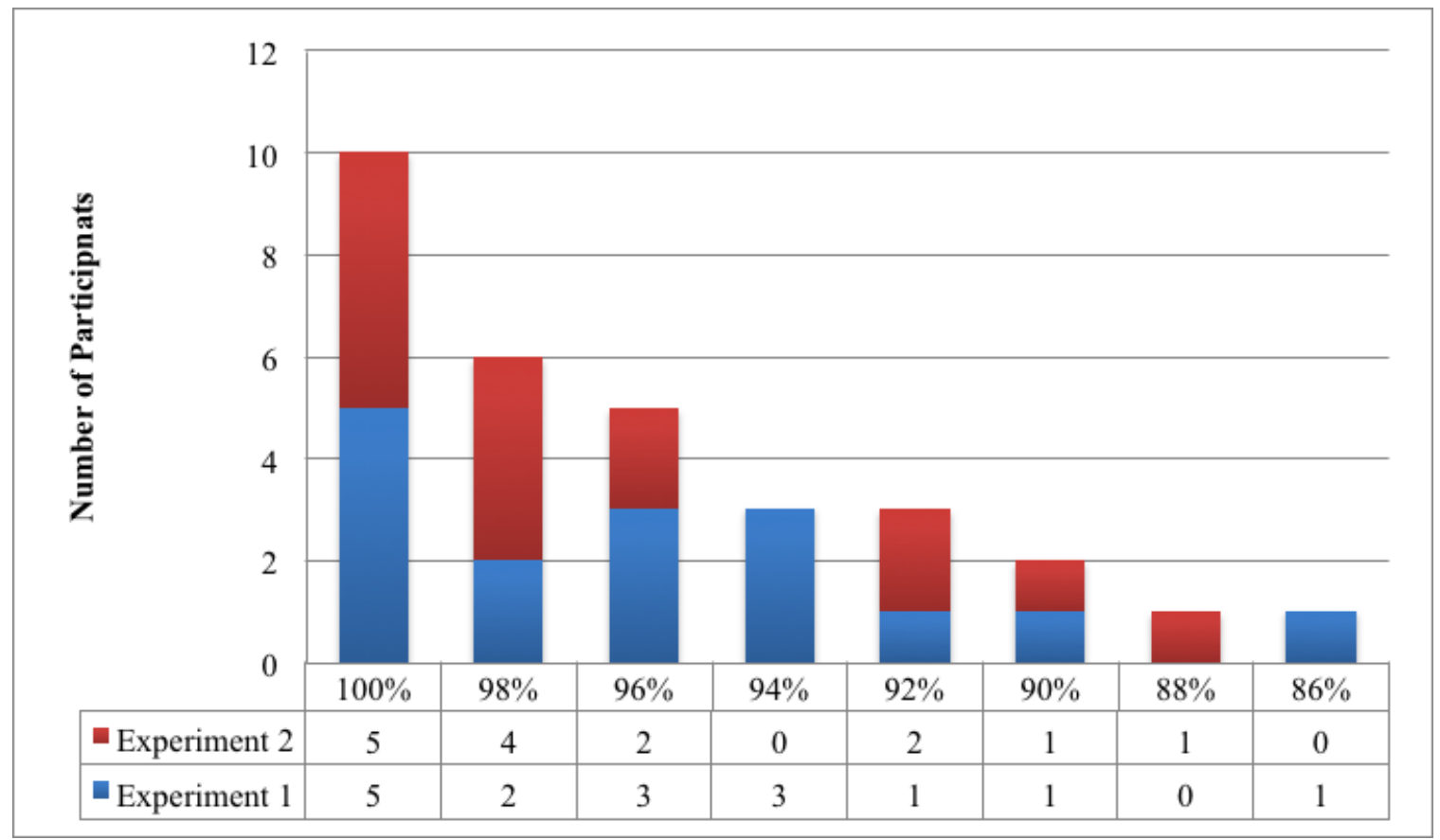

\subsection{Self-Paced Reading Task}

As explained in Section 3.5, the results for the Self-Paced Reading Task (SPRT) were analyzed in several ways. First, the reading times (RTs) for P-Stranding Sentences and Pied-Piped Sentences were compared; this is explained in Section 4.2.1. Next, the RTs per Sentence Type were separated into three groups, depending on which whcomplement underwent movement (what followed by a noun, which followed by a noun, and whose followed by a noun), and analyzed by group. The results for this can be found in Section 4.2.2.

Further, the RTs were compared in two ways: RTs for whole sentences were compared, and RTs for sentences divided by the number of characters in those sentences were compared. 


\subsubsection{Reading Times per Sentence Type}

This section provides a comparison of Reading Times (RTs) for sentences with PStranding and Pied-Piped Constructions. The purpose of this section is to examine whether monolingual English speakers find either construction more costly processingwise. Because RTs are reflective of processing difficulty, significantly longer RTs for either Sentence Type would show that monolingual English speakers find either PStranding or Pied-Piping Constructions more difficult to process. However, if the RTs are not significantly different, this shows that monolingual English speakers do not process sentences with P-Stranding and Pied-Piped Constructions in a significantly different way.

\subsubsection{Reading Times per Sentence Type: Whole Sentence}

The mean reading times (RT) for sentences with P-Stranding Constructions (PStranding Sentences) and sentences with Pied-Piped Constructions (Pied-Piped Sentences) were calculated and compared. Results from all thirty participants were included, as no participant was missing greater than $25 \%$ of his or her data (due to incorrect answers for the Comprehension Question Task or outliers). The mean RT for all P-Stranding Sentences (including both Experiment 1 and 2) was $4024.06 \mathrm{~ms}$. The mean RT for all Pied-Piped Sentences (including both Experiment 1 and 2) was $4079.39 \mathrm{~ms}$. A paired samples t-test did not reveal a significant difference between RTs for P-Stranding and RTs for Pied-Piped Sentences.

A similar pattern emerges when Experiment 1 and Experiment 2 are analyzed separately. Again, results from all thirty participants were included (15 participants per Experiment 1 and Experiment 2). For Experiment 1, the mean RT for P-Stranding 
Sentences was $3962.31 \mathrm{~ms}$, and the mean RT for Pied-Piped Sentences was $4221.18 \mathrm{~ms}$.

For Experiment 2, the mean RT for P-Stranding Sentences was $4085.80 \mathrm{~ms}$, and the mean RT for Pied-Piped Sentences was 3937.60 ms. For both Experiment 1 and 2, a paired samples t-test did not reveal a significant difference in RTs for P-Stranding and PiedPiped Sentences.

According to these results, monolingual English speakers are not processing PStranding Sentences and Pied-Piped Sentences significantly differently; this holds if mean RTs for both sentence types for all sentences (including both Experiment 1 and 2) are compared, as well as if mean RTs for Experiment 1 and Experiment 2 are compared separately. These results are presented in Figure 4.2.1.1.a.

(2) Figure 4.2.1.1 Reading Times per Sentence Type: Whole Sentence

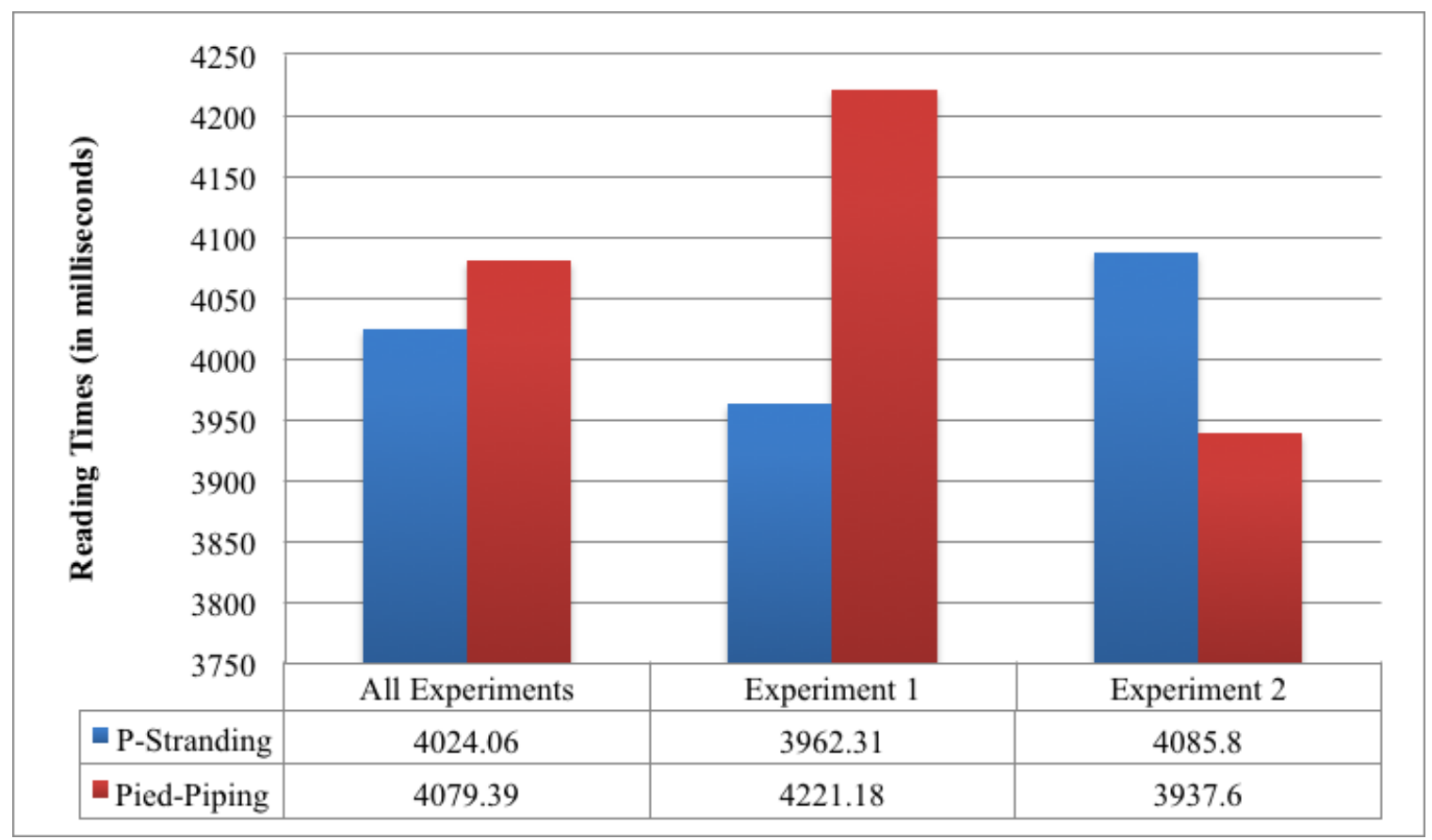




\subsubsection{Reading Times per Sentence Type: Sentence per Character}

As previously mentioned, to control for differences in sentence length, reading times (RTs) for each sentence were divided by the number of characters in the sentence. When comparing the RTs per character, results from all thirty participants were included. The mean RT per character for all P-Stranding Sentences (including both Experiment 1 and 2) was $76.17 \mathrm{~ms}$. The mean RT per character for all Pied-Piped Sentences (including both Experiment 1 and 2) was $77.01 \mathrm{~ms}$. Again, a paired samples t-test did not reveal a significant difference between RTs per character for P-Stranding and Pied-Piped Sentences.

Similarly, when both Experiment 1 and Experiment 2 were analyzed separately, a paired samples t-test did not reveal a significant difference in RTs per character for PStranding and Pied-Piped Sentences. For Experiment 1, the mean RT per character for PStranding Sentences was $74.55 \mathrm{~ms}$, and the mean RT per character for Pied-Piped Sentences was 79.95 ms. For Experiment 2, the mean RT per character for P-Stranding Sentences was 77.78 ms, while the mean RT per character for Pied-Piped Sentences was $74.08 \mathrm{~ms}$. Results from all thirty participants were included (15 participants per Experiment 1 and 2).

Again, these results show that monolingual English speakers are not processing PStranding Sentences and Pied-Piped Sentences in a significantly different manner, and the results are not affected by sentence length. This pattern can be seen if mean RTs per character for both sentence types for all sentences are compared and if mean RTs per character for Experiment 1 and Experiment 2 are compared separately. These results are presented in Figure 4.2.1.2. 
(3) Figure 4.2.1.2 Reading Times per Sentence Type: Sentence per Character

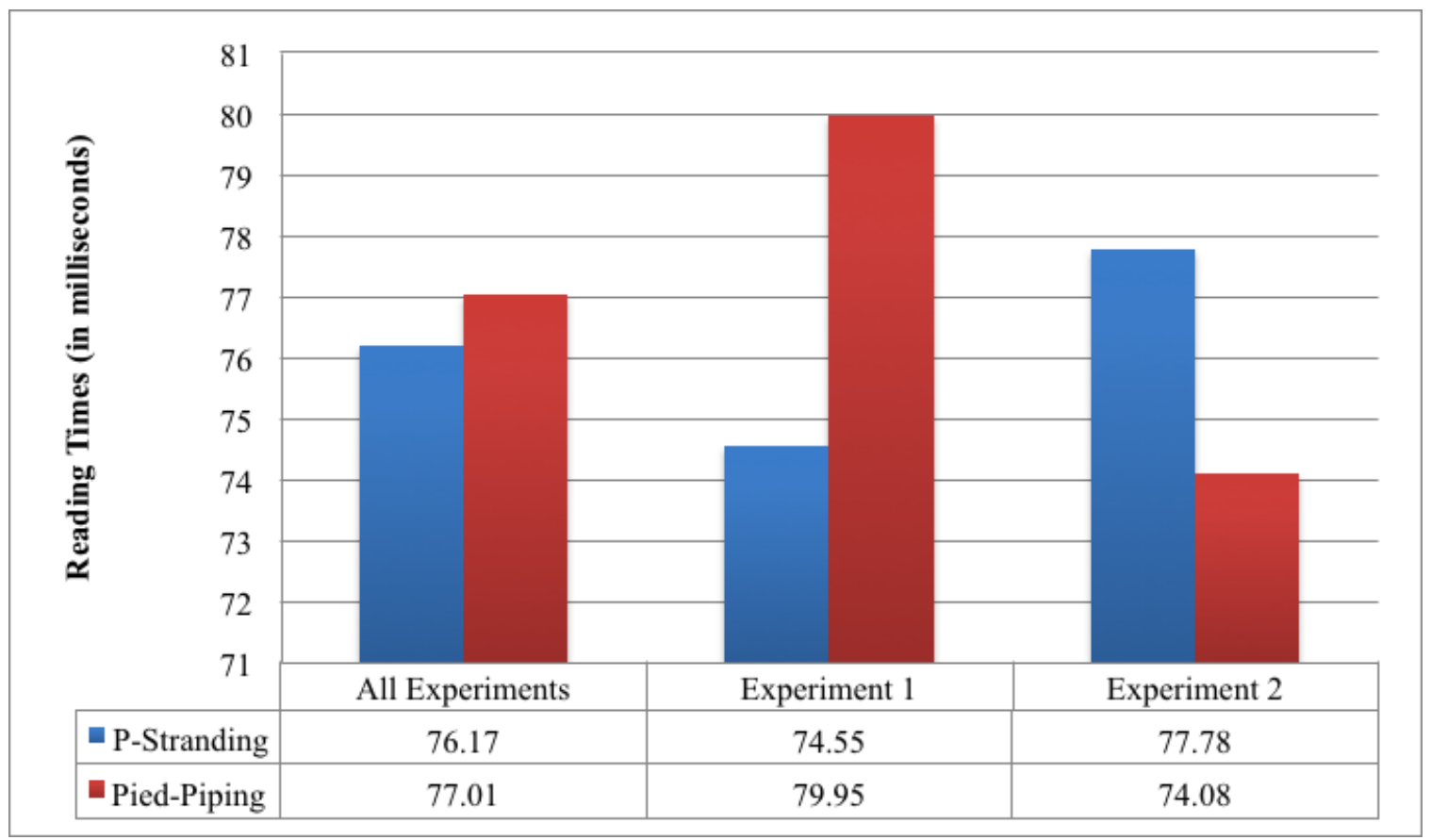

\subsubsection{Reading Times per Sentence Type and Complement Type}

This section provides a comparison of Reading Times (RTs) for sentences with PStranding and Pied-Piped Constructions, as was discussed in the previous section; however, this section compares these RTs by wh-complement type. The purpose of this is to determine whether the type of preposition complement undergoing movement (with or without the preposition) affected the processing costs. Three different wh-complements were used in the experimental sentences: what followed by a noun, which followed by a noun, and whose followed by a noun. As in the previous section, significantly greater mean RTs for either P-Stranding or Pied-Piped Sentences would indicate a processing contrast; RTs that are not significantly different, on the other hand, indicate that monolingual English speakers do not process these sentence types differently. 


\subsubsection{Reading Times per Sentence Type and Complement Type: Whole Sentence}

For each wh-complement type, the mean reading time (RT) for P-Stranding Sentences and Pied-Piped Sentences were calculated and compared. For wh-complement what followed by a noun (what+noun), results from all thirty participants were included; no participant had more than $25 \%$ of his or her data removed due to outliers or incorrect Comprehension Question Task responses. For wh-complement what+noun, the mean RT for P-Stranding Sentences was 3908.19 ms, and the mean RT for Pied-Piped Sentences was $3966.21 \mathrm{~ms}$. A paired samples t-test did not reveal a significant difference between RTs for P-Stranding and RTs for Pied-Piped Sentences for wh-complement what + noun.

When Experiment 1 and 2 were analyzed separately, wh-complement what + noun showed similar results. All thirty participants' results were included (15 per Experiment 1 and 2). For Experiment 1, the mean RT for P-Stranding Sentences was $3946.28 \mathrm{~ms}$, while the mean RT for Pied-Piped Sentences was 3955.18 ms. For Experiment 2, the mean RT for P-Stranding Sentences was $3870.10 \mathrm{~ms}$, and the mean RT for Pied-Piped Sentences was 3977.25 ms. For both Experiment 1 and 2, a paired samples t-test did not reveal a significant difference in RTs for each sentence type. Therefore, when RTs for whole sentences are compared, monolingual English speakers do not process P-Stranding and Pied-Piped Sentences with wh-complement what+noun in different ways. These results are presented below: 
(4) Figure 4.2.2.1.a Reading Times per Sentence Type with wh-Complement what +noun: Whole Sentence

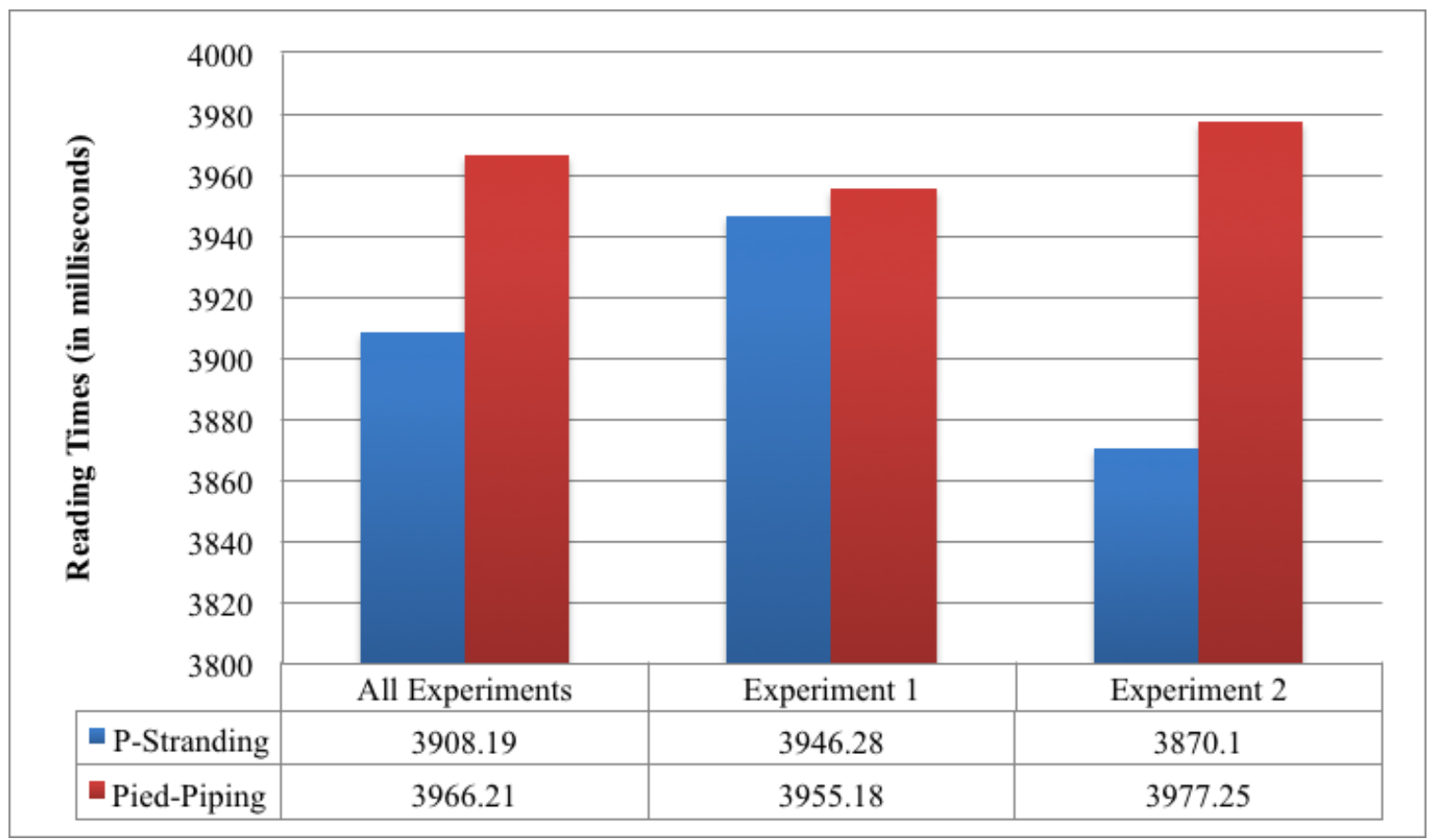

For wh-complement which followed by a noun (which+noun), results were comparable to that of wh-complement what+noun. The mean RT for all P-Stranding Sentences was $4117.45 \mathrm{~ms}$, and the mean RT for all Pied-Piped Sentences was 4094.30 ms. The data for all thirty participants was included. Again, a paired samples t-test did not reveal a significant difference in RTs for P-Stranding and Pied-Piped Sentences when the preposition complement was which+noun.

The results for Experiment 1 and 2 were analyzed separately for wh-complement which+noun as well. All thirty participants' data was included. For Experiment 1, the mean RT for P-Stranding Sentences was 4029.49 ms; the mean RT for Pied-Piped Sentences was 4394.76 ms. For Experiment 2, the mean RT for P-Stranding Sentences was $4159.11 \mathrm{~ms}$, and the mean RT for Pied-Piped Sentences was $3840.13 \mathrm{~ms}$. For both 
Experiment 1 and 2, a paired samples t-test did not reveal a significant difference in RTs for P-Stranding and Pied-Piped Sentences with the preposition complement which + noun. These results are presented below:

(5) Figure 4.2.2.1.b Reading Times per Sentence Type with wh-Complement which+noun: Whole Sentence

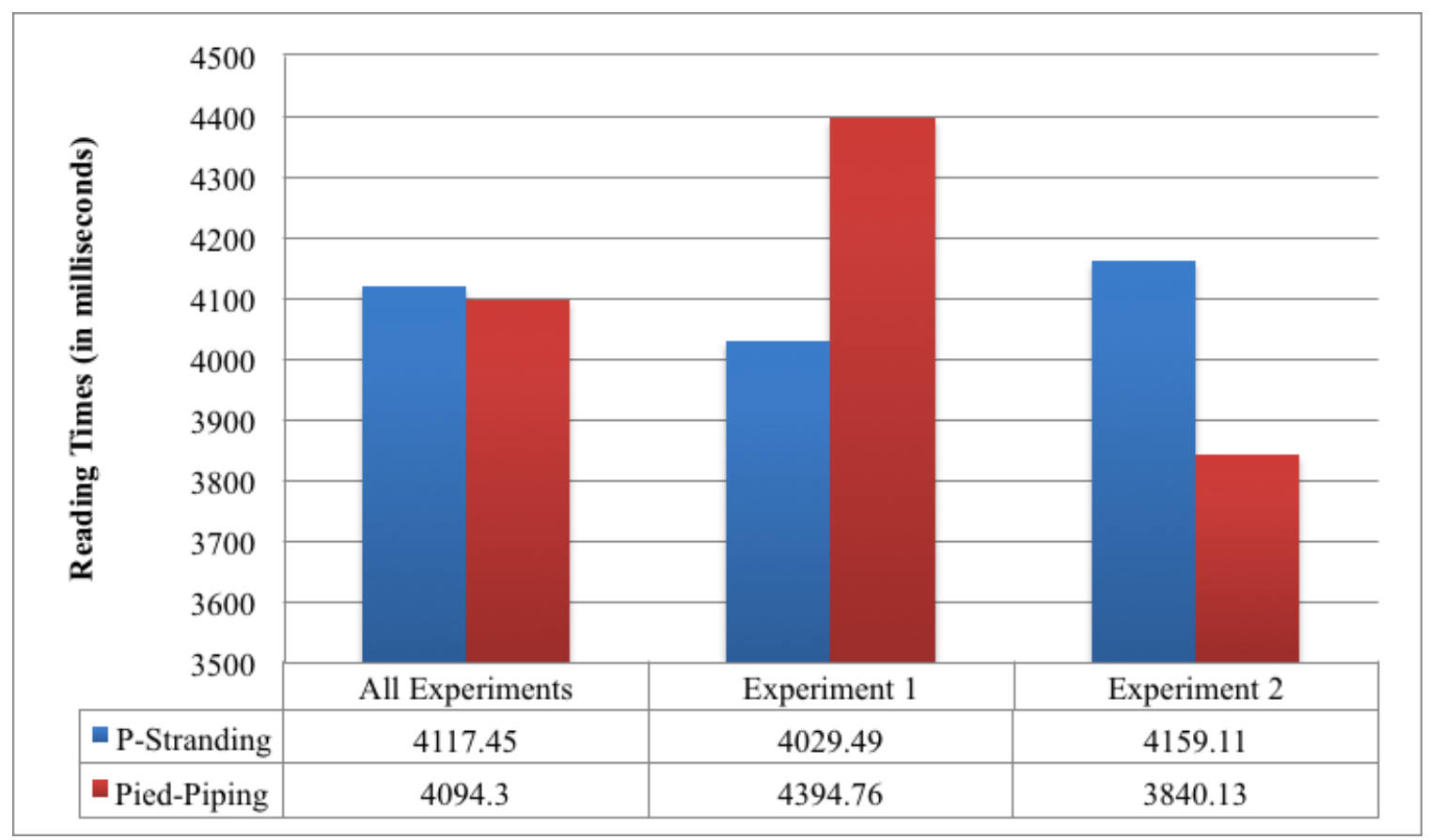

Last, mean RTs for both sentence types with wh-complement whose followed by a noun (whose+noun) were calculated and compared. For this comparison, only 29 participants' data were the minimum of $75 \%$ complete; thus, only 29 participants' RTs were included in the RT mean calculations. The mean RT for P-Stranding Sentences with wh-complement whose+noun was 3998.81 ms; the mean RT for Pied-Piped Sentences with wh-complement whose+noun was $4007.92 \mathrm{~ms}$. Again, a paired samples t-test did not reveal a significant difference in the aforementioned mean RTs. 
Further, for wh-complement whose+noun, results from Experiment 1 and 2 were compared separately. For Experiment 1, only 14 participants (as opposed to 15) had less than $25 \%$ of their data missing; thus, 14 participants' results were used in calculating the means. The mean RT for P-Stranding Sentences with wh-complement whose+noun in Experiment 1 was $3725.55 \mathrm{~ms}$, while the mean RT for Pied-Piped Sentences was 4017.50 ms. For Experiment 2, the mean RT for P-Stranding Sentences with wh-complement whose+noun was 4253.85 ms; the mean RT for Pied-Piped Sentences was 3998.98 ms. A paired samples t-test was used to analyze the results from Experiment 1 and 2; as is consistent with all previous results, there was no significant difference in RTs for PStranding and Pied-Piped Sentences with wh-complement whose+noun. These results are presented below:

(6) Figure 4.2.2.1.c Reading Times per Sentence Type with wh-Complement whose+noun: Whole Sentence

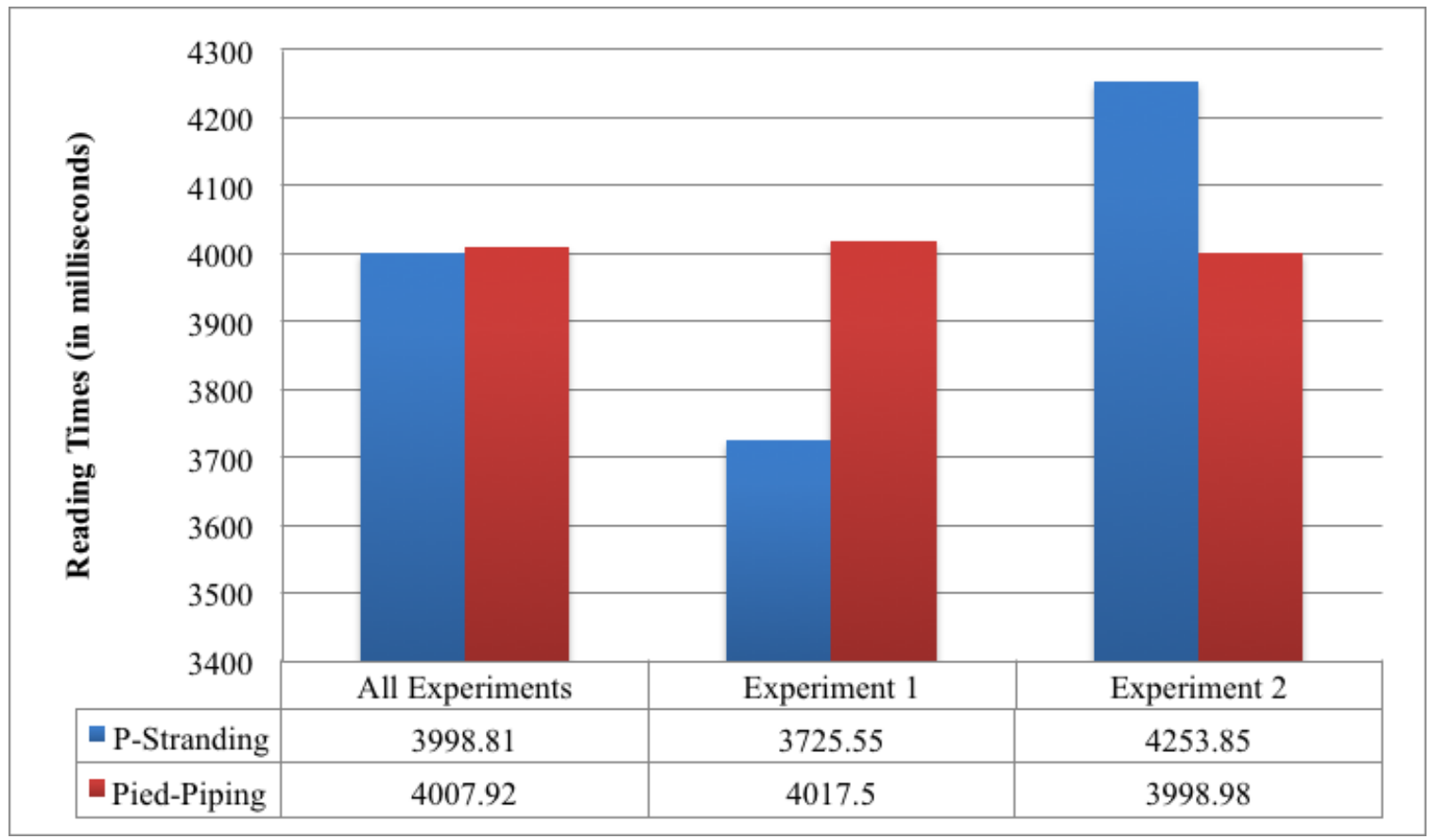


Therefore, when RTs for whole sentences are compared, monolingual English speakers do not find either P-Stranding Sentences or Pied-Piped Sentences significantly more difficult to process. Further, the type of wh-complement that undergoes movement when a P-Stranding or Pied-Piped Construction is formed does not affect processing costs. This conclusion holds when means for both Experiments are compared and when means for Experiment 1 and 2 are compared separately.

\subsubsection{Reading Times per Sentence Type and Complement Type: Sentences per Character}

In addition to comparing mean reading times (RTs) of whole sentences, the mean RTs of sentences per character were compared for each wh-complement type. (Sentences per character, as previously mentioned, refers to the division of a participant's RT for a sentence by the number of characters present in that sentence; this is done to control for length.)

For wh-complement what followed by a noun (what + noun), the mean RT for PStranding Sentences per character was 76.96 ms; the mean RT for Pied-Piped Sentences per character was $76.83 \mathrm{~ms}$. Results from all 30 participants were included in the mean calculations. A paired samples t-test did not reveal significant differences in the mean RTs of these two sentence types per character with wh-complement what+noun.

Similarly, when comparing results from Experiment 1 and 2 separately, a paired samples t-test did not reveal significant RT differences. For Experiment 1 and 2, results for all 15 participants were included. For Experiment 1, the mean RT for P-Stranding Sentences per character with wh-complement what + noun was $77.82 \mathrm{~ms}$, while the mean 
RT for Pied-Piped Sentences was 76.53 ms. For Experiment 2, the mean RT for PStranding Sentences per character with wh-complement what+noun was $76.10 \mathrm{~ms}$, and the mean RT for Pied-Piped Sentences was $77.12 \mathrm{~ms}$. These results are shown in Figure 4.2.2.2.a.

(7) Figure 4.2.2.2.a Reading Times per Sentence Type with wh-Complement what +noun: Sentences per Character

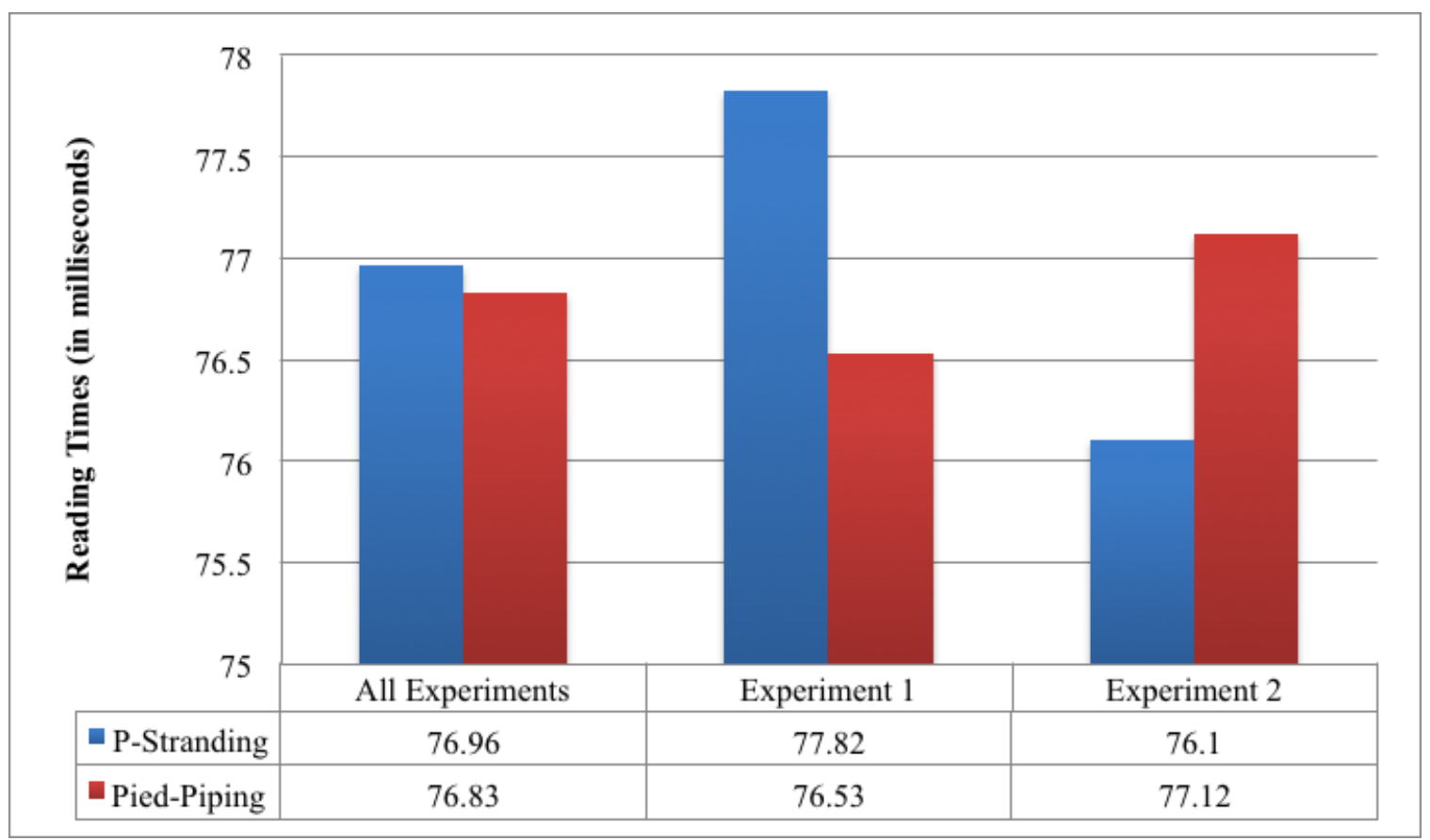

Next, RTs for sentences per character with wh-complement which followed by a noun (which+noun) were calculated and compared. When results from all experiments are compared, the mean RT for P-Stranding Sentences per character with wh-complement which+noun was $73.53 \mathrm{~ms}$; the mean RT for Pied-Piped Sentences was $74.92 \mathrm{~ms}$. Results from all thirty participants were included in these mean calculations. Comparing these 
results, a paired samples t-test did not reveal a significant difference in RTs for PStranding and Pied-Piped Sentences per character with wh-complement which+noun. Contrastingly, when results for Experiment 1 and 2 were analyzed separately, different results occur. For both Experiment 1 and 2, all thirty participants' (15 per Experiment 1 and 2) results were included in calculating the means. For Experiment 1, the mean RT for P-Stranding Sentences per character with wh-complement which+noun was 70.29 ms; the mean RT for Pied-Piped Sentences was 81.54 ms. For Experiment 1, a paired-samples t-test did not reveal significant differences in RTs; however, for Experiment 2, a paired samples t-test revealed a significant difference between mean RTs for P-Stranding and Pied-Piped Sentences per character with wh-complement which + noun $(\mathrm{M}=-8.48, \mathrm{SD}=14.98), \mathrm{t}(14)=-2.19, \mathrm{p}=.046$. The mean RT for PStranding Sentences per character with wh-complement which+noun was $76.77 \mathrm{~ms}$; the mean RT for Pied-Piped Sentences was 68.29 ms. It should be noted that, while these results are statistically significant, they occurred only in one version of the experiment, Experiment 2, and not both Experiment 1 and 2. These results are presented in Figure 4.2.2.2.b.

(8) Figure 4.2.2.2.b Reading Times per Sentence Type with wh-Complement which+noun: Sentences per Character 


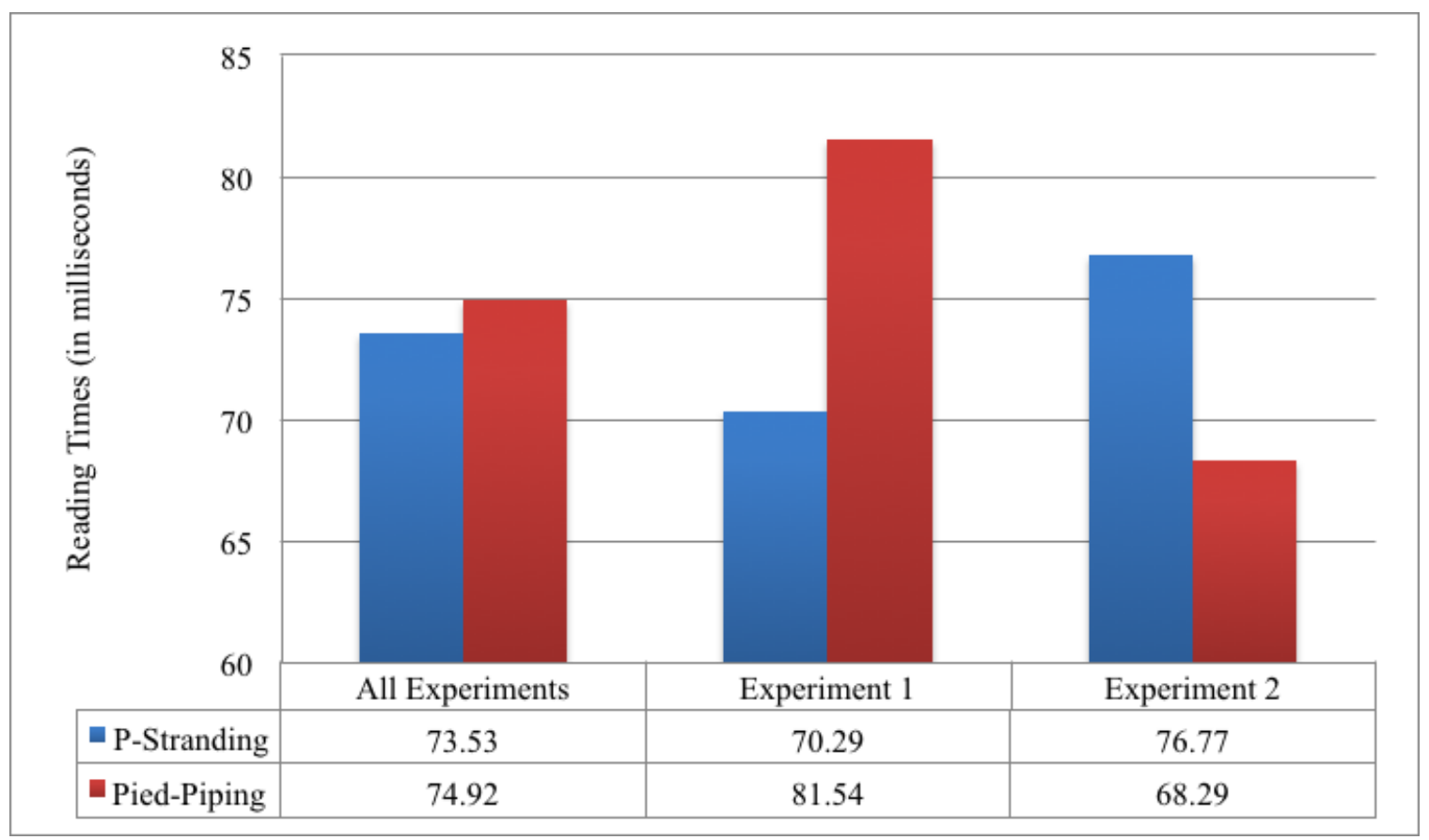

Last, RTs for P-Stranding and Pied-Piped Sentences per character with whcomplement whose followed by a noun (whose+noun) were calculated and compared. All thirty participants' results were used to calculate the mean RTs. For P-Stranding Sentences per character with whose+noun, the mean RT was $77.72 \mathrm{~ms}$; the mean RT for Pied-Piped Sentences was $79.02 \mathrm{~ms}$. A paired samples t-test did not reveal significant differences in the RT means for the two sentence types.

When Experiment 1 and Experiment 2 were analyzed separately, similar results occurred. Again, all thirty participants' (15 for Experiment 1 and 15 for Experiment 2) results were included in the mean RT calculations. For Experiment 1, the mean RT for PStranding Sentences per character with wh-complement whose+noun was $75.15 \mathrm{~ms}$; the mean RT for Pied-Piped Sentences was 81.05 ms. For Experiment 2, the mean RT for PStranding Sentences with wh-complement whose+noun was $80.28 \mathrm{~ms}$; the mean RT for Pied-Piped Sentences was 76.99 ms. A paired samples t-test did not reveal a significant 
difference in RTs for P-Stranding and Pied-Piped Sentences per character with whcomplement whose+noun. These results are presented below:

(9) Figure 4.2.2.2.c Reading Times per Sentence Type with wh-Complement whose+noun: Sentences per Character

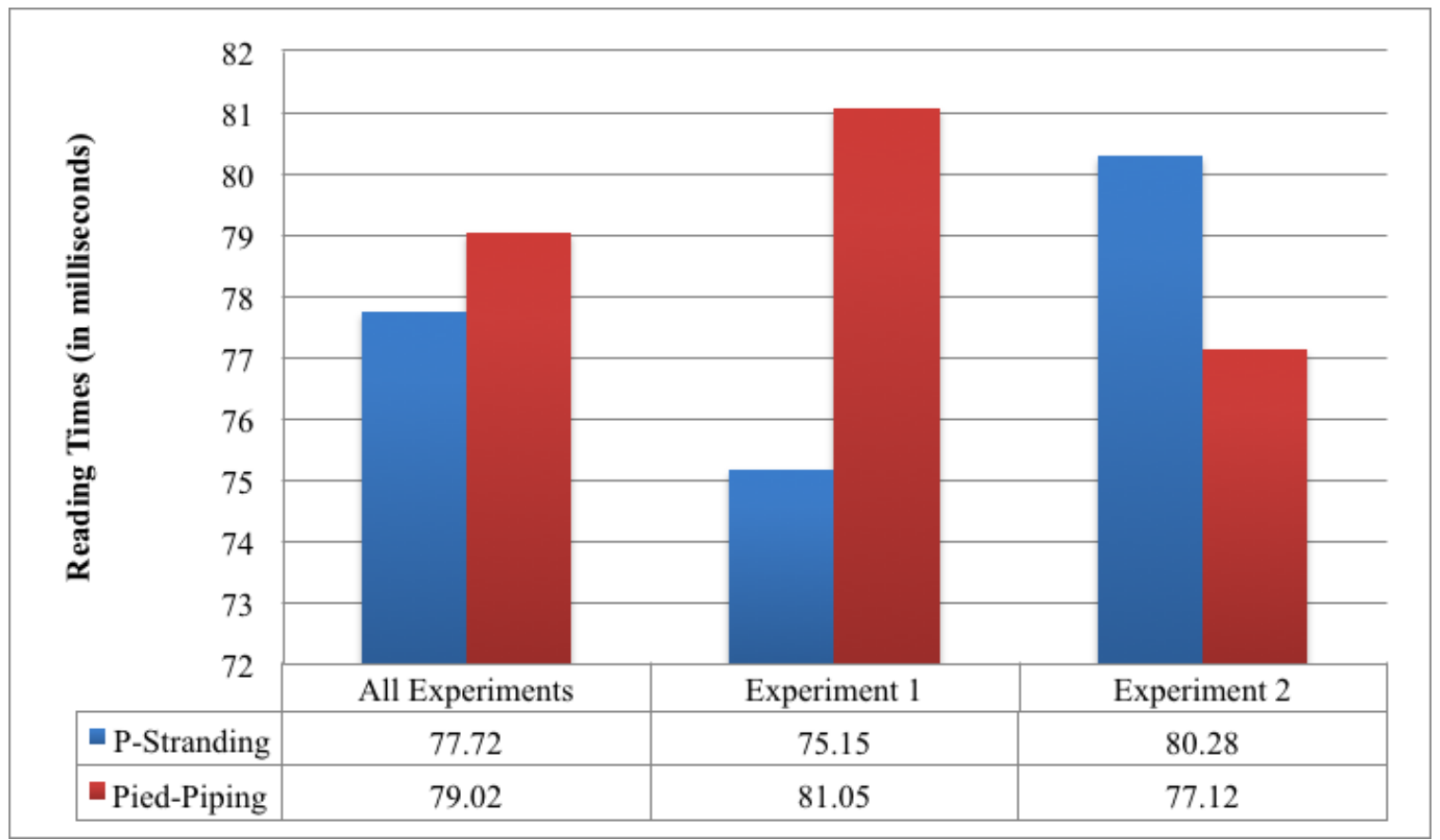

Therefore, we can conclude that the type of wh-complement that undergoes movement when a P-Stranding or Pied-Piped Construction is formed does not affect processing costs. In one case, the RTs differed significantly between the two sentence types; however, because this occurred for one experiment and not both, it cannot be concluded that this difference was related to the construction type present in the sentence.

\subsection{Summary of Results}

As previously explained, the purpose of this study was to determine whether monolingual English speakers process P-Stranding Sentences and Pied-Piped Sentences 
differently. Assuming reading times (RTs) are reflective of processing difficulty, longer RTs are expected to show greater processing costs. The results indicate that monolingual English speakers do not have significantly longer RTs for either sentence type, meaning that the two sentence types are not processed differently. This was true when mean RTs of both P-Stranding and Pied-Piped Sentences were compared per whole sentence and per character. Further, in every instance except one, there was no significant difference among the RTs of sentences containing distinct wh-expressions.

The sole exception was in Experiment 2, when the mean RT for Pied-Piped Sentences per character with wh-complement which+noun was significantly shorter than the mean RT for P-Stranding Sentences. However, as this only occurred in Experiment 2 and not Experiment 1, it cannot be concluded that a difference in construction type results in a difference in RTs.

In the following chapter, these findings are discussed further and are examined in the context of the theories presented in chapter two.

\section{CHAPTER 5. Conclusion and Discussion}

\subsection{Conclusion}

As presented in the previous chapter, monolingual English speakers did not have greater processing difficulty for either P-Stranding or Pied-Piped Constructions. In Chapter 3, it was hypothesized that P-Stranding Constructions would be easier to process than Pied-Piped Constructions if the Minimal Structure Principle (MSP), an economy principle, were active during language processing. According to Weinberg (1999), economy principles that are present during language learning are active during language 
processing. However, the results from this experiment do not support the hypothesis. Specifically, the claim that the MSP would be active during sentence processing was not supported. In section 5.2, possible explanations for the results are discussed. In addition, directions for future projects that would address these explanations are given.

\subsection{Discussion}

\subsubsection{Transitive and Not-Transitive Sentences}

In section 2.2.1, a study by Gries (2002) was summarized. In this study, Gries claims that the length and barrierhood of the bridging structure influence a speaker's choice of construction. Further, he claims that this preference was related to the high processing costs of these sentences. Gries supports these claims with corpus data, presented in (1) below:

(1) Table 5.2.1: Distribution of constructions relative to VERB

\begin{tabular}{|c|c|c|c|c|c|c|}
\hline & Transitive & Intransitive & Prep. & Phrasal-prep. & Copula & Totals \\
\hline PPC & 73 & 24 & 4 & 0 & 21 & 122 \\
\hline SC & 38 & 65 & 14 & 6 & 56 & 179 \\
\hline Total & 111 & 89 & 18 & 6 & 77 & 301 \\
\hline
\end{tabular}

The chart above shows that Pied-Piped Constructions (PPC) occurred more frequently than P-Stranding Constructions (SC) in transitive sentences; contrastingly, the SC occurred more frequently in not-transitive sentences.

If Gries's (2002) claim is true and a frequency-based approach to processing is adopted, the results of this study may be related to whether transitive or not-transitive verbs were used in the target sentences. In Experiment 1, the P-Stranding Sentences used 11 transitive verbs and 13 not-transitive verbs; the Pied-Piped Sentences used 13 
transitive verbs and 11 not-transitive verbs. Accordingly, in Experiment 2, the PStranding Sentences used 13 transitive verbs and 11 not-transitive verbs; the Pied-Piped Sentences used 11 transitive verbs and 13 not-transitive verbs. Therefore, there was a near-even distribution of transitive and not-transitive verb type in the target sentences, which may account for the processing times of the two constructions not differing significantly. In the future, another experiment could be conducted where verb type is accounted for and compared; this would indicate whether Gries's (2002) claim could be made for the on-line processing of sentences.

\subsubsection{Written Frequency}

Further, Gries (2002) provided corpus data that showed the frequency of PStranding (SC) and Pied-Piped Constructions (PPC) in written and spoken corpora. The results are presented in (2):

(2) Table 5.2.2: Analyzed data from the BNC (raw frequencies + column percentages)

\begin{tabular}{|c|c|c|c|}
\hline & Written & Spoken & Row totals \\
\hline PPC & $122(49.39 \%)$ & $0(0 \%)$ & $122(40.53 \%)$ \\
\hline SC & $125(50.61 \%)$ & $54(100 \%)$ & $179(59.47 \%)$ \\
\hline Column totals & $247(100 \%)$ & $54(100 \%)$ & $301(100 \%)$ \\
\hline
\end{tabular}

In the chart above, P-Stranding Constructions occurred in $100 \%$ of the spoken corpora; also, overall, the P-Stranding Construction occurs more frequently than the Pied-Piped Construction (40.53\% PPC; 59.47\% SC). However, in the written corpora, the PStranding and Pied-Piped Construction occur almost equally (PPC 49.39\%; SC 50.61\%). Thus, depending on the mode of input (reading or listening), the P-Stranding and PiedPiped Construction may not differ significantly in frequency of occurrence. 
Under a frequency-based approach that takes into consideration mode of input, the insignificantly different processing costs for the two constructions may be accounted for. The experiment conducted in this study was a self-paced reading task. Therefore, if the two constructions occur with the same frequency in written language, it may be expected that the processing costs would not differ when reading sentences with these constructions. To test whether the results are linked to frequency, an experiment could be conducted in the future in which a different experimental task is used. For example, a self-paced listening task may yield new results due to the difference of input mode.

\subsubsection{Minimal Attachment}

In sections 2.2.2 and 2.2.3, the Minimal Attachment Principle, presented in (3), is discussed.

\section{(3) Minimal Attachment Principle}

"Attach incoming material into the phrase-marker being constructed using the fewest nodes consistent with the well-formedness rules of the language under analysis" (Bader \& Schmid, 2009, p. 1467).

The claim made with this principle is that the parser processes a sentence one node at a time, initially constructing a representation that has the fewest nodes possible. This representation is built as information is received, as is stated in (4). If the parser constructs the incorrect representation, there is reanalysis, which adds processing costs to the sentence. 


\section{Left-to-Right Constraint}

Each item is incorporated into a constituent structure representation of a sentence (essentially) as the item is encountered" (Bader \& Schmid, 2009, p. 1467).

The Minimal Attachment Principle could have consequences for the processing of P-Stranding and Pied-Piped Constructions in some cases. Consider the sentences in (5):
a. P-Stranding
What couch did Samantha take a nap on?
b. Pied-Piping

On what couch did Samantha take a nap?

Above, (5a) may be syntactically ambiguous. Initially, the parser may interpret what couch to be the direct object of the verb take. Then, when the preposition on is encountered, a reanalysis would need to take place, adding processing costs to (5a). Contrastingly, (5b) would not require this reanalysis. Rather, it is likely that the parser would construct the prepositional phrase (PP) on what couch initially, leaving no ambiguity as to what the direct object is ( $a$ nap). Therefore, for (5), (5a) may have greater processing costs than $(5 b)$.

If the structural ambiguity of certain P-Stranding Sentences causes these sentences to have higher processing costs, then Pied-Piped Sentences should be expected to have lower processing costs; however, as the results show, this is not the case. The reason for this may be accounted for in two ways. First, a frequency-based approach may be used. If P-Stranding Constructions occur more frequently than Pied-Piped Constructions (not taking into account mode of input), then frequency of occurrence and 
structural ambiguity may influence processing costs simultaneously. Second, an updated version of this study's initial hypothesis may be used: if structural ambiguity adds processing costs to P-Stranding Sentences but P-Stranding Sentences are favored by the Minimal Structure Principle, these two factors may influence processing costs simultaneously. To test this, an eye-tracking experiment should be conducted, as this would help to pinpoint where in the target sentences participants have the most processing difficulty.

\subsubsection{Conclusion}

The purpose of this study was two-fold: to compare the processing of P-Stranding and Pied-Piped Constructions and to investigate the role of Generative Grammar Principles in language processing. In regards to the Minimal Structure Principle (MSP), it cannot be concluded that the MSP is active in language processing; if the MSP is active, other factors - specifically, structural ambiguity or frequency - may be influencing the parser as well. As discussed in the previous sections, changing the experimental method or controlling for verb type may assist in locating a more definite source of processing costs. 


\section{References}

Bader, M., \& Schmid, T. (2009). Minimality in verb-cluster formation. Lingua, 119(10), 1458-1481. doi: 10.1016/j.lingua.2008.03.003

Bošković, Ž. (1997). Selection and the Categorial Status of Infinitival Complements. In The syntax of nonfinite complementation: An economy approach (pp. 7-47). Cambridge, MA: MIT Press.

Bošković, Ž. (2011). Last resort with move and agree in derivations and representations. In The Oxford handbook of linguistic minimalism.

Burkhardt, P., \& Domahs, U. (2009). Experimental evidence for minimal structure. Lingua, 119(10), 1373-1379. doi: 10.1016/j.lingua.2008.06.004

Enzinna, N., \& Thompson, E. (2012, November 7). The processing of PrepositionStranding Constructions in English. Paper presented at Experimental Psycholinguistics Conference in Universidad Nacional de Educación a Distancia, Madrid.

Enzinna, N., \& Thompson, E. (2013, February 10). The Minimal Structure Principle and the processing of Preposition Stranding. Paper presented at West Coast Conference on Formal Linguistics in Arizona State University, Tempe.

Ferreira, F., \& Clifton, C., Jr. (1986). The independence of syntactic processing. Journal of Memory and Language, 25, 348-368. doi: 10.1016/0749-596X(86)90006-9

Gries, S. T. (2002). Preposition stranding in English: Predicting speakers' behaviour. In Proceedings of the Western Conference on Linguistics (Vol. 12, pp. 230-241). Fresno, CA: California State University. Retrieved from www.linguistics.ucsb.edu/faculty/stgries/research/overview-research.html

Hawkins, J. (1999). Processing complexity and filler-gap dependencies across grammars. Language, 75(2), 244-285.

Heck, F., \& Muller, G. (2011). Translocal Constraints in the Minimalist Program [Scholarly project].

Hirotani, M., Frazier, L., \& Rayner, K. (2006). Puntuation and intonation effects on clause and sentence wrap-up: Evidence from eye movements. Journal of Memory and Language, 54, 425-443.

Law, P. (2006). Preposition stranding. In M. Everaert \& H. Van Riemsdijk (Eds.), The Blackwell companion to syntax (Vol. 3, pp. 631-684). Wiley-Blackwell. 
Levelt, W. J. (1989). Speaking: From intention to articulation. Cambridge, MA: MIT Press.

Marinis, T. (2010). Using on-line processing methods in language acquisition research. In E. Blom \& S. Unsworth (Eds.), Experimental methods in language acquisition research (pp. 139-162). Philadelphia, PA: John Benjamins Publishing Company.

Merchant, J. (1999). The syntax of silence: Sluicing, islands, and identity in ellipsis (Doctoral dissertation, University of California Santa Cruz) (pp. 125-144). Dissertation Abstracts International, A: The Humanities and Social Sciences. Retrieved from http://proquest.com

Rayner, K., \& Sereno, S. C. (1994). Eye movements in reading: Psycholinguistic studies. In M. A. Gernsbacher (Author), Handbook of psycholinguistics. San Diego: Academic Press.

Sugisaki, K. (2011). Preposition stranding: Its parametric variation and acquisition. In Workshop on Verbal Elasticity. Retrieved from http://filcat.uab.cat/clt/verbalelasticity/program.html

Trustwell, R. (2009). Preposition-stranding, passivization, and extraction from adjuncts in Germanic. Linguistic Variation Yearbook, 9, 131-177.

Wanner, E., \& Maratsos, M. (1978). An ATN approach to comprehension. In M. Halle, J. Bresnan, \& G. A. Miller (Authors), Linguistic theory and psychological reality (pp. 119-161). Cambridge, MA: MIT Press.

Weinberg, A. (2001). A minimalist theory of human sentence processing. In Epstein \& N. Hornstein (Eds.), Working Minimalism (pp. 283-314). Cambridge, MA: MIT Press. 


\section{Appendices}

Appendix A: Language Background Questionnaire

\section{Personal Information}

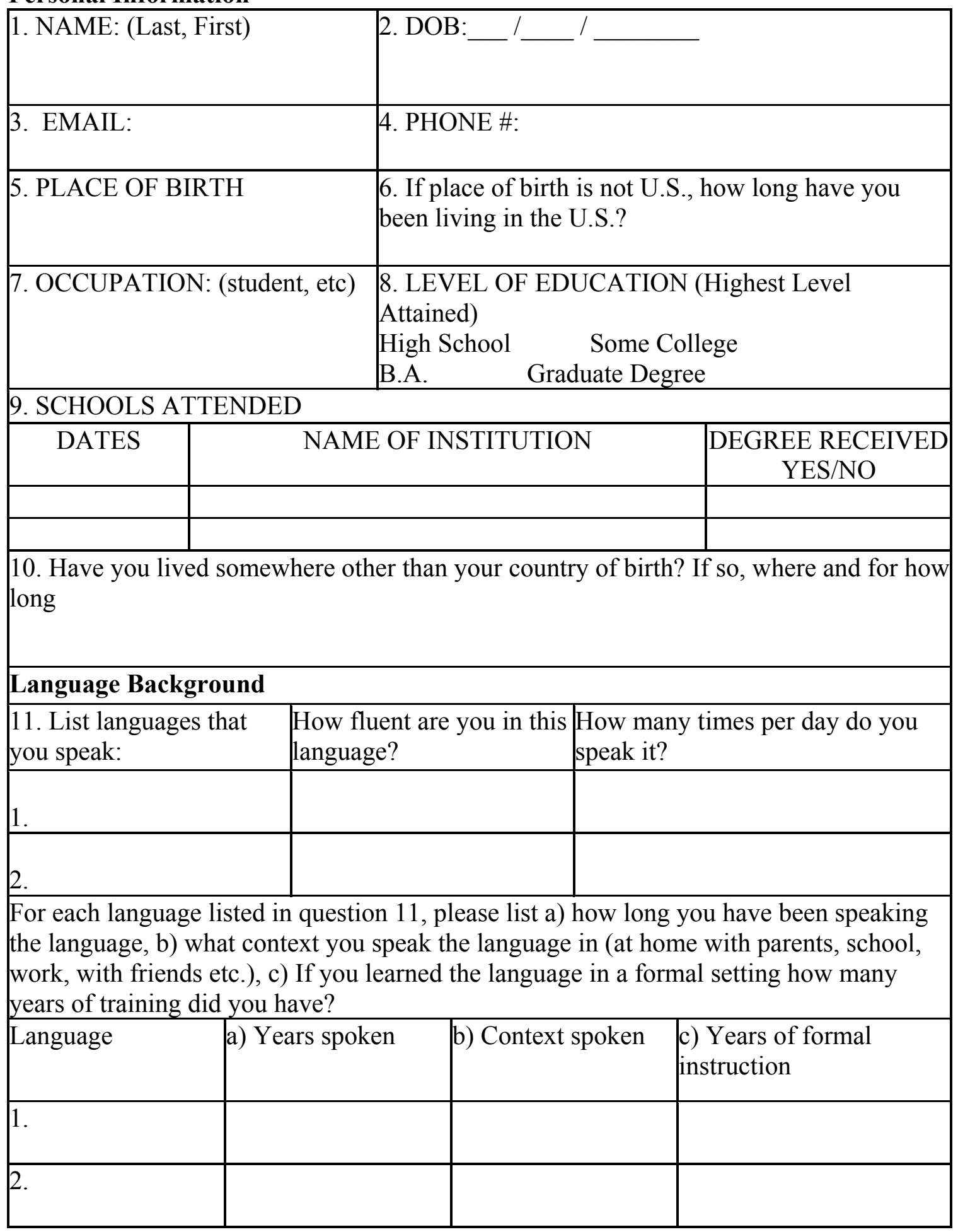


Appendix B: Experimental Sentences

\section{FILLER SENTENCES}

52 sentences

26 comprehension questions: 13 Yes/13 No

1. The couple held hands all night.

DID THE COUPLE HOLD HANDS? Yes

2. Lisa gave Jane a book last holiday season.

DID LISA GIVE JANE A BOOK LAST HOLIDAY SEASON? Yes

3. Joseph saved his money to travel this summer.

DID JOSEPH SAVE HIS MONEY TO TRAVEL? Yes

4. The dog slept peacefully.

DID THE DOG SLEEP PEACEFULLY? Yes

5. Jill considered the movie interesting enough to watch again.

DID JILL CONSIDER THE MOVIE INTERESTING ENOUGH TO WATCH

AGAIN? Yes

6. The waitress served the man a pizza this afternoon.

DID THE WAITRESS SERVE THE MAN A PIZZA? Yes

7. The frame fit the photograph perfectly.

DID THE FRAME FIT THE PHOTOGRAPH? Yes

8. Dan's bike was stolen last night.

DID SOMEONE STEAL DAN'S BIKE? Yes

9. The discount shoppers bought all the toys quickly.

DID THE DISCOUNT SHOPPERS BUY ALL THE TOYS? Yes 
10. The radio was playing Harry's favorite song this afternoon. DID THE RADIO PLAY HARRY'S FAVORITE SONG? Yes

11. The security guard questioned the stranger suspiciously. DID THE SECURITY GUARD QUESTION THE STRANGER? Yes

12. The store had to close permanently last week.

DID THE STORE CLOSE? Yes

13. Mary enjoyed growing a garden last year.

DID MARY ENJOY GROWING A GARDEN? Yes

14. Steve met Larry last July.

DID STEVE AND LARRY MEET IN DECEMBER? No

15. Martin handed Lucy roses today.

DID MARTIN HAND LUCY TULIPS? No

16. Max sent Tom a postcard that showed a beautiful beach.

DID MAX SEND TOM A FRUIT BASKET? No

17. Bob claimed that Martha walks three miles every day.

DID BOB CLAIM THAT MARTHA RUNS FIVE MILES EVERY DAY? No

18. Erica forgot to purchase milk this morning.

DID ERICA FORGET TO PURCHASE ONIONS THIS MORNING? No

19. The festival ended early unfortunately.

DID THE FESTIVAL END LATE? No

20. Joe left the kitchen a mess Friday night.

DID JOE CLEAN THE KITCHEN FRIDAY NIGHT? No

21. Frank got the little girl a porcelain doll yesterday. 


\section{DID FRANK GET THE LITTLE GIRL A PONY? No}

22. Bill didn't hear the sirens because the music was blaring. DID BILL HEAR THE SIRENS? No

23. Sandra painted landscapes often. DID SANDRA PAINT PORTRAITS? No

24. Stan skipped the lecture yesterday. DID STAN ATTEND THE LECTURE YESTERDAY? No

25. The weather was rainy and gloomy last week.

WAS THE WEATHER SUNNY LAST WEEK? No

26. Dana ordered Eddie shirts online.

DID DANA ORDER EDDIE VITAMINS ONLINE? No

27. The newspaper article informed the town that a storm was approaching quickly.

28. Karen wished that the shampoo would work better.

29. Jared owns a pool now.

30. Most people bathe once a day.

31. Sally is a vegetarian but still consumes fish sometimes.

32. The athlete cried when the team lost the championship last year.

33. Jessica only dated guys who were Libras or Leos, typically.

34. Andrew would choose Pepsi over Coca-Cola any day.

35. All birds that fly must eventually land somewhere.

36. Andrea bakes oatmeal cookies often.

37. TV stations run the same commercials all day. 
38. The thunderstorm spoiled Nick's plans to barbecue this afternoon.

39. The job applicant was hired right away.

40. The actor practiced the script every day.

41. Babies make funny faces all the time.

42. Barbara said Danielle looked pretty last night.

43. Children love to swim when it's summertime.

44. Skype is becoming more and more popular nowadays.

45. Food can turn rotten if not stored properly.

46. Cats can purr all day long.

47. Carolina climbed a mountain two years ago.

48. Autumn seemed picturesque last year.

49. Bananas develop dark spots when overripe.

50. The sports fans cheered when the game finished.

51. Spaghetti sauce stained the carpet last night.

52. The university hosted a fundraiser last week.

\section{EXPERIMENTAL SENTENCES}

48 sentences: 24 P-Stranding \& 24 Pied-Piping

24 comprehension questions: 12 Yes/12 No

\section{Set 1:}

24 P-Stranding

Preposition complements: 
8 what + noun -2 yes, 2 no

8 which + noun -2 yes, 2 no

8 whose+noun -2 yes, 2 no

1. What remark did Jack apologize for yesterday?

DID JACK APOLOGIZE? Yes

2. What time did Maura study until last night?

DID MAURA STUDY LAST NIGHT? Yes

3. What knife did the chef chop the vegetables with last night?

DID THE CHEF CHOP MEAT? No

4. What walls did Aaron hang the posters on this afternoon?

DID AARON HANG A MIRROR ON THE WALL? No

5. What steel did the crew build the new structure with downtown?

6. What news was Chris speaking about the other day?

7. What bar did the band perform at originally?

8. What meeting did the president appear at last week?

9. Which bed was the kitten crouching under earlier?

DID THE KITTEN CROUCH UNDER SOMETHING? Yes

10. Which competition did the gymnast score a perfect ten in last month?

DID THE GYMNAST SCORE A PERFECT TEN? Yes

11. Which computers did the sixth graders learn to type on last year?

DID THE SIXTH GRADERS LEARN TO SPELL? No

12. Which stage did Julia present the dance on completely alone?

DID JULIA PRESENT A POEM? No 
13. Which building did the thief escape from yesterday?

14. Which closet did the cousins hide in when playing hide-and-seek?

15. Which parking lot did Luis leave the car in yesterday?

16. Which ship did the sailors trail behind slowly?

17. Whose friend did Mary go to the theatre with last night?

DID MARY GO TO THE THEATRE LAST NIGHT? Yes

18. Whose land did the neighbors fight over all the time?

DID THE NEIGHBORS FIGHT OVER LAND? Yes

19. Whose yard did the puppy bury the bone in yesterday?

DID THE PUPPY BURY A BISCUIT? No

20. Whose blanket were the kids whispering under quietly?

DID THE KIDS YELL UNDER THE BLANKET? No

21. Whose go-kart did Derrick slam into violently?

22. Whose house does Ashley stay at nowadays?

23. Whose money did the Chess Club reserve a room with last year?

24. Whose sister did Charles go to the prom with last year?

\section{Pied-Piping}

8 what + noun -2 yes, 2 no

8 which + noun -2 yes, 2 no

8 whose+noun -2 yes, 2 no

1. For what event did Fred wait all year?

DID FRED WAIT FOR AN EVENT? Yes 
2. On what couch did Samantha take a nap yesterday? DID SAMANTHA TAKE A NAP ON A COUCH? Yes

3. At what park did Marlin feed the ducks yesterday? DID MARLIN FEED THE DOLPHINS? No

4. Along what river did the tourists stroll last summer? DID THE TOURISTS STROLL ALONG THE OCEAN? No

5. For what company was Melissa employed last year?

6. With what ornaments did the family decorate the Christmas tree this year?

7. With what crayons did Zack draw pictures last class?

8. At what restaurant does the businessman eat every week?

9. At which mall did Mark shop today? DID MARK SHOP AT A MALL? Yes

10. Next to which bench did Bill find the hidden treasure last night? DID BILL FIND TREASURE? Yes

11. With which yarn did the grandmother knit a scarf last night? DID THE GRANDMOTHER KNIT A SWEATER? No

12. About which videogame does the teenager think frequently? DOES THE TEENAGER THINK ABOUT GRADES? No

13. Down which street did the parade march repeatedly?

14. In which journal did the sad poet write every night?

15. From which parent did Claire keep a secret all these years?

16. Behind which platform did the conductor stand every day?

17. To whose birthday did Gina bring a cake last week? 


\section{DID GINA BRING A CAKE? Yes}

18. In whose shoe did Laura find a mouse yesterday?

\section{DID LAURA FIND A MOUSE IN A SHOE? Yes}

19. For whose graduation did Melanie throw the party this month? DID MELANIE THROW A RETIREMENT PARTY? No

20. To whose wedding did Alice wear the black dress last week? DID ALICE WEAR A TUXEDO? No

21. With whose father did the Boy Scouts camp last summer?

22. Next to whose girlfriend was John seen yesterday?

23. After whose speech did Paul applaud finally?

24. Out of whose hat did the magician pull a rabbit surprisingly?

\section{Set 2:}

24 Pied-Piping

Preposition complements:

8 what + noun -2 yes, 2 no

8 which + noun -2 yes, 2 no

8 whose+noun -2 yes, 2 no

1. For what remark did Jack apologize yesterday?

DID JACK APOLOGIZE? Yes

2. Until what time did Maura study last night?

DID MAURA STUDY LAST NIGHT? Yes

3. With what knife did the chef chop the vegetables last night? 


\section{DID THE CHEF CHOP MEAT? No}

4. On what walls did Aaron hang the posters this afternoon?

DID AARON HANG A MIRROR ON THE WALL? No

5. With what steel did the crew build the new structure downtown?

6. About what news was Chris speaking the other day?

7. At what bar did the band perform originally?

8. At what meeting did the president appear last week?

9. Under which bed was the kitten crouching earlier?

DID THE KITTEN CROUCH UNDER SOMETHING? Yes

10. In which competition did the gymnast score a perfect ten last month?

DID THE GYMNAST SCORE A PERFECT TEN? Yes

11. On which computers did the sixth graders learn to type last year?

DID THE SIXTH GRADERS LEARN TO SPELL? No

12. On which stage did Julia present the dance completely alone?

DID JULIA PRESENT A POEM? No

13. From which building did the thief escape yesterday?

14. In which closet did the cousins hide when playing hide-and-seek?

15. In which parking lot did Luis leave the car yesterday?

16. Behind which ship did the sailors trail behind slowly?

17. With whose friend did Mary go to the theatre last night?

DID MARY GO TO THE THEATRE LAST NIGHT? Yes

18. Over whose land did the neighbors fight all the time?

DID THE NEIGHBORS FIGHT OVER LAND? Yes 
19. In whose yard did the puppy bury the bone yesterday? DID THE PUPPY BURY A BISCUIT? No

20. Under whose blanket were the kids whispering quietly? DID THE KIDS YELL UNDER THE BLANKET? No

21. Into whose go-kart did Derrick slam violently?

22. At whose house does Ashley stay nowadays?

23. With whose money did the Chess Club reserve a room last year?

24. With whose sister did Charles go to the prom last year?

24 P-Stranding

8 what + noun -2 yes, 2 no

8 which + noun -2 yes, 2 no

8 whose+noun -2 yes, 2 no

1. What event did Fred wait for all year?

DID FRED WAIT FOR AN EVENT? Yes

2. What couch did Samantha take a nap on yesterday?

DID SAMANTHA TAKE A NAP ON A COUCH? Yes

3. What park did Marlin feed the ducks at yesterday?

DID MARLIN FEED THE DOLPHINS? No

4. What river did the tourists stroll along last summer?

DID THE TOURISTS STROLL ALONG THE OCEAN? No

5. What company was Melissa employed for last year?

6. What ornaments did the family decorate the Christmas tree with this year? 
7. What crayons did Zack draw pictures with last class?

8. What restaurant does the businessman eat at every week?

9. Which mall did Mark shop at today?

DID MARK SHOP AT A MALL? Yes

10. Which bench did Bill find the hidden treasure next to last night?

DID BILL FIND TREASURE? Yes

11. Which yarn did the grandmother knit a scarf with last night?

DID THE GRANDMOTHER KNIT A SWEATER? No

12. Which videogame does the teenager think about frequently?

DOES THE TEENAGER THINK ABOUT GRADES? No

13. Which street did the parade march down repeatedly?

14. Which journal did the sad poet write in every night?

15. Which parent did Claire keep a secret from all these years?

16. Which platform did the conductor stand behind every day?

17. Whose birthday did Gina bring a cake to last week?

DID GINA BRING A CAKE? Yes

18. Whose shoe did Laura find a mouse in yesterday?

DID LAURA FIND A MOUSE IN A SHOE? Yes

19. Whose graduation did Melanie throw the party for this month?

DID MELANIE THROW A RETIREMENT PARTY? No

20. Whose wedding did Alice wear the black dress to last week?

DID ALICE WEAR A TUXEDO? No

21. Whose father did the Boy Scouts camp with last summer? 
22. Whose girlfriend was John seen next to yesterday?

23. Whose speech did Paul applaud after finally?

24. Whose hat did the magician pull a rabbit out of surprisingly? 